\title{
DESEMPENHO DO REFLECTÔMETRO NO DOMÍNIO DO TEMPO NA DETECÇÃO DE VARIAÇÕES DE UMIDADE DO SOLO
}

\author{
GILBERTO OLIVEIRA JOAQUIM JUNIOR
}

Dissertação apresentada à Escola Superior de Agricultura "Luiz de Queiroz", Universidade de São Paulo, para obtenção do título de Mestre em Agronomia, Área de Concentração: Física do Ambiente Agrícola.

P I R A C I C A B A

Estado de São Paulo - Brasil

Junho -2003 


\title{
DESEMPENHO DO REFLECTÔMETRO NO DOMÍNIO DO TEMPO NA DETECÇÃO DE VARIAÇÕES DE UMIDADE DO SOLO
}

\author{
GILBERTO OLIVEIRA JOAQUIM JUNIOR \\ Engenheiro Agrônomo
}

Orientador: Prof. Dr. SERGIO OLIVEIRA MORAES

Dissertação apresentada à Escola Superior de Agricultura "Luiz de Queiroz", Universidade de São Paulo, para obtenção do título de Mestre em Agronomia, Área de Concentração: Física do Ambiente Agrícola.

P I R A C I C A B A

Estado de São Paulo - Brasil

Junho -2003 
Dados Internacionais de Catalogação na Publicação (CIP) DIVISÃO DE BIBLIOTECA E DOCUMENTAÇÃO - ESALQ/USP

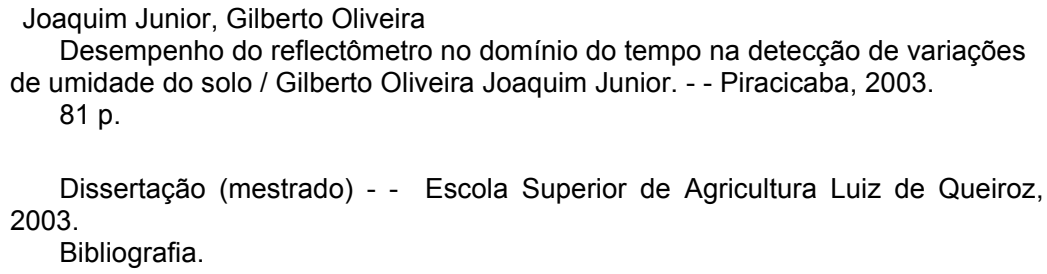

1. Constante dielétrica 2. Física do solo 3. Reflectometria no Domínio Temporal 4. Tensiometro 5. Umidade do solo I. Título

CDD 631.432

\section{"Permitida a cópia total ou parcial deste documento, desde que citada a fonte - $\mathrm{O}$ autor"}


A minha querida mãe Maria do Carmo, irmãs Christiane e Luciane

DEDICO 


\section{AGRADECIMENTOS}

A Deus, por tudo.

À Coordenação do Programa de Pós-Graduação em Física do Ambiente Agrícola da ESALQ/USP pela oportunidade concedida.

Ao Conselho Nacional de Desenvolvimento Científico e Tecnológico-CNPq, pela concessão da bolsa de estudo.

Ao Professor Dr. Sergio Oliveira Moraes, por ser mais que um orientador, transmitindo segurança, ou melhor, um sentimento paternal.

Ao Professor Dr. Quirijn de Jong van Lier, por ser um segundo orientador, propiciando um ambiente familiar e agradável durante a convivência.

Ao Professor Dr. Paulo Leonel Libardi pela amizade e apoio.

Ao Professor Dr. Paulo César Sentelhas, pela amizade, incentivo desde o início do curso e, sobretudo, pela compreensão por não ter sido possível produzir a altura.

À Professora Dra. Sônia Maria De Stefano Piedade, pela oportunidade de realização de estágio de docência do Programa de Aperfeiçoamento de Ensino da USP.

À Professora Dra. Cláudia Fernanda Almeida Teixeira, por ser responsável pela realização de parte deste trabalho. 
Ao Engenheiro Agrícola M.S. Rogério Cichota, pelo companheirismo e, principalmente, pelo auxílio em diversas situações.

Aos funcionários do Departamento de Ciências Exatas, em especial, Francisco Bernardo Dias, pelo auxílio na realização deste trabalho.

Aos companheiros: Antonio Carlos Cruz, Luciana Gomes Castro, Maria da Glória Bastos Freitas de Mesquita, José Fernandes Filho, Ana Lúcia Hurtado, Genelício Crusoé Rocha, Laércio de Carvalho pela amizade e convivência agradável durante a realização do trabalho.

A todos os colegas dos Programas de Pós-Graduação da ESALQ/USP.

A todos aqueles que direta ou indiretamente colaboraram para a realização deste trabalho. 


\section{SUMÁRIO}

Página

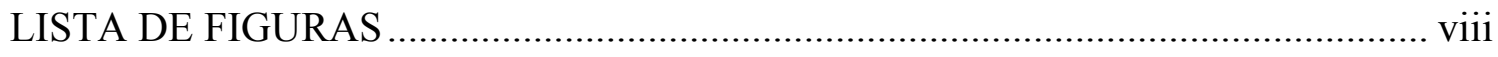

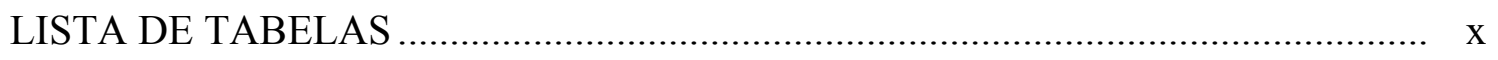

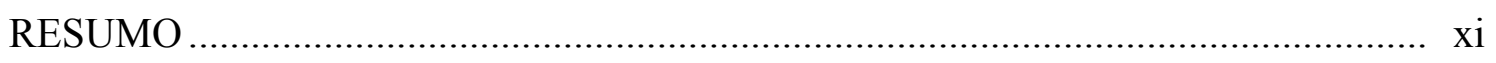

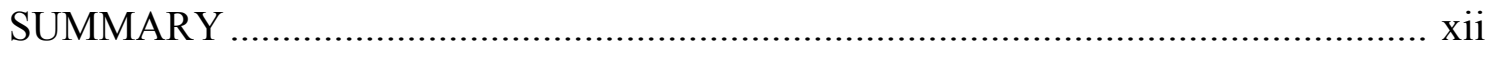

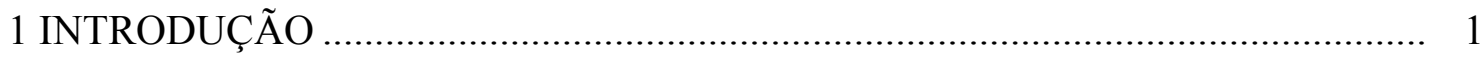

2 REVISÃO DE LITERATURA .................................................................. 3

2.1 Instrumentos mais utilizados na obtenção da umidade do solo ............................. 3

2.2 Medição da umidade do solo pela técnica de TDR (Reflectometria no Domínio

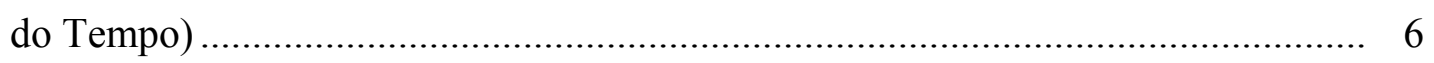

2.2.1 Princípio de funcionamento ................................................................... 6

2.2.2 Fatores que afetam as medidas do TDR ...................................................... 10

2.3 Comparações entre tensiometria e TDR ....................................................... 12

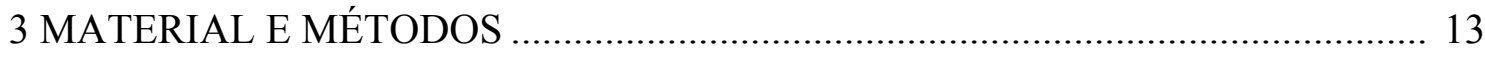

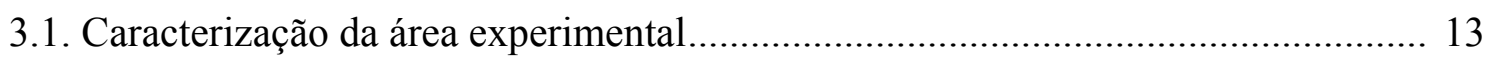

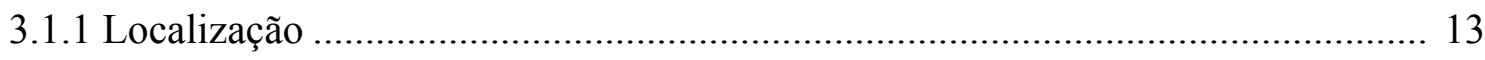

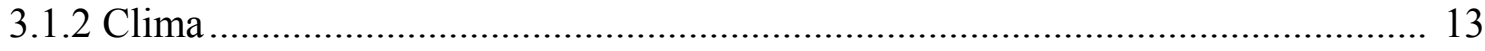

3.2 Equipamentos utilizados e sua localização ......................................................... 14

3.3 Medidas de tensiômetros e TDR .......................................................................... 19

3.4 Sensibilidade do TDR na detecção de variações de umidade do solo ..................... 20

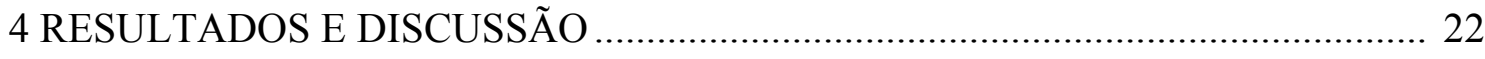

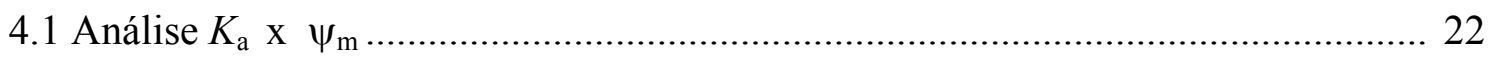


4.1.1 Dados de um ensaio de condutividade hidráulica conforme o MPI.................... 28

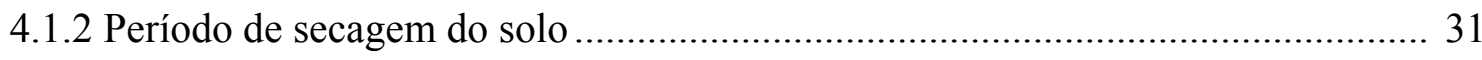

4.1.3 Período de inundação intermitente ................................................................ 34

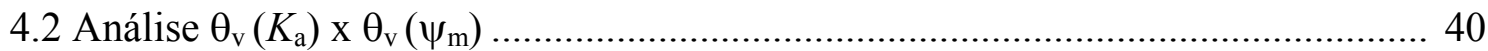

4.2.1 Dados de um ensaio de condutividade hidráulica conforme o MPI.................... 40

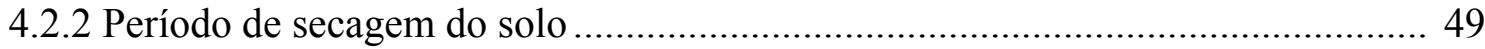

4.2.3 Período de inundações intermitentes.................................................................. 57

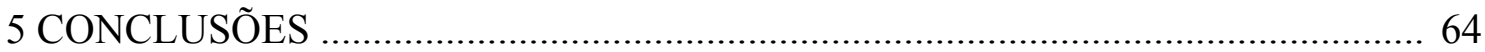

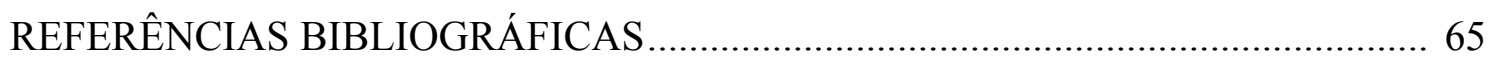

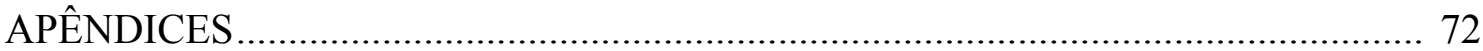




\section{LISTA DE FIGURAS}

Página

1 Esquema simplificado mostrando o comprimento aparente e o comprimento real da sonda (sem escala) e detalhe de um sistema em funcionamento monitorando uma coluna de solo.

2 Parcela experimental: vista geral, mostrando a área delimitada pela chapa de aço, coberta com o telhado e distribuição dos tensiômetros, com respectivas distâncias e profundidades de instalação (adaptado de Teixeira, 2001)

3 Equipamentos utilizados: a)dentro da caixa de força, onde foram instalados; b) caixa ambientalmente selada contendo,: SDM1505, "datalogger" CR10X e supressor de transientes; c)"datalogger" e "keyboard display"; d) testador de cabos; e) sensor de umidade de três hastes, modelo CS605.

4 Comportamento do potencial matricial $(\mathrm{em} \mathrm{kPa})$ e da constante dielétrica ao longo do tempo, para a profundidade $0,40 \mathrm{~m}$, nas três situações estudadas: (a) durante ensaio de condutividade hidráulica pelo MPI; (b) período de secagem do solo; (c) período de inundação intermitente.

5 Correlação entre o potencial matricial (em kPa) e a constante dielétrica, para as profundidades estudadas

6 Correlação entre o potencial matricial e a constante dielétrica, para as profundidades estudadas, utilizando os dados de um ensaio de condutividade hidráulica pelo MPI.

7 Correlação entre o potencial matricial e a constante dielétrica aparente, para as profundidades estudadas, durante o período de secagem do solo.

8 Dados do comportamento da constante dielétrica ao longo do tempo, durante o período de secagem do solo.

9 Correlação entre o potencial matricial e a constante dielétrica aparente, para as profundidades estudadas, para o período de secagem do solo.

10 Correlação entre o potencial matricial (em $\mathrm{kPa}$ ) e a constante dielétrica, para as profundidades estudadas, utilizando os dados das inundações.

11 Umidades volumétricas $\left(\mathrm{m}^{3} \mathrm{~m}^{-3}\right)$ obtidas através do tensiômetro $\left[\theta\left(\psi_{\mathrm{M}}\right)\right]$ e do TDR, utilizando o tensiômetro na calibração $((\theta(\mathrm{Ka}) 1)$ e o modelo de Topp et al., $1980(\theta(\mathrm{Ka}) 2)$ 
12 Correlação entre os valores de umidade volumétrica $\left(\mathrm{m}^{3} \mathrm{~m}^{-3}\right)$ obtidas por tensiometria e curva de retenção e pelo TDR (calibrado com umidades obtidas pelo tensiômetro), utilizando dados de um ensaio de $K(\theta)$ utilizando o MPI, para as profundidades estudadas.

13 Correlação entre os valores de umidade volumétrica $\left(\mathrm{m}^{3} \mathrm{~m}^{-3}\right)$ obtidas por tensiometria e curva de retenção e pelo TDR (calibrado com umidades obtidas pelo tensiômetro), utilizando dados de um ensaio de $K(\theta)$ utilizando o MPI, para as profundidades estudadas.

14 Correlação entre os valores de umidade volumétrica $\left(\mathrm{m}^{3} \mathrm{~m}^{-3}\right)$ obtidas por tensiometria e curva de retenção e pelo TDR (calibrado com umidades obtidas pelo tensiômetro), utilizando dados de um ensaio de $K(\theta)$ utilizando o MPI, para as profundidades estudadas.

15 Umidades volumétricas $(\mathrm{m} 3 \mathrm{~m}-3)$ obtidas pelo tensiômetro $\left[\theta\left(\psi_{\mathrm{M}}\right)\right]$ e TDR, utilizando o tensiômetro na calibração [ $\theta(\mathrm{Ka}) 1]$ e utilizando a equação de Topp et al., 1980 [ $\theta(\mathrm{Ka}) 2]$, durante o período de secagem do solo.

16 Seqüência de valores de umidade volumétrica $\left(\mathrm{m}^{3} \mathrm{~m}^{-3}\right)$, obtidos pelo tensiômetro e pelo TDR, durante o intervalo que engloba os dados do ensaio de $\mathrm{K}(\theta)$ utilizando o método do perfil instantâneo e os do período de secagem do solo...... 51

17 Correlação entre os valores de umidade volumétrica $\left(\mathrm{m}^{3} \mathrm{~m}^{-3}\right)$ obtidos por tensiometria e curva de retenção e TDR (calibrado via tensiômetro), ao longo do período de secagem do solo.

18 Correlação entre os valores de umidade volumétrica $\left(\mathrm{m}^{3} \mathrm{~m}^{-3}\right)$ obtidos por tensiometria e curva de retenção e TDR (calibrado pelo modelo de Topp et al., 1980), ao longo do período de secagem do solo.

19 Correlação entre os valores de umidade volumétrica $\left(\mathrm{m}^{3} \mathrm{~m}^{-3}\right)$ obtidos por TDR calibrado com umidade obtida por tensiometria e curva de retenção e do TDR calibrado pela equação de Topp et al. (1980), ao longo do período de secagem do solo.

20 Correlação entre os valores de umidade volumétrica $\left(\mathrm{m}^{3} \mathrm{~m}^{-3}\right)$ obtidos por tensiometria e curva de retenção e do TDR (calibrado via tensiômetro), para os dados de inundação intermitente do solo.

21 Correlação entre os valores de umidade volumétrica $\left(\mathrm{m}^{3} \mathrm{~m}^{-3}\right)$ obtidos por tensiometria e curva de retenção e TDR (calibrado pelo modelo de Topp et al., 1980), para os dados de inundação intermitente do solo.

22 Correlação entre os valores de umidade volumétrica $\left(\mathrm{m}^{3} \mathrm{~m}^{-3}\right)$ obtidos pelo TDR calibrado com umidade obtida por tensiometria e TDR calibrado pela equação de Topp et al. (1980), ao longo do período de inundação intermitente. 


\section{LISTA DE TABELAS}

Página

1 Dados de granulometria (areia, silte e argila), classe textural, matéria orgânica (M.O.) e densidade dos sólidos $\left(\rho_{\mathrm{s}}\right)$ do solo nas camadas de interesse

2 Teores (\%) dos óxidos de Silício, Alumínio, Ferro, Titânio e Manganês para as camadas de interesse.

3 Valores médios e coeficientes de variação da densidade do solo nas diferentes camadas de interesse.

4 Valores médios e coeficientes de variação da condutividade hidráulica saturada (Ksat) obtida com permeâmetro de carga constante, para as diferentes camadas de interesse

5 Valores médios e coeficientes de variação da porosidade total calculada, para as diferentes camadas do perfil em estudo .

6 Parâmetros de ajuste da equação de van Genuchten (1980) correspondentes às diferentes profundidades de interesse

7 Valores de potencial matricial, constante dielétrica e umidades volumétricas $\left(\mathrm{m}^{3}\right.$ $\mathrm{m}^{-3}$ ) em função do potencial matricial e da constante dielétrica, com calibração feita utilizando o tensiômetro e curva de retenção $(\theta(K a) 1)$ e pelo modelo de Topp et al., $1980(\theta(\mathrm{Ka}) 2)$, durante a última inundação, para as profundidades $0,40,0,50$ e $0,60 \mathrm{~m}$.

8 Valores de potencial matricial, constante dielétrica e umidades volumétricas $\left(\mathrm{m}^{3}\right.$ $\mathrm{m}^{-3}$ ) em função do potencial matricial e da constante dielétrica, com calibração feita utilizando o tensiômetro e curva de retenção $(\theta(K a) 1)$ e pelo modelo de Topp et al., $1980(\theta(K a) 2)$, durante a última inundação, para as profundidades $0,70,0,80$ e $0,90 \mathrm{~m}$.

9 Valores de potencial matricial, constante dielétrica e umidades volumétricas $\left(\mathrm{m}^{3}\right.$ $\mathrm{m}^{-3}$ ) em função do potencial matricial e da constante dielétrica, com calibração feita utilizando o tensiômetro e curva de retenção $(\theta(K a) 1)$ e pelo modelo de Topp et al., $1980(\theta(K a) 2)$, durante a última inundação, para as profundidades $1,00,1,10$ e $1,20 \mathrm{~m}$. 


\title{
DESEMPENHO DO REFLECTÔMETRO NO DOMÍNIO DO TEMPO NA DETECÇÃO DE VARIAÇÕES DE UMIDADE DO SOLO
}

\author{
Autor: GILBERTO OLIVEIRA JOAQUIM JUNIOR \\ Orientador: Prof. Dr. SERGIO OLIVEIRA MORAES
}

\section{RESUMO}

O objetivo do trabalho foi avaliar o desempenho do reflectômetro no domínio do tempo (TDR) comparativamente ao tensiômetro com manômetro de mercúrio (considerado como instrumento padrão), dando-se ênfase na sensibilidade de detecção de variações na umidade do solo sob condições de molhamento e secagem. Foi instalado um experimento em um solo classificado como Nitossolo Vermelho distrófico latossólico de textura muito argilosa, localizado próximo ao Posto Meteorológico do Departamento de Ciências Exatas, ESALQ/USP, Piracicaba (SP), Brasil, 22 $42^{\circ}$ '30" de latitude sul e $47^{\circ} 38^{\prime} 00^{\prime \prime}$ de longitude oeste. Com dados de um ensaio de determinação da condutividade hidráulica do solo pelo Método do Perfil Instantâneo, de um período de secagem e de inundações intermitentes do solo, analisou-se a concordância entre a constante dielétrica obtido pelo TDR e o potencial matricial da água no solo obtido pelo tensiômetro, além dos valores de umidade volumétrica obtidos pelas mesmas técnicas. Concluiu-se que o desempenho do TDR foi superior ao do tensiômetro sob condições de secagem do solo e na detecção de variações de umidade. 


\title{
PERFORMANCE OF A TIME DOMAIN REFLECTOMETER IN THE DETECTION OF SOIL MOISTURE VARIATIONS
}

\author{
Author: GILBERTO OLIVEIRA JOAQUIM JUNIOR \\ Adviser: Prof. Dr. SERGIO OLIVEIRA MORAES
}

\section{SUMMARY}

The performance of a time domain-reflectometer (TDR) was compared with a mercury tensiometer (considered to be the norm), emphasizing the detection of variations in soil water content under wetting and drying conditions (as in instantaneous profile method to determine soil hydraulic conductivity). An experiment was performed in a Nitossolo Vermelho distrófico latossólico argiloso (Brazilian classification system), close to the meteorological observatory of the ESALQ/USP, Piracicaba (SP), Brazil, latitude $22^{\circ} 42^{\prime} 30^{\prime}$, S, longitude $47^{\circ} 38^{\prime} 00^{\prime}$, W. Data of matric potential, dieletric constant and water content during a dry period and water application were analyzed. The TDR cable tester was better than the tensiometer to detect the soil moisture variation. 


\section{INTRODUÇÃO}

A evolução da conscientização da necessidade do uso racional dos recursos naturais, principalmente da água, aliada ao avanço da eletrônica, tem contribuído para a intensificação dos estudos do monitoramento da água no solo. Na agricultura - um dos maiores consumidores de água - por exemplo, a otimização do uso da irrigação, baseado na melhoria de informações sobre a umidade do solo, daria substancial contribuição, evitando o desperdício observado em diversas situações. Logo, a determinação in situ do conteúdo de água no solo é de grande interesse para a irrigação de precisão.

O crescente aumento nos estudos de instrumentação voltada a obtenção de informações sobre o sistema água-solo evidencia sua importância. O conteúdo de água no solo é uma importante variável na dinâmica de solutos, calor, gases e da própria água. Numa escala global, sua importância relaciona-se à interação com o sistema climático do planeta.

Estimativas confiáveis da umidade do solo são requeridas para utilização em modelos hidrológicos (Gardner et al., 2000). Algumas características físicas do solo dependentes da umidade, como a condutividade hidráulica do solo não saturado, podem ser determinadas por modelos exponenciais, nos quais qualquer pequena variação no valor da umidade do solo, causará um grande efeito no seu valor. Desta forma é necessário o desenvolvimento de técnicas que permitam a obtenção de valores confiáveis.

Algumas características desejáveis de um método (ou instrumento) para monitoramento da água no solo são: 
1) Evitar a amostragem destrutiva;

2) Permitir repetição no espaço e no tempo;

3) Permitir automação;

4) Fácil calibração;

5) Custo acessível;

6) Segurança do operador;

7) Rapidez na obtenção de resultados.

Uma técnica que preenche a maioria destes requisitos é a reflectometria no domínio do tempo (time domain reflectometry - TDR). Segundo Topp \& Ferré (2000), a técnica de TDR tem se tornado amplamente aceita e mais de dez companhias vendem instrumentos ou componentes para medir o conteúdo de água no solo nela baseados. Como foi desenvolvida para o setor de comunicações, possui boa estabilidade temporal e de temperatura, tendo por isso vantagens sobre outras técnicas.

O seu custo é alto, uma de suas desvantagens. Desta forma, a possível superioridade na detecção de variações de umidade do solo, sob diferentes condições hídricas, poderia ser um fator adicional que justifique sua adoção, entre as demais técnicas.

Com o objetivo de avaliar o desempenho da técnica de TDR, na detecção de variações de umidade do solo, realizou-se ensaios sob condições de umedecimento e secagem de um solo muito argiloso, tendo o tensiômetro como instrumento de referência. Desta forma, o estudo foi direcionado para dois objetivos específicos:

1) Acompanhar o funcionamento do TDR comparativamente ao tensiômetro na época seca;

2) Promover a embebição do solo e avaliar seu desempenho sob condições de molhamento e redistribuição da água no solo. 


\section{REVISÃO DE LITERATURA}

\subsection{Instrumentos mais utilizados na obtenção da umidade do solo}

Hignett (2000), analisando diversos métodos utilizados em medições do conteúdo de água no solo concluiu que cada um tem suas vantagens e desvantagens, sendo que em diferentes aplicações, a vantagem em uma pode ser desvantagem em outra. Portanto, não existe um método perfeito para todos os casos. Para selecionar o melhor, é necessário ter um bom conhecimento das propriedades do solo de interesse, das tecnologias disponíveis e dos objetivos desejados.

Segundo Ribeiro (2001), o desenvolvimento de sensores tem seguido os critérios de baixo requerimento de mão-de-obra, sem necessidade de amostragem destrutiva após a instalação e adaptabilidade à mensuração e gravação eletrônicas. E os sensores que preenchem esses critérios são os tensiômetros, as sondas de nêutrons, sensores de capacitância elétrica, sensores de resistência elétrica, sensores de dissipação de calor, reflectômetros no domínio do tempo (TDR) e reflectômetros no domínio da frequência (FDR).

O método padrão de medida do conteúdo de água no solo é o método gravimétrico, por ser o mais simples e permitir diretamente a obtenção da umidade do solo. Apresenta, no entanto, as desvantagens de ser demorado, destrutivo e de não permitir a repetição da amostragem no mesmo local. Os demais métodos são indiretos, ou seja, medem propriedades físicas do solo dependentes da sua umidade. Os mais comuns são as técnicas nucleares, a tensiometria e os métodos dielétricos ou eletromagnéticos. 
Entre as técnicas nucleares, a mais utilizada é a atenuação de nêutrons (cujo equipamento é conhecido como sonda de nêutrons). Segundo Herrmann Jr. (1993), as sondas de nêutrons apresentam as seguintes vantagens, em relação a outros métodos de medida da umidade do solo:

1) o conteúdo médio de água no solo pode ser determinado em diferentes profundidades;

2) pode ser interfaceada com coletores automáticos de dados, possibilitando sua armazenagem;

3) a variação temporal da umidade do solo pode ser facilmente monitorada;

4) as rápidas variações na umidade do solo podem ser detectadas;

5) as leituras estão diretamente relacionadas com a umidade do solo;

6) as medidas podem ser feitas repetidas vezes no mesmo local.

Em contrapartida, apresentam as seguintes desvantagens:

1) o posicionamento incorreto da sonda dentro do tubo de acesso pode causar erros no conteúdo de água no solo;

2) a medida de umidade depende de muitas propriedades físico-químicas do solo, as quais são por si só difíceis de medir;

3) utiliza material radioativo;

4) a esfera de influência de sondas de profundidade não possibilita medidas precisas na superfície.

Uma desvantagem da sonda de nêutrons não citada pelo autor é a sua limitação quando se deseja monitoramento contínuo, devido a não possibilidade de ser deixada no local em que está sendo utilizada. 
A utilização de tensiômetros para obtenção da umidade no solo através da curva de retenção, é a alternativa mais barata, sendo por isso mais acessível. Possui ainda, as vantagens de ser de utilização relativamente fácil e de produzir resultados de boa precisão.

Um tensiômetro consiste de uma cápsula porosa, geralmente feita de cerâmica, conectada a um manômetro através de um tubo, geralmente de PVC, preenchido com água. O tensiômetro deve ser instalado de forma a proporcionar um bom contato entre a cápsula porosa e o solo. Quando o potencial matricial da água no solo é menor (mais negativo) que o da água nos poros da cápsula, a água se desloca do tensiômetro para o solo, através dos poros saturados, criando uma sucção medida pelo manômetro. Quando o solo é umedecido, o fluxo ocorre na direção reversa, até que um novo equilíbrio seja alcançado (Or \& Wraith, 2000).

Manômetros comuns, como os de mercúrio podem ser substituídos por sensores eletrônicos (transdutores de pressão), possibilitando maior facilidade e acurácia na medida, além da automatização. Segundo Or \& Wraith (2000), estes sensores proporcionam maior precisão na leitura do que outros manômetros e o monitoramento contínuo do potencial matricial.

A relação entre o potencial matricial e o conteúdo de água do solo é conhecida como curva de retenção ou curva característica de água no solo. A sua determinação, em geral, é demorada e trabalhosa.

Como desvantagens da técnica podem ser citadas:

1) Dificuldade de automação: a necessidade de automação é sentida principalmente nos casos de monitoramento constante, em tempo real, como por exemplo, em sistemas de irrigação de alta precisão. Por sua vez, a utilização de instrumentos não automatizados implica na necessidade de mão-de-obra tecnificada para realização das leituras;

2) O uso de mercúrio nos manômetros: fundamental no barateamento do conjunto de tensiômetros, o mercúrio é tóxico e de elevado potencial de poluição 
ambiental. Apesar de existir outros tipos de manômetros, o de mercúrio, pela sua sensibilidade e menor custo, ainda é o mais utilizado.

3) Limitada faixa de utilização: (zero até aproximadamente 0,8 da pressão atmosférica local). A faixa de utilização limitada do tensiômetro impossibilita a medição do potencial matricial em solos muito secos.

4) Tempo de resposta: é o tempo necessário para que ocorra o equilíbrio entre a energia da água no tensiômetro e a água no solo. Klute \& Gardner (1962) consideram que o tempo de resposta dos tensiômetros é influenciado pela sensibilidade do tensiômetro, pela condutância hidráulica da cápsula porosa e condutividade hidráulica do solo. Villagra et al. (1988), em trabalho utilizando terra roxa estruturada, concluiu que quanto mais negativo é o potencial matricial, maior o tempo de resposta, sendo que para potenciais em torno de $-50 \mathrm{kPa}$, não ultrapassou oito horas.

A performance do tensiômetro depende, em primeiro lugar, da sensibilidade do manômetro utilizado na leitura. Segundo Dirksen (1999), manômetros de água têm a mais baixa sensibilidade e os transdutores de pressão, as mais altas. Manômetros de mercúrio geralmente têm maior precisão do que os de água.

\subsection{Medição da umidade do solo pela técnica de TDR (Reflectometria no Domínio do Tempo)}

\subsubsection{Princípio de funcionamento}

É amplamente conhecido que as propriedades dielétricas são influenciadas pela umidade, o que não é diferente no caso das propriedades dielétricas do solo (Hallikainen at al., 1985; Zegelin at al., 1992). O fato da constante dielétrica da água $(80,4$ a $293 \mathrm{~K})$ ser muito maior do que a do ar $(1,0)$ e dos constituintes minerais do solo $(3,0$ a 7,0$)$ faz das medidas das propriedades dielétricas do solo uma alternativa atrativa para monitorar a umidade (Topp et al., 1980; Ledieu et al., 1986; Zegelin et al., 1989; Zegelin et al. 1992; Salve, 1998; Noborio, 2001). 
Devido ao mecanismo de polarização da água, o solo úmido é um material dielétrico que tem uma permissividade relativa complexa dependente da frequência, e de maneira simplificada pode ser representada por:

$$
\varepsilon(\mathrm{f})=\varepsilon^{\prime}(\mathrm{f})-\varepsilon{ }^{\prime \prime}(\mathrm{f})
$$

onde $\mathrm{f}$ é a freqüência e $\varepsilon$ e e $\varepsilon$, são a parte real e a imaginária da permissividade $\varepsilon$, respectivamente. A parte real da permissividade é freqüentemente chamada de constante dielétrica $\left(K_{\mathrm{a}}\right)$ e é uma medida da quantidade de energia de um campo elétrico externo que pode ser armazenada no interior de um material contido no respectivo campo. A parte imaginária da permissividade representa as perdas elétricas, tornando-se significante a freqüências superiores a $10 \mathrm{GHz}$.

A técnica de TDR determina a constante dielétrica, $K_{\mathrm{a}}$, medindo o tempo de propagação de uma onda eletromagnética, através de um cabo coaxial até o sensor (geralmente um conjunto de hastes feitas de aço inoxidável ou latão), imerso em um meio. Parte da onda incidente, que pode ser produzida por um testador de cabos, é refletida ao atingir o sensor devido a diferença de impedância entre este e o cabo coaxial. O remanescente da onda propaga-se pelo sensor até alcançar a sua extremidade, sendo também refletida. O tempo de propagação da onda $(t)$, entre o início e o final do sensor, pode ser medido pelo osciloscópio do testador de cabos (Noborio, 2001) e obtido pela equação 2 (Fellner-Feldegg, 1969, entre outros):

$$
t=\frac{2 L K_{a}^{0,5}}{c}
$$

onde $t$ é dado em segundos; $L$, é o comprimento do sensor (m); $K$ é a constante dielétrica do meio e $c$, a velocidade da luz no vácuo $\left(3.10^{8} \mathrm{~m} \mathrm{~s}^{-1}\right)$. Rearranjando a equação 2 , temse:

$$
K_{a}=\left(\frac{c t}{2 L}\right)^{2}
$$


Em um testador de cabos comercial, o termo (ct/2) na equação 3 é reduzido a um comprimento aparente da sonda $L_{\mathrm{a}}$ (equação 4 ), mostrado no testador de cabos (Baker \& Allmaras, 1990) (figura 1):

$$
K_{a}=\left(\frac{L_{a}}{L}\right)^{2}
$$

onde $L_{\mathrm{a}}$ é a distância entre as reflexões no início e final do sensor.

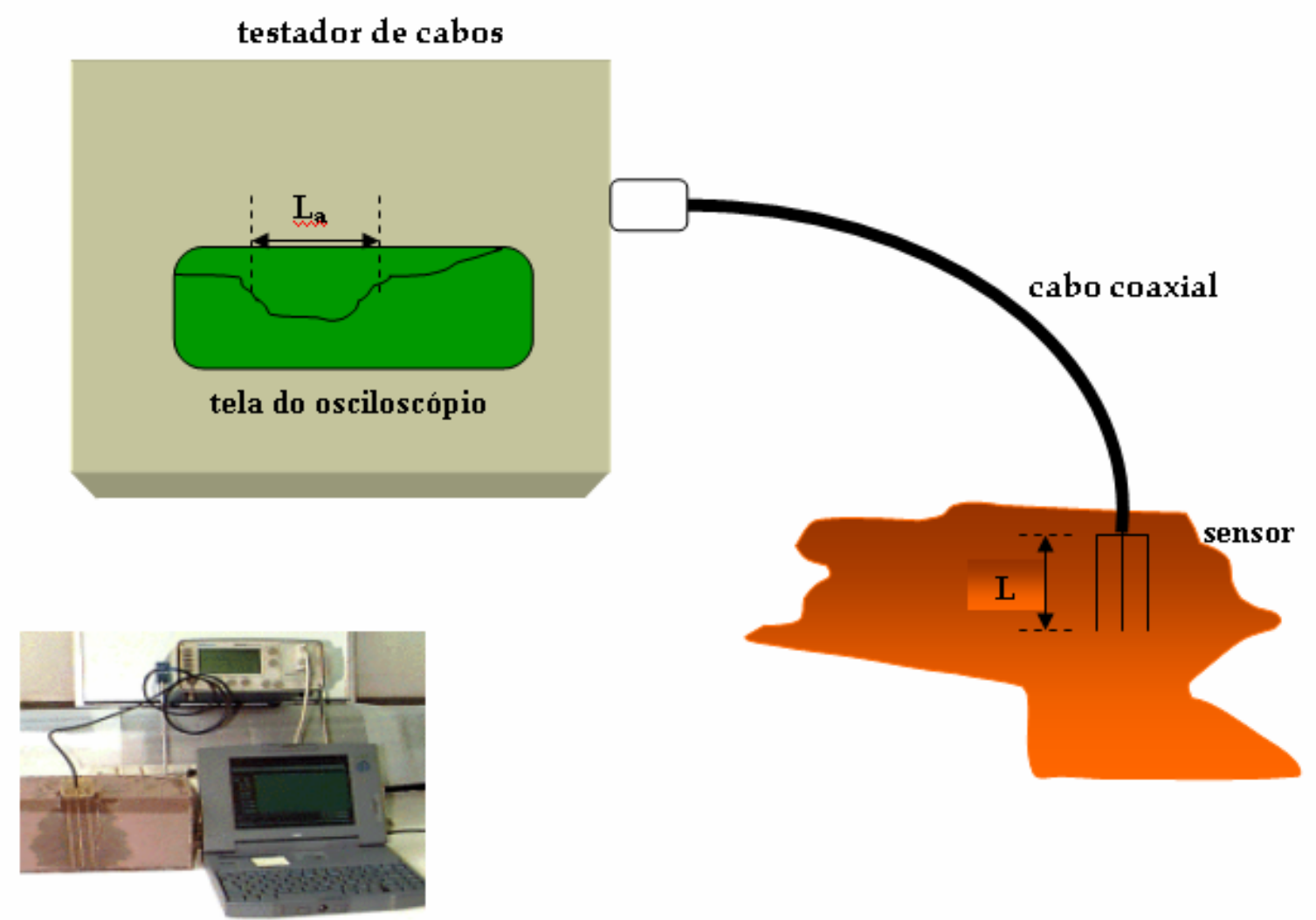

Figura 1 - Esquema simplificado mostrando o comprimento aparente e o comprimento real da sonda (sem escala) e detalhe de um sistema em funcionamento monitorando uma coluna de solo.

Topp et al. (1980) verificaram que a água é a variável mais influente na constante dielétrica do solo. Foram os primeiros a propor um modelo de calibração 
empírico para determinar a umidade volumétrica em função da constante dielétrica do meio:

$$
\theta_{v}=-5,3 \times 10^{-2}+2,92 \times 10^{-2} K-5,5 \times 10^{-4} K^{2}+4,3 \times 10^{-6} K^{3}
$$

onde $\theta_{\mathrm{v}}=$ umidade volumétrica.

Apesar da aplicabilidade da equação 5 para muitas situações, outras calibrações têm sido propostas, baseadas na relação linear entre $\theta_{v}$ e $K^{0,5}$ (Ledieu et al., 1986; Ferré et al., 1996) ou ainda, na relação teórica entre $K$ e os constituintes do solo, baseada em um modelo misto (Roth et al., 1990; Dirksen \& Dasberg, 1993; Friedman, 1997; Weitz et al., 1997). Malicki et al (1996) propôs uma nova equação geral incorporando a densidade do solo:

$$
\theta_{v}=\left(\frac{K^{0,5}-0,819-0,168 \rho_{b}-0,159 \rho_{b}^{2}}{7,17+1,18 \rho_{b}}\right)
$$

onde $\rho_{b}$ é a densidade do solo em $\mathrm{Mg} \mathrm{m}^{-3}$.

As principais vantagens da técnica são: característica não destrutiva, rapidez na obtenção dos resultados, segurança do operador, monitoramento contínuo da água no solo, tanto no espaço quanto no tempo; automatização (Baker \& Allmaras, 1990; Herkelrath et al.,1991), com alta resolução; possibilidade de utilização para medidas simultâneas de conteúdo de água e condutividade elétrica no mesmo volume de amostra, tanto para medidas no campo (Dasberg \& Dalton, 1985; Dalton \& van Genuchten,1986), como em colunas no laboratório (Nadler et al., 1991), principalmente onde os métodos de moderação de nêutrons e radiação gama se tornam inadequados. 


\subsubsection{Fatores que afetam as medidas do TDR}

Os experimentos de Topp et al. (1980) foram, sem dúvida, de grande impulso na determinação dos fatores potencialmente influentes nas medidas da umidade do solo por TDR. Eles verificaram a sensibilidade da constante dielétrica $K$ do solo em relação à temperatura (283-309 K), textura do solo (argiloso ou arenoso), densidade do solo (1140-1440 kg m-3) e teor de sais solúveis (0,01 N CaSO4 ou 2000 ppm de solução de $\mathrm{NaCl})$.

De maneira geral, os trabalhos citados na literatura identificaram os fatores influentes na constante dielétrica do solo como sendo:

1) Temperatura: Davis \& Chudobiak (1975) encontraram um aumento de $10 \%$ na constante dielétrica para um incremento de $39 \mathrm{~K}$ na temperatura de solos arenosos e argilosos. Segundo Look \& Reeves (1982), temperaturas na faixa de 273 a $298 \mathrm{~K}$ têm efeito mínimo sobre a constante dielétrica do solo, contradizendo Selig \& Mansukhani (1975) e Rada et al. (1994), que encontraram efeito significativo para essa mesma faixa de temperatura. Segundo Zegelin et al. (1992), em situações onde podem ocorrer grandes flutuações de temperatura, a influência da mesma na constante dielétrica da água livre deve ser considerada. Ainda segundo o autor, à superfície do solo, onde a temperatura pode chegar a $323 \mathrm{~K}$, a correção da constante dielétrica da água é de quase $11 \%$. Portanto, para medidas próximas à superfície, determinações simultâneas de temperatura são necessárias.

2) Textura do solo: de acordo com Dobson et al. (1985), Roth et al. (1990) e Dasberg \& Hopmans (1992), este efeito não deve ser desprezado tal como colocado por Topp et al. (1980), principalmente no caso de solos argilosos. Segundo Klemunes Jr. (1998), solos argilosos e arenosos têm composições minerais distintas: nos argilosos, predominam magnésio e cálcio, enquanto que nos arenosos, sílica e quartzo. Esta diferença produz um grande variação nos valores de constante dielétrica: cerca de 4,0 para solos de textura argilosa e 8,0 para solos de textura arenosa. Zegelin et al. (1992) relata que a equação 5 funciona melhor em solos arenosos do que em argilosos. 
3) Densidade do solo: de acordo com Hallikainen et al. (1985), a constante dielétrica do solo é função da sua densidade volumétrica. Para solos de textura fina, a densidade é uma variável importante na determinação da constante dielétrica (Tommaselli, 1997)

4) Teor de matéria orgânica: de acordo com Herkelrath et al. (1991), a constante dielétrica está relacionada ao conteúdo de matéria orgânica.

5) Teor de sais no solo: a constante dielétrica complexa usada no TDR assume que a sua porção imaginária é insignificante (Roth et al., 1990). Porém este fato não é verdadeiro sob condições salinas. Na sonda pode ocorrer um curto-circuito, tornando o ponto de inflexão final difícil de identificar (Scott et al., 1983).

6) Teor de óxidos de ferro e manganês no solo: para Tommaselli (1997), não é variável significativa. Roth et al. (1992) detectaram variações na curva de calibração para solos com altos teores de óxido de ferro.

7) Teor de água higroscópica no solo: Dirksen \& Dasberg (1993), Or \& Wraith (2000) e Robinson et al. (2002) tratam da contribuição da água fortemente retida no solo para a constante dielétrica. Para Robinson et al. (2002) existe a necessidade de incorporar o efeito dessa água, pois em solos onde ele ocorre, a equação (5) pode subestimar em até $10 \%$ o valor da umidade do solo.

O efeito da estrutura do solo na equação 5 é negligível (Keng \& Topp, 1983) assim como o efeito da histerese para solos arenosos (Topp et al., 1980).

Além dos efeitos das propriedades do solo sobre a constante dielétrica, existem fatores de ordem técnica que afetam as medidas, tais como: ruídos eletromagnéticos, comprimento e especificação do cabo coaxial, metodologia para obtenção do comprimento aparente (Klemunes Jr., 1998), etc. Com relação ao efeito do comprimento do cabo de TDR na reflexão do sinal, Herkelrath et al. (1991) encontraram, em estudos realizados em laboratório, que os cabos longos tendem a atenuar o sinal. Os autores concluíram que cabos que apresentam um comprimento de até $27 \mathrm{~m}$ não causam problemas na reflexão do sinal. Hook \& Livingston (1995) 
verificaram que os cabos coaxiais de $75 \Omega$ apresentam "menor tempo de resposta" (rise time), menor diâmetro e mais baixo custo quando comparado ao cabo RG58 de $50 \Omega$. Em relação ao tipo de sonda, Zegelin et al.(1989) encontraram que sonda de três e quatro hastes são muito similares na determinação da constante dielétrica, mas em função do distúrbio causado na introdução da sonda de quatro hastes, são menos atrativas para aplicações no campo.

\subsection{Comparações entre tensiometria e TDR}

Diversos trabalhos avaliaram o uso combinado da reflectometria no domínio do tempo e do tensiômetro (Whaley et al., 1994; Otto \& Alcaide, 2001; Herrmann Jr., 2001, Vaz, 2001). Poucos, porém, são os que comparam as duas técnicas na determinação do conteúdo de água do solo.

Kunzelmann \& Paschold (1988), compararam blocos de gesso (método da resistência elétrica), tensiometria e TDR na determinação da umidade do solo em local cultivado com aspargo, a fim de regular o tempo e a intensidade de um sistema de irrigação automatizado. Concluíram que tensiômetros são recomendáveis para irrigação no cultivo de aspargo e TDRs são muito caros para culturas intensivas, mas apresentam dados adequados.

Teixeira (2001), comparando tensiômetros, TDR e sonda de nêutrons, concluiu que a técnica de TDR apresentou sensibilidade inferior na detecção de bolsões de ar (oscilações entre potencial de pressão e mátrico), durante o processo de embebição do solo. Também não pôde concluir se a técnica de TDR apresenta superioridade ao tensiômetro na obtenção de valores de umidade ao longo do tempo. 


\section{MATERIAL E MÉTODOS}

\subsection{Caracterização da área experimental}

\subsubsection{Localização}

O experimento foi instalado próximo ao Posto Meteorológico do Departamento de Ciências Exatas da Escola Superior de Agricultura Luiz de Queiroz, Universidade de São Paulo, em Piracicaba (SP), cujas coordenadas geográficas são: $22^{\circ}$ $42^{\prime} 30^{\prime \prime}$ de latitude sul, $47^{\circ} 38^{\prime} 00^{\prime}$ ' de longitude oeste, a $546 \mathrm{~m}$ de altitude.

\subsubsection{Clima}

Em Piracicaba o clima é do tipo $C w a$, segundo a classificação de Köppen, denominado "tropical de altitude". É um clima de inverno seco, em que a temperatura média do mês mais frio é inferior a $18{ }^{\circ} \mathrm{C}$ e a do mês mais quente ultrapassa $22{ }^{\circ} \mathrm{C}$. As médias anuais de temperatura, precipitação e umidade relativa são de $21,1{ }^{\circ} \mathrm{C}, 1.257 \mathrm{~mm}$ e $74 \%$, respectivamente. A estação seca ocorre entre os meses de abril e setembro, sendo julho o mês mais seco. O mês mais chuvoso oscila entre janeiro e fevereiro e o total das chuvas do mês mais seco não ultrapassa $30 \mathrm{~mm}$. 


\subsubsection{Solo}

Conforme Embrapa (1999) o solo é classificado como Nitossolo Vermelho Distrófico latossólico (NVdf). A caracterização morfológica do solo (realizada em trincheira aberta na área, anteriormente a instalação do experimento) e análises de características físicas do solo estão detalhadas em Teixeira (2001). As tabelas contendo as caracterizações físico-hídricas do solo são apresentadas no Apêndice.

Uma rápida análise das Tabelas 1, 3, 4 e 5 mostra que as camadas 0,40-0,50 e 0,90-1,00m apresentam, em termos médios, as maiores variabilidades, comparativamente às demais. A escolha deste solo deu-se propositadamente em função dessa variabilidade físico hídrica, o que tem representado problema em estudos de monitoramento de água no solo (Prevedello et al., 1981; Pauletto et al., 1988; Jong van Lier \& Libardi, 1999) e, portanto, uma oportunidade de comparar-se o desempenho de instrumentos em situações-problema.

\subsection{Equipamentos utilizados e sua localização}

A descrição detalhada do preparo da área experimental, dos tensiômetros utilizados (teste das cápsulas porosas, construção e instalação), equipamento de TDR e sistema automático de aquisição de dados utilizados (componentes do sistema, designação de endereçamentos, coleta e recuperação de dados, proteção eletromagnética, aterramento e proteção contra surtos de tensão nos equipamentos) pode ser encontrada em Teixeira (2001).

Foram estudados os dados produzidos pelos tensiômetros e equipamentos que utilizam a técnica de reflectometria no domínio do tempo, mais comumente denominada TDR, instalados em uma área experimental contendo um volume de solo de 7,07 $\mathrm{m}^{2}$ de área e 1,30 $\mathrm{m}$ de profundidade, delimitada por uma chapa galvanizada de $1,00 \mathrm{~m}$ de altura e $1,5 \mathrm{~m}$ de raio, introduzida no solo até $0,80 \mathrm{~m}$ de profundidade. $\mathrm{O}$ objetivo da utilização da chapa galvanizada foi "quebrar" o B textural e dessa forma evitar o fluxo 
de água lateralmente, forçando a infiltração vertical e, portanto, o molhamento das camadas mais profundas do solo.

As profundidades de instalação dos equipamentos foram definidas como sendo de $0,10 \mathrm{em} 0,10 \mathrm{~m}$, sendo a primeira profundidade a $0,40 \mathrm{~m}$ da superfície e a última 1,30 m. Desta forma, procurou-se evitar o efeito da temperatura nas medidas dos tensiômetros e de TDR (Zegelin et al., 1992), além de qualquer possível interferência de camadas superficiais compactadas por pisoteio.

No centro da área experimental estão instaladas três baterias de tensiômetros, composta por 10 tensiômetros cada, distanciados lateralmente entre si de 0,20 m (Figura 2). Procurou-se dispor os tensiômetros na parcela de forma que os mais profundos ficassem no centro e os mais superficiais lateralmente, a fim de diminuir as chances de que os tensiômetros mais profundos fossem atingidos pela frente de molhamento devido ao fluxo lateral. Três manômetros de mercúrio foram instalados externamente a aproximadamente $0,50 \mathrm{~m}$ da parcela experimental em uma posição em que houvesse a menor interferência possível de aquecimento pelo sol, principalmente durante os horários de leitura. Com esta finalidade também, foi colocada sobre a área uma cobertura de telhas de chapa de aço (Figura 2), evitando ainda, a entrada de água por precipitação.

Para a utilização da técnica da reflectometria no domínio do tempo, foram empregados os seguintes componentes:

- testador de cabos (Figura 3d) da marca Tektronix, modelo 1502B;

- um "datalogger" (Figura 3c), modelo CR10X (que controla e analisa as formas de onda produzidas pelo testador de cabos, possibilitando o acesso aos sensores de TDR através do sistema de multiplexação);

- "synchronous device for measurement ", SDM 1502 (interface responsável pelas funções de comunicação para a transferência das instruções e dados entre o TDR e "datalogger");

- dois multiplexadores do tipo coaxial 8:1, modelo SDMX50, impedância de 
50 ohms; supressor de transientes 6590 (a fim de reduzir as variações de tensão a um nível que não cause danos aos equipamentos a ele conectados);

- sensores de umidade, modelo CS605 (os quais transportam um sinal não balanceado).

Os sensores de umidade utilizados foram o de três hastes (Figura 3e), num total de 15 sensores distribuídos nas camadas do perfil do solo, conectados aos multiplexadores por meio de conectores do tipo BNC (Teixeira, 2001).

Para a coleta dos dados do "datalogger", utilizou-se um módulo de armazenamento, modelo SM192, o qual conectado ao "keyboard display" (Figura 3c), modelo CR10KD e de posse das instruções adequadas, possibilitou o armazenamento dos dados e posterior recuperação dos mesmos. Para o descarregamento dos dados para o computador utilizou-se o "software" PC208W, em ambiente Windows, que possibilita a coleta e armazenamento dos dados e também a transferência de programas para o “datalogger”. Para o descarregamento foi necessária a utilização de uma interface SC532 e seus cabos associados, para a conexão do módulo de armazenamento à porta COM do computador. 

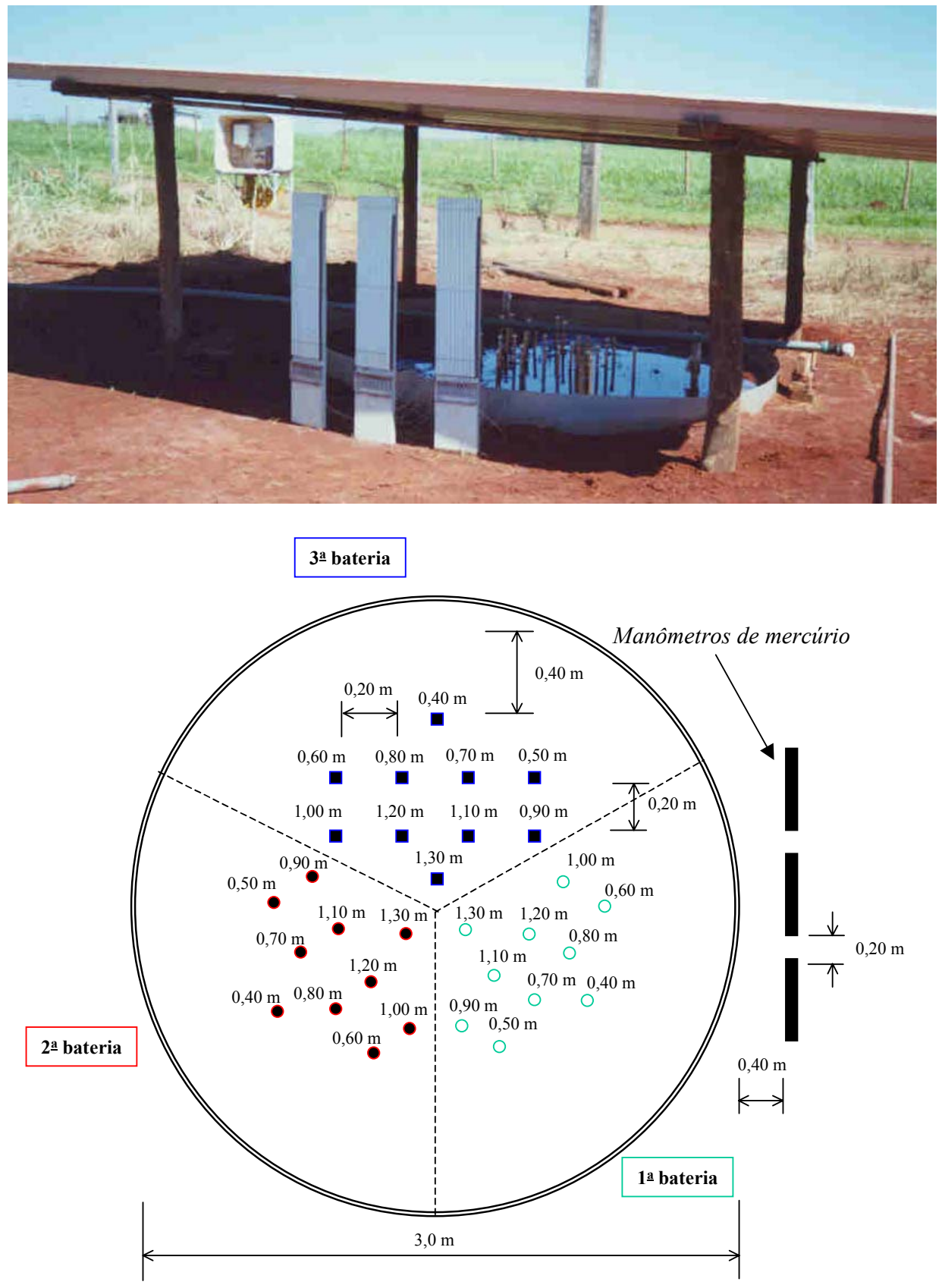

Figura 2 - Parcela experimental: vista geral, mostrando a área delimitada pela chapa de aço, coberta com o telhado e distribuição dos tensiômetros, com respectivas distâncias e profundidades de instalação (adaptado de Teixeira, 2001) 
a)

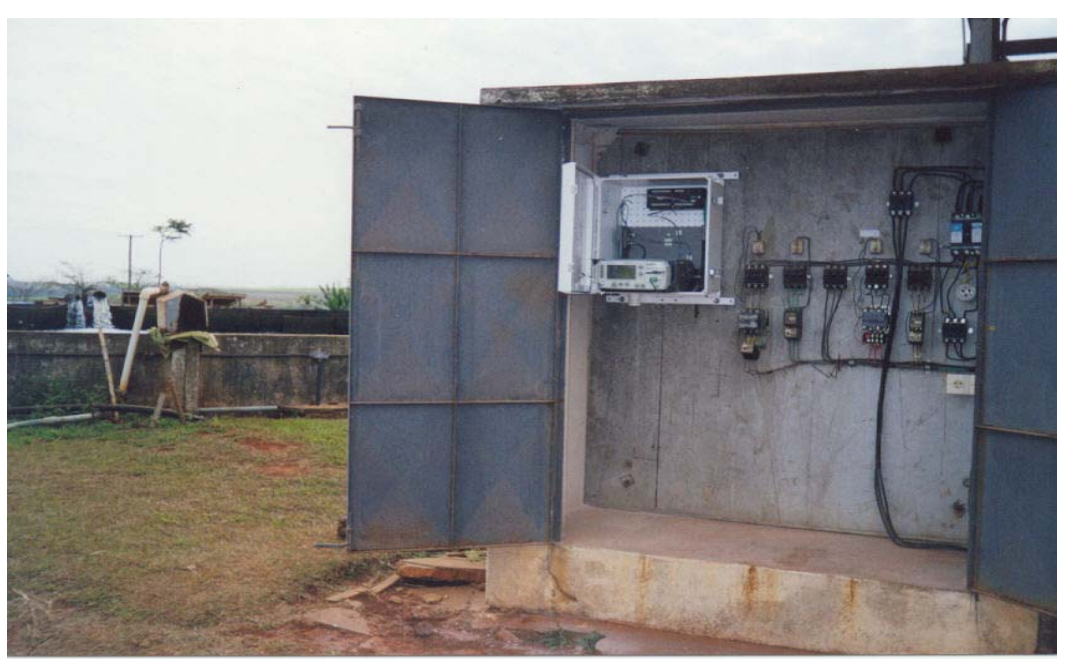

b)

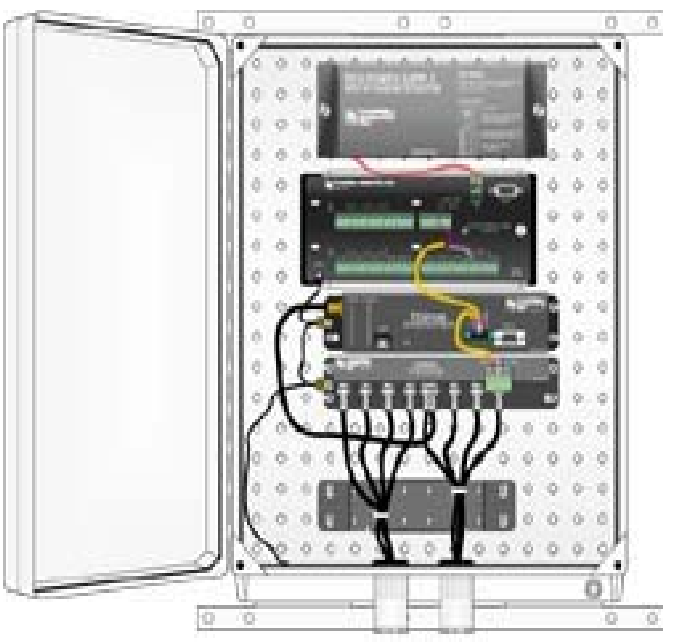

c)
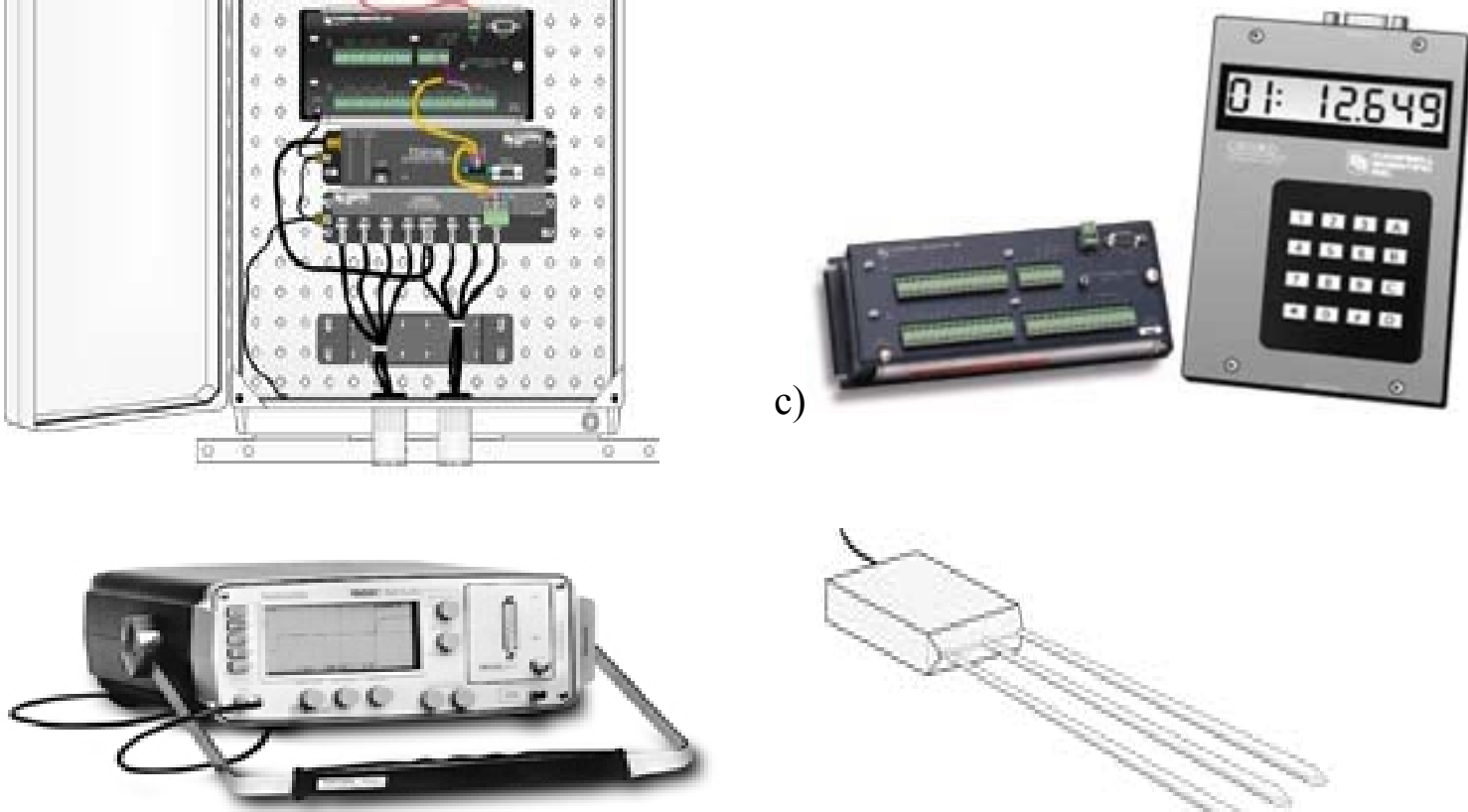

d)

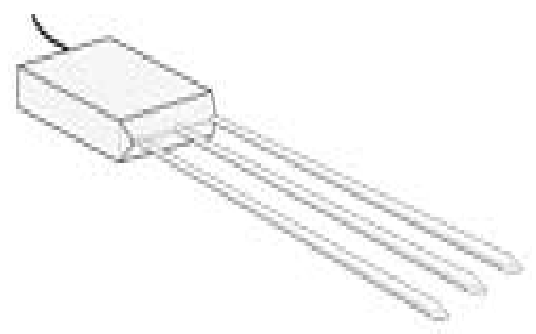

e)

Figura 3 - Equipamentos utilizados: a)dentro da caixa de força, onde foram instalados; b) caixa ambientalmente selada contendo,: SDM1505, "datalogger" CR10X e supressor de transientes; c)"datalogger" e "keyboard display"; d) testador de cabos; e) sensor de umidade de três hastes, modelo CS605. 


\subsection{Medidas de tensiômetros e TDR}

Os tensiômetros foram previamente fluxados com água destilada e deaerada. A equação para transformação das leituras de alturas de coluna de mercúrio das baterias de tensiômetros em potencial mátrico é:

$$
\psi_{m}=-12,5 H+h_{c}+z
$$

onde $H$ é o valor da leitura, $h_{c}$ a altura da cuba de mercúrio e $z$ a profundidade de instalação do tensiômetro, considerada desde a superfície do solo até a metade do comprimento da cápsula porosa. Como os manômetros foram instalados com diferentes alturas, os valores de $h_{c}$ para cada bateria de tensiômetros são variáveis.

Quando foi realizada apenas uma leitura no dia, procurou-se fazer aproximadamente nos horários de temperatura mais amena, de forma a evitar a sua influência nos manômetros de mercúrio e, conseqüentemente, nas leituras.

As leituras dos sensores de TDR foram obtidas a uma frequência de 1800s, possível pelo uso do sistema automático de aquisição de dados.

Para a transformação dos valores de constante dielétrica em umidade volumétrica utilizou-se duas calibrações: uma utilizando valores de umidade obtidas pelos tensiômetros; e outra utilizando a equação 5 desenvolvida por Topp et al. (1980). No primeiro caso, utilizou-se uma faixa de umidade de 0,256 a $0,482 \mathrm{~m}^{3} \mathrm{~m}^{-3}$ para a profundidade $0,40 \mathrm{~m}$; para $0,50 \mathrm{~m}$; para $0,60 \mathrm{~m}$; para $0,70 \mathrm{~m}$; para $0,80 \mathrm{~m}$; para $0,90 \mathrm{~m}$; para $1,00 \mathrm{~m}$; para $1,10 \mathrm{~m}$; para $1,20 \mathrm{~m}$ e para $1,30 \mathrm{~m}$. Convém observar que antes a faixa para $0,40 \mathrm{~m}$ era de 0,373 a $0,482 \mathrm{~m}^{3} \mathrm{~m}^{-3}$; o valor $0,256 \mathrm{~m}^{3} \mathrm{~m}^{-3}$ não foi obtido pelo tensiômetro, mas por amostragem direta na área, por ocasião de instalação de um tubo para sonda de nêutrons, em um período de solo seco. Ocorreu o mesmo para as demais profundidades.

Para fazer a comparação entre as medidas de TDR e de tensiômetro, utilizouse os dados nos quais havia coincidência de horário de leitura. 


\subsection{Sensibilidade do TDR na detecção de variações de umidade do solo}

Para avaliação do desempenho do TDR, na detecção de variações de umidade do solo, foram efetuadas leituras sob diferentes conteúdos de água no solo.

Para as análises dos dados, dividiu-se o período total do experimento em três subperíodos:

1.) Durante a realização de um ensaio de determinação de condutividade hidráulica do solo não saturado $(\mathrm{K}(\theta))$, de acordo com o método do perfil instantâneo

Foram utilizados dados de um ensaio de $\mathrm{K}(\theta)$ conforme o método do perfil instantâneo - M.P.I. (Teixeira, 2001). Este período compreende um intervalo de tempo de 1462 horas. O seu início corresponde ao momento em que o potencial matricial está próximo a zero, e o seu fim, no ponto a partir do qual ele não apresenta variação significativa com o tempo.

Para aplicação do método do perfil instantâneo, além do telhado de chapa galvanizada foi feita a cobertura da parcela experimental com plástico de polietileno preto a fim de evitar os processos de evaporação e também entrada de água proveniente de chuvas. A estrutura possibilita o livre acesso para a fluxagem dos tensiômetros. Aplicou-se aproximadamente $24 \mathrm{~m}^{3}$ de água, durante 10 dias.

O método do perfil instantâneo não é de interesse neste estudo, mas possibilita obtenção de dados sob condições de secagem. Ele é utilizado para determinação da condutividade hidráulica do solo não saturado e pode ser encontrado, por exemplo, em Dirksen (1999) ou em Libardi (2000).

\section{2.) Período de secagem do solo}

É um período intermediário, de 4840 horas, em que há redução da umidade do solo. Na prática, é o período em que não é aplicada água no solo. Exceto quando foi removida a telha que recobria a parcela experimental, expondo-a a entrada de água da chuva. Porém, a quantidade de água não foi suficiente para resultar em grandes 
mudanças nos valores de umidade.

A umidade do solo chegou a valores próximos a umidade volumétrica residual. Desta forma, objetivou-se verificar o comportamento dos instrumentos nestas condições e no momento de variação brusca da umidade (aplicação de água) no período seguinte.

3.) Período de inundação intermitente

O processo de inundação intermitente tem o objetivo de conseguir uma melhor embebição, melhorando a saturação dos poros do solo e favorecendo a redistribuição da água. Foram feitas inundações diárias, adicionando ao solo água gradativamente.

Neste período, de 768 horas, foi aplicada água durante diferentes intervalos de tempo. Foram realizadas 10 inundações diárias, a uma vazão de aproximadamente 25.10-5 m3 s-1. Na primeira, aplicou-se 2,55 $\mathrm{m}^{3}$ de água; nas seguintes: $1,45 \mathrm{~m}^{3}$; $4,77 \mathrm{~m}^{3} ; 0.52 \mathrm{~m}^{3} ; 5,53 \mathrm{~m}^{3} ; 2,95 \mathrm{~m}^{3} ; 4,38 \mathrm{~m}^{3} ; 4,29 \mathrm{~m}^{3} ; 4,36 \mathrm{~m}^{3}$ e na última, $4,35 \mathrm{~m}^{3}$. As duas primeiras não foram aproveitadas devido a problemas no funcionamento do testador de cabos, posteriormente resolvido.

As leituras dos tensiômetros durante as inundações foram realizadas em intervalos que variaram de $1800 \mathrm{~s}$ a $3600 \mathrm{~s}$, sendo a primeira antes do início do acionamento da motobomba e a última após infiltração da água da superfície. A partir dos dados obtidos em cada camada, com os equipamentos citados, foi possível a realização dos cálculos correspondentes. 


\section{RESULTADOS E DISCUSSÃO}

Como são duas propriedades físicas distintas (constante dielétrica e potencial matricial) utilizadas para obter uma mesma variável, umidade volumétrica, optou-se por fazer primeiramente uma análise da correlação entre os valores das propriedades, com o objetivo de se ter uma percepção preliminar da coerência dos mesmos. Após a utilização da respectiva curva de calibração para o TDR e de retenção para os tensiômetros, comparou-se, então, os valores obtidos de umidade volumétrica.

\subsection{Análise $K_{\mathrm{a}} \times \psi_{\mathrm{m}}$}

A figura 4 , que utiliza a profundidade $0,40 \mathrm{~m}$ como exemplo, possibilita uma idéia inicial do comportamento das variáveis constante dielétrica e potencial matricial do solo ao longo do tempo. Antes da discussão pertinente, é indispensável explicar como foi obtida.

Dada a necessidade de referenciar as escalas, em torno de uma umidade volumétrica conhecida, com o objetivo de proporcionar uma visualização gráfica mais adequada, adotou-se dois pontos:

- Umidade de saturação do solo, onde o potencial matricial é zero;

- $0,35 \mathrm{~m}^{3} \mathrm{~m}^{-3}$, um valor não muito superior a umidade volumétrica residual para a maioria das profundidades (Tabela 6, Apêndice). 
No primeiro ponto, conhecendo-se o potencial matricial (zero), faltava o valor de $K_{\mathrm{a}}$ correspondente. Para obtê-lo, utilizou-se o seguinte artifício: inseriu-se o valor da umidade de saturação $(0,494$, Tabela 6 , Apêndice) na curva do experimento 9 de Topp et al. (1980), referente a um solo classificado como muito argiloso, com $66 \%$ de argila, similar ao solo em estudo $(65 \%$ de argila para a maioria das camadas - Tabela 1, Apêndice). Este valor na referida curva corresponde a $K_{\mathrm{a}}=35$.

Para o segundo ponto, $\theta=0,35 \mathrm{~m}^{3} \mathrm{~m}^{-3}$, o potencial matricial correspondente obtido pela curva de retenção é de $-28 \mathrm{kPa}$ (Teixeira, 2001) e o valor de $K_{\mathrm{a}}$ na mesma curva de Topp anteriormente citada é 19.

O objetivo principal da Figura 4 não foi verificar se houve superestimação ou subestimação dos valores obtidos pelo TDR, mas se houve acompanhamento das variações da constante dielétrica com o potencial matricial. Ou seja, se, por exemplo, um acréscimo de umidade do solo e um correspondente aumento do potencial matricial (menos negativo), foi seguido de aumento da constante dielétrica. Nesse sentido, observa-se que nas três figuras (4a, $4 b$ e $4 c)$ houve alguma discordância entre as duas propriedades físicas em relação ao seu comportamento ao longo do tempo. Esta pode ter ocorrido ou não devido a dados discrepantes (mais provavelmente no caso da Figura 4a). Entretanto, como foi realizada uma verificação da consistência dos dados, presume-se que haja realmente alguma diferença de sensibilidade na detecção de variações da umidade do solo entre os dois instrumentos.

$\mathrm{Na}$ Figura $4 \mathrm{a}$ observa-se, ainda, que $K_{\mathrm{a}}$ decresce mais rapidamente que o potencial matricial. Como os valores de $K_{\mathrm{a}}$ da água (em torno de 80) são muito maiores do que os valores do solo, as propriedades eletromagnéticas do solo são enormemente afetadas por pequenas quantidade de água livre (Schumugge \& Jackson, 1980). Em baixos níveis de umidade existe um pequeno aumento da constante dielétrica com a umidade do solo, mas, acima de um certo ponto, a declividade da curva $K_{\mathrm{a}} \times \theta_{\mathrm{v}}$ incrementa acentuadamente (Herrmann, 2001), 
a)
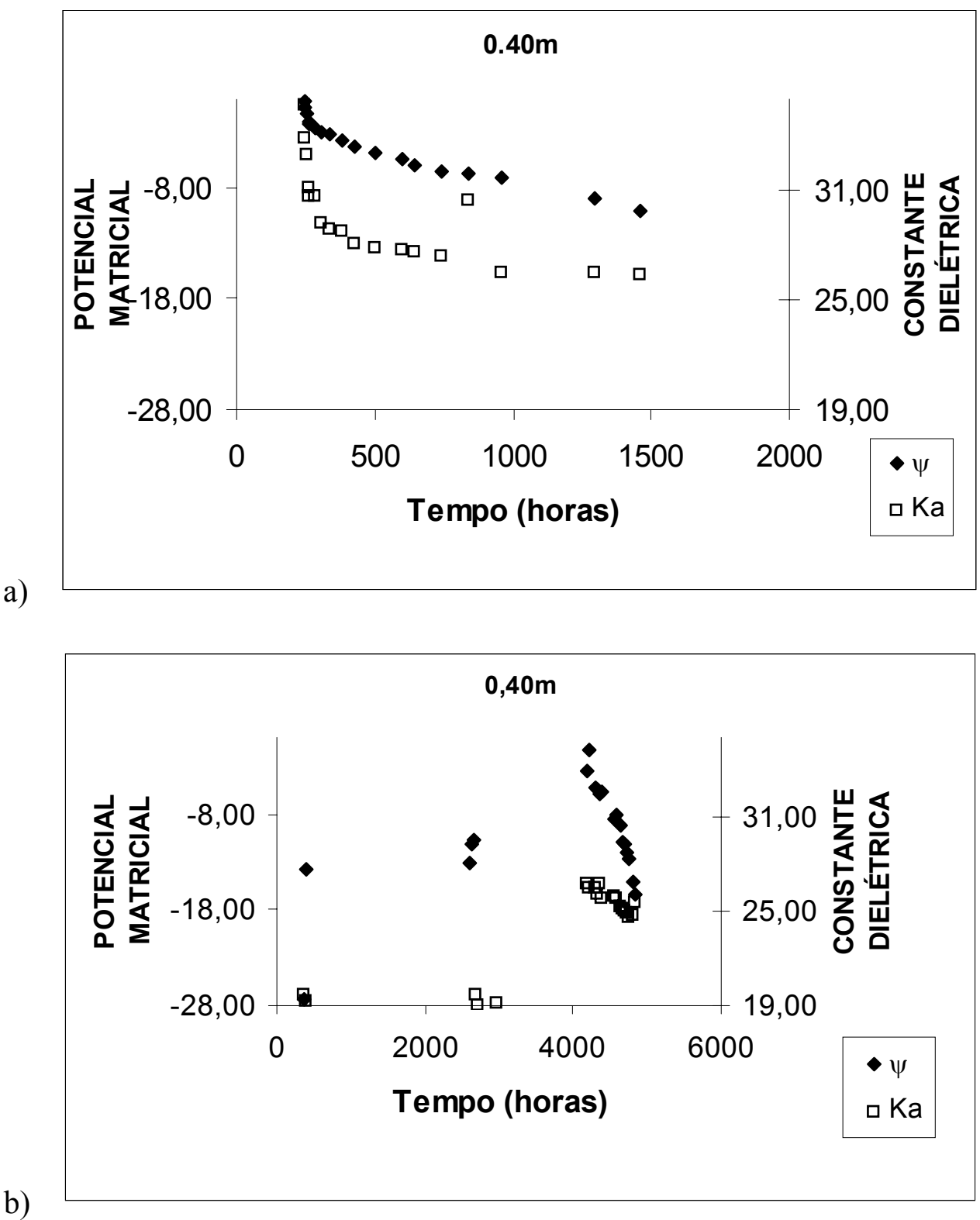

Figura 4 - Comportamento do potencial matricial (em $\mathrm{kPa}$ ) e da constante dielétrica ao longo do tempo, para a profundidade $0,40 \mathrm{~m}$, nas três situações estudadas: (a) durante ensaio de condutividade hidráulica pelo MPI; (b) período de secagem do solo; (c) período de inundação intermitente. 
c)

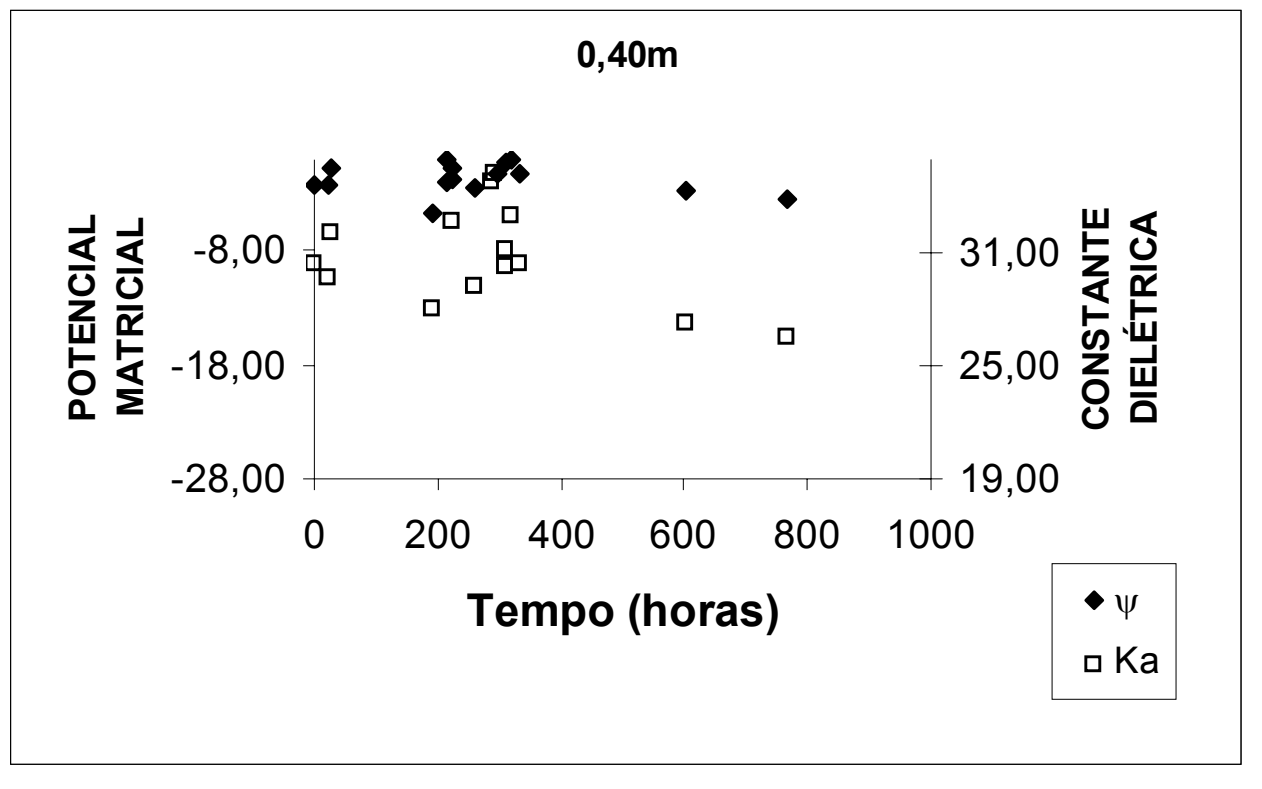

Figura 4 - Comportamento do potencial matricial (em $\mathrm{kPa}$ ) e da constante dielétrica ao longo do tempo, para a profundidade $0,40 \mathrm{~m}$, nas três situações estudadas: (a) durante ensaio de condutividade hidráulica pelo MPI; (b) período de secagem do solo; (c) período de inundação intermitente.

Como no período de secagem do solo (Figura 4b) houve falta de dados, resultando em grandes descontinuidades nas curvas, a visualização do seu comportamento ficou bastante comprometida. Talvez haja uma tendência a maior distância entre as curvas do que nos outros períodos.

Observa-se na Figura 4c, pela dispersão dos pontos para as duas curvas, que os valores de constante dielétrica apresentam maior variação do que os de potencial matricial. Tendo em vista que no período foram realizadas várias inundações da parcela experimental, resultando em sucessivos aumentos e diminuições da umidade do solo, que deveriam corresponder a variações proporcionalmente semelhantes das propriedades físicas em estudo, a figura sugere a possibilidade de superioridade do TDR na detecção de variações de umidade. Pode-se supor que embora a profundidade escolhida $(0,40 \mathrm{~m})$ seja próxima a superfície e, portanto, sondas de TDR e tensiômetros foram atingidos pela frente de molhamento (a chapa metálica também garante este fato), o tempo de 
resposta do tensiômetro não foi suficiente para acusar as variações que ocorrem em curto espaço de tempo (Villagra et al., 1988).

A partir dessas indicações de diferença de sensibilidade entre os dois instrumentos na medição da umidade do solo, realizou-se, em seguida, a correlação entre os dados de constante dielétrica e potencial matricial obtidos. O objetivo deste procedimento foi ter uma idéia do grau de concordância no comportamento destas duas variáveis mediante a variação da umidade do solo.

Inicialmente, foram correlacionados os dados das três situações conjuntamente e em seguida, separadamente para cada situação, visando a comparação entre os coeficientes de determinação para análise conjunta e em separado.

A Figura 5 apresenta a correlação entre as duas propriedades, utilizando todos os dados disponíveis, ou seja, de todas as situações estudadas.

Esperava-se uma correlação positiva entre as variáveis, uma vez que à medida que o solo vai secando, o potencial matricial vai diminuindo, ou melhor, se tornando mais negativo, e os valores de constante dielétrica também diminuem.

Nota-se nas figuras que os maiores coeficientes de determinação estão nas profundidades $0,40 \mathrm{~m}, 0,50 \mathrm{~m}, 0,80 \mathrm{~m}$ e $0,90 \mathrm{~m}$. Isto sugere que para as primeiras profundidades os dois instrumentos tiveram desempenho similar na detecção de variações de umidade do solo; nas profundidades seguintes, porém, um dos instrumentos foi superior ao outro (exceto na região do "B textural", onde o movimento da água é lento, $\operatorname{logo}$, o desempenho dos dois instrumentos volta a ser similar).

De acordo com a classificação de Levin (1987), que mensura a "força" da correlação entre duas variáveis, as correlações obtidas foram do tipo positiva fraca para as profundidades 0,60 e $0,70 \mathrm{~m}$ e positiva moderada a forte para as demais. Uma hipótese para tal intensidade de correlação seria a existência de valores incoerentes. Verificou-se, no conjunto total de dados, o seguinte problema: para um mesmo valor de potencial mátrico, existiam dois valores de constante dielétrica e vice-versa. Este fato somado ao das leituras nas inundações serem feitas a cada meia ou uma hora, indica que um dos 
dois instrumentos ou ambos não apresentou sensibilidade suficiente na detecção das variações na umidade do solo.

Visando identificar o período que mais contribuiu para as diferenças entre as maiores e menores correlações para as profundidades estudadas, realizou-se a análise de correlação para cada período, conforme discutido a seguir.
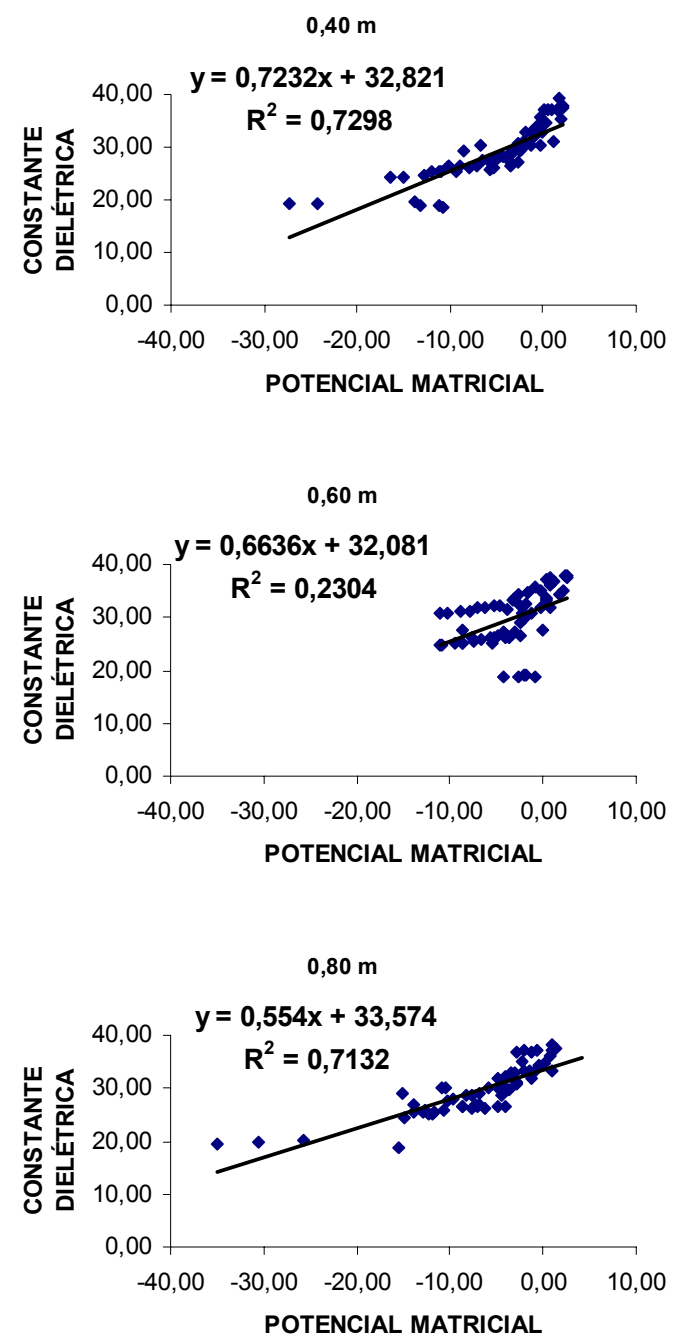
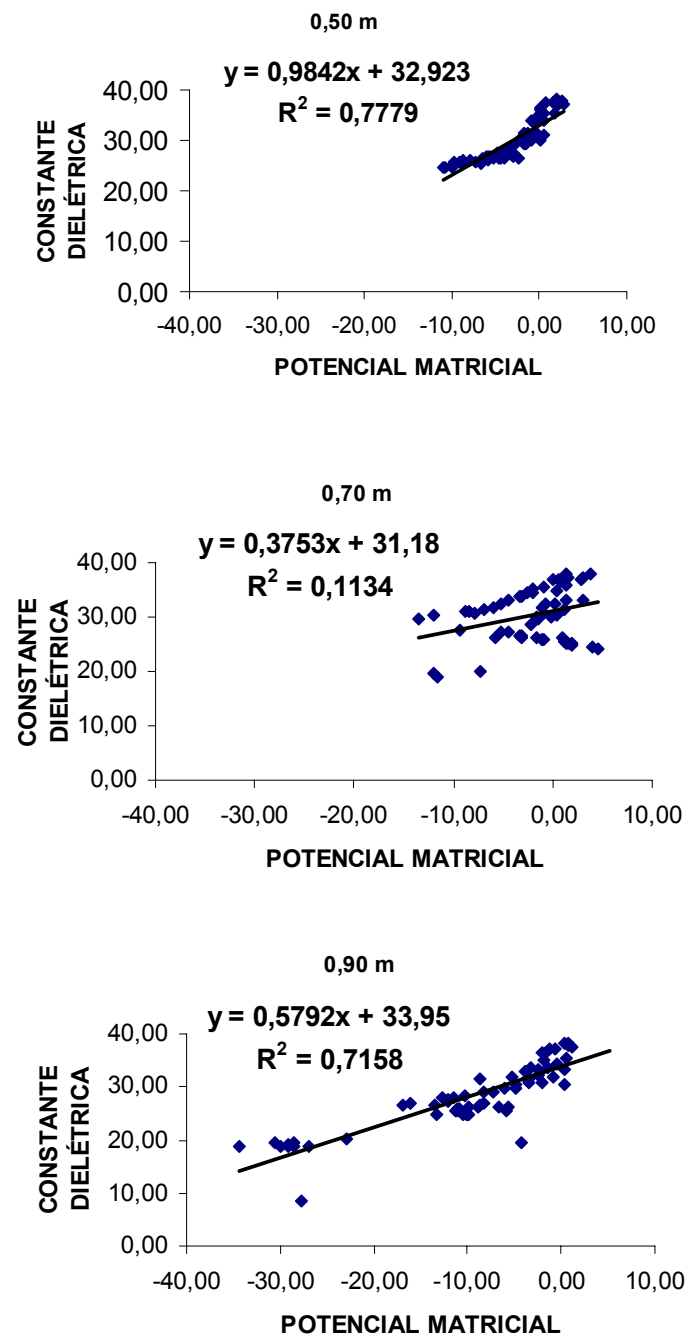

Figura 5 - Correlação entre o potencial matricial (em $\mathrm{kPa}$ ) e a constante dielétrica, para as profundidades estudadas 

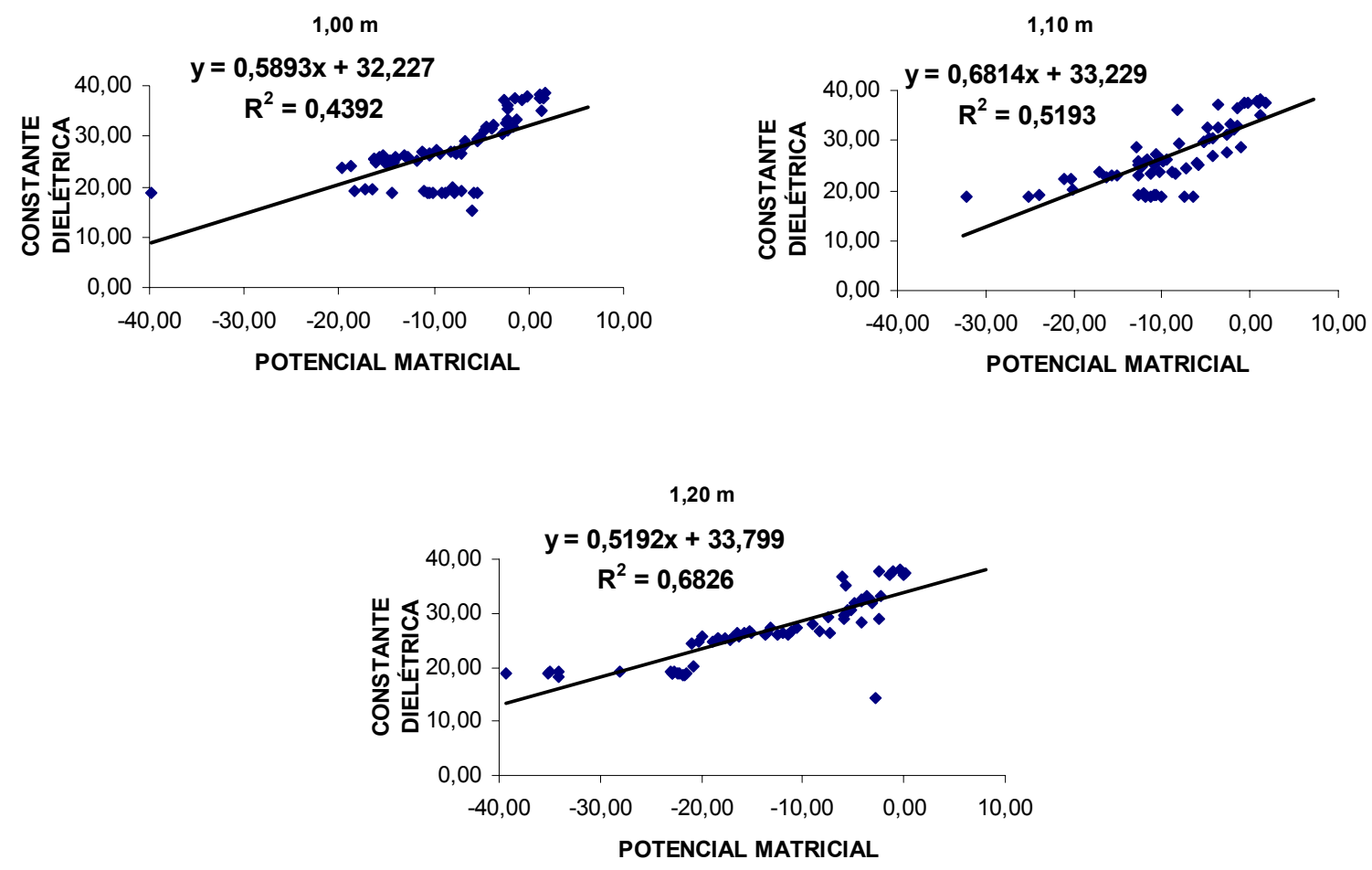

Figura 5 -Correlação entre o potencial matricial (em $\mathrm{kPa}$ ) e a constante dielétrica, para as profundidades estudadas

\subsubsection{Dados de um ensaio de condutividade hidráulica conforme o MPI}

A Figura 6 apresenta, para as profundidades em estudo, a correlação entre os valores de potencial mátrico e constante dielétrica na ocasião do ensaio de condutividade hidráulica utilizando o método do perfil instantâneo.

Para o período, o coeficiente de determinação foi superior a 0,70 para a maioria das profundidades. Isto sugere um bom grau de concordâncias entre as duas propriedades no período. Pela classificação de Levin (1987), a correlação foi do tipo moderada a forte em todas, não havendo nenhuma do tipo fraca, como no caso anterior, em que foram correlacionados todos os dados em conjunto. Portanto, a correlação obtida 
confirma o que já a Figura 4a indicava, uma concordância razoavelmente boa entre os dois instrumentos.

O menor coeficiente de determinação foi obtido para a profundidade $0,90 \mathrm{~m}$. Existe a possibilidade de influência do "B textural", presente nesta região, sobre este resultado. Teixeira (2001) verificou que nesta profundidade foram obtidos as maiores faixas de umidade para a calibração do TDR, e na seguinte, 1,00 m, as menores, sugerindo a presença do "B textural" ou camada compactada, provocando fluxo lateral e dificuldade de saturação nas profundidades abaixo.

$$
0,40 \mathrm{~m}
$$

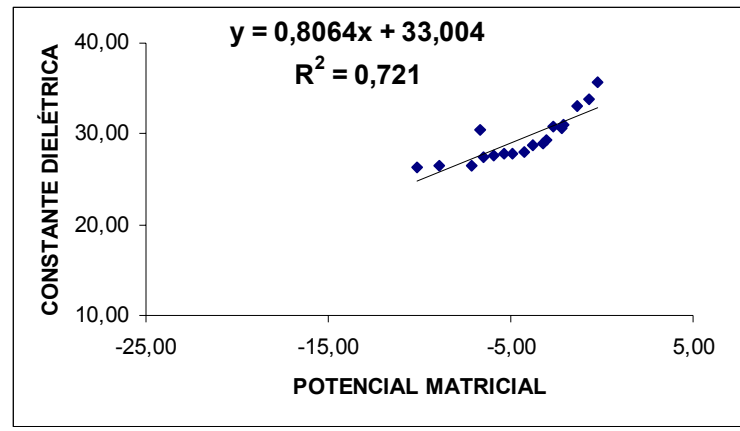

\section{$0,60 \mathrm{~m}$}

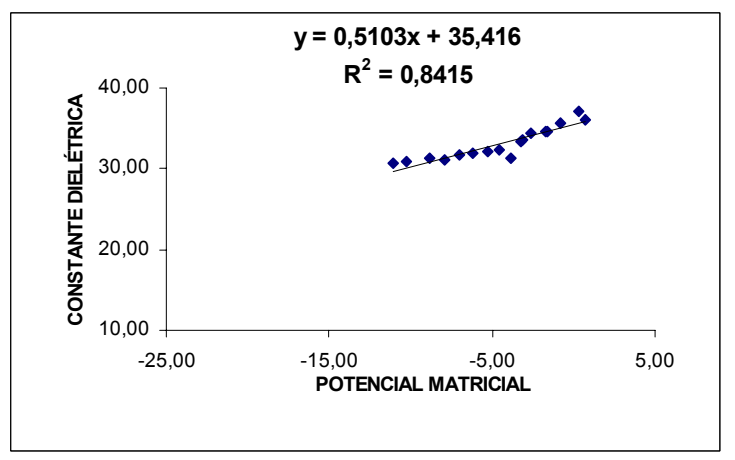

\section{$0,50 \mathrm{~m}$}

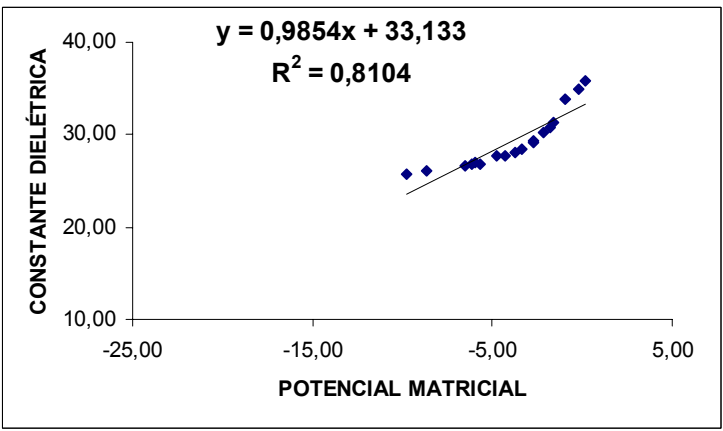

$0,70 \mathrm{~m}$

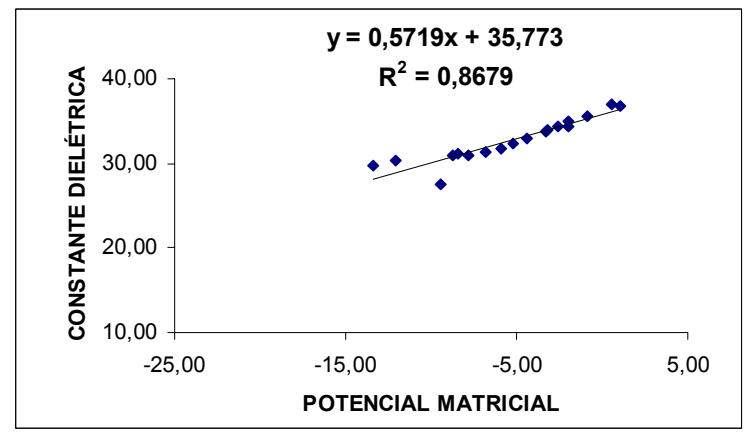

Figura 6 - Correlação entre o potencial matricial e a constante dielétrica, para as profundidades estudadas, utilizando os dados de um ensaio de condutividade hidráulica pelo MPI 

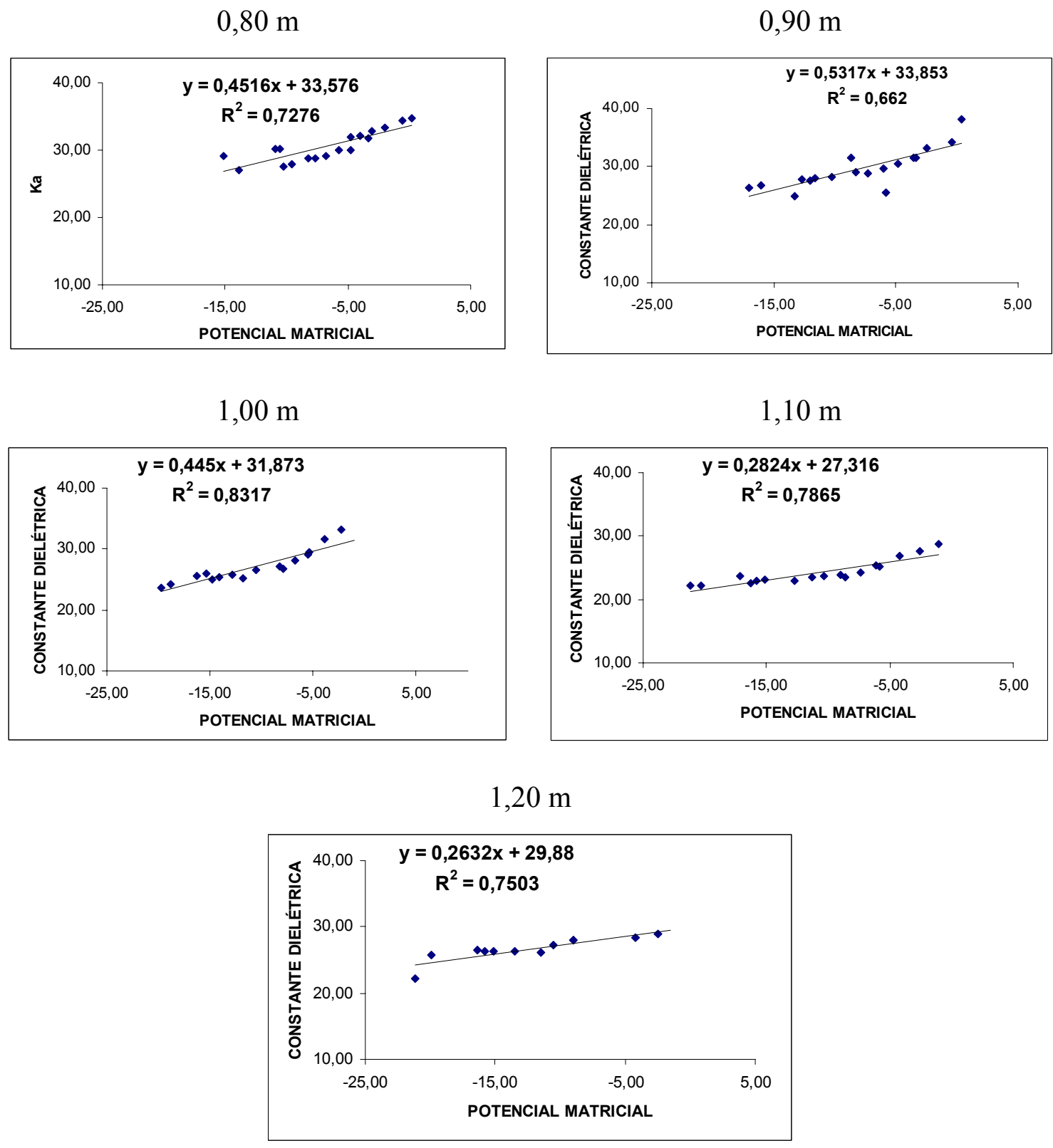

Figura 6 - Correlação entre o potencial matricial e a constante dielétrica, para as profundidades estudadas, utilizando os dados de um ensaio de condutividade hidráulica pelo MPI 


\subsubsection{Período de secagem do solo}

Como os valores de umidade do solo atingiram níveis muito baixos, o que resultou na extrapolação do limite de utilização do tensiômetro, $-80 \mathrm{kPa}$ (Libardi, 2000) o número de pares de leitura disponíveis para este período foi reduzido substancialmente, provocando a diminuição do coeficiente de determinação.

A Figura 7 apresenta a correlação entre as duas propriedades no período. Os valores de coeficiente de determinação foram menores que 0,70 para a maioria das profundidades. A correlação foi do tipo positiva fraca para as profundidades $0,40,0,60$, 1,00, 1,10 e 1,30 m; e moderada para as demais. Desta forma, iguala-se ao grau de correlação obtido quando foram utilizados os dados dos três períodos em conjunto e difere da análise anterior (dados só do primeiro período). Supõe-se, portanto, que os dados deste período são a maior causa de baixa correlação quando são utilizados todos os dados disponíveis do experimento. Falta, ainda, verificar as correlações do terceiro período para confirmação.

A baixa correlação indica baixa concordância ou diferença no comportamento das duas propriedades. A Figura $4 \mathrm{~b}$ já deixava alguma suspeita sobre esta hipótese, agora mais evidente. Há, portanto, a possibilidade de superioridade de desempenho de um dos instrumentos sobre o outro. Sabendo que as medidas do tensiômetro são duvidosas, à medida em que o potencial matricial se aproxima do limite de utilização, pode-se afirmar que em situações de baixos níveis de umidade, o desempenho do TDR na medição da umidade do solo é superior ao do tensiômetro.

Embora tenham sido poucos os dados utilizados de constante dielétrica nas análises descritas acima, pelo motivo já anteriormente mencionado (poucos dados de potencial matricial, para correlação), seria um desperdício ignorar tão grande riqueza de dados produzidos desde o início do experimento. A Figura 8 apresenta os dados de constante dielétrica para a profundidade $0,40 \mathrm{~m}$, desde agosto de 2001 , época em que os tensiômetros já tinham sido desativados pela baixa umidade do solo, até fevereiro de 2002. São mais de 9600 pontos, que se transformados em dados de umidade volumétrica, ilustram a grande utilidade da técnica, o monitoramento contínuo (no caso, 
de 30 em 30 minutos) da umidade do solo, num período de baixa disponibilidade hídrica.

Observando a figura, verifica-se uma razoável quantidade de dados discrepantes devido possivelmente, aos erros de medida de $K$ e $\theta$ (Tommaselli, 2001) ou outros inerentes à técnica, como por exemplo, influência de ruídos eletromagnéticos (não barrados pelo sistema de proteção adotado). Estes podem ser também o motivo da considerável variabilidade temporal observada. Outra hipótese em relação a esta última está no fato da grande variabilidade dos valores de constante dielétrica relativa, de acordo com Tommaselli (1997), se encontrar em conteúdos de água no solo abaixo de $0,05 \mathrm{~m}^{3} \mathrm{~m}^{-3}$ e acima de $0,25 \mathrm{~m}^{3} \mathrm{~m}^{-3}$ (equivalente, no caso do solo em estudo, a valores de constante dielétrica abaixo de 5 e acima de 15).

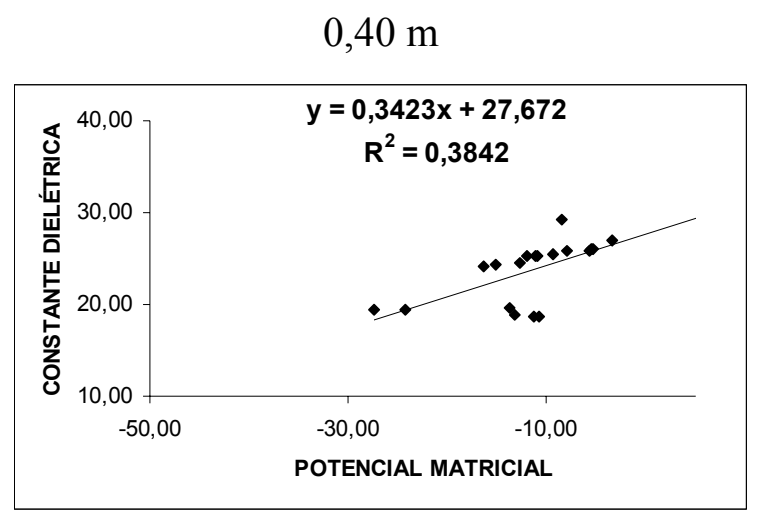

$0,60 \mathrm{~m}$

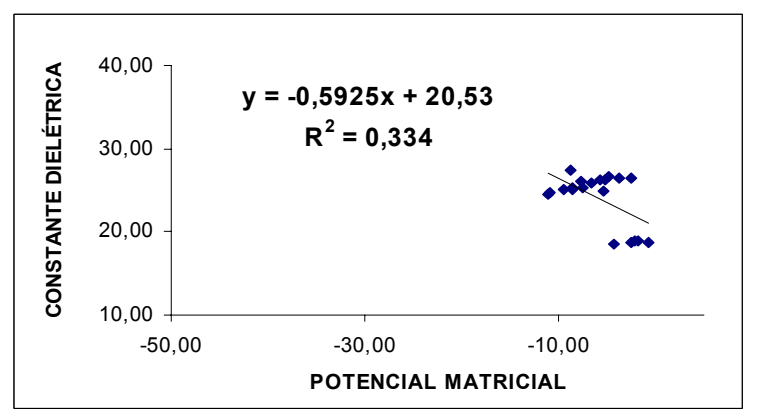

$0,50 \mathrm{~m}$

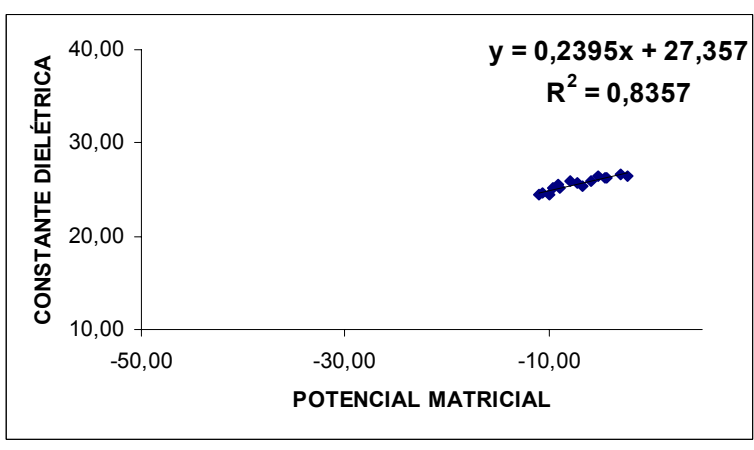

$0,70 \mathrm{~m}$

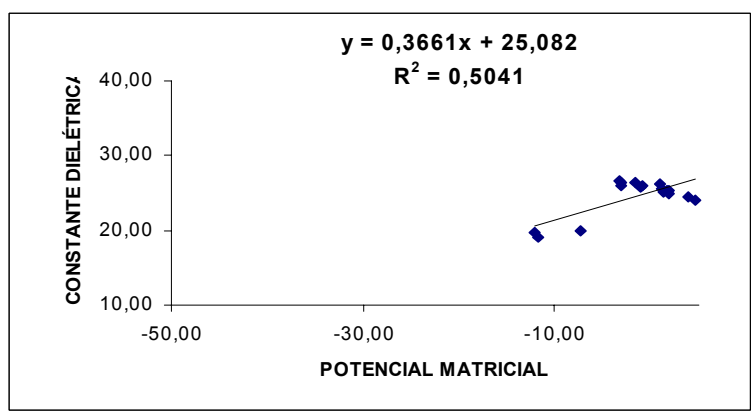

Figura 7 - Correlação entre o potencial matricial e a constante dielétrica aparente, para as profundidades estudadas, durante o período de secagem do solo. 

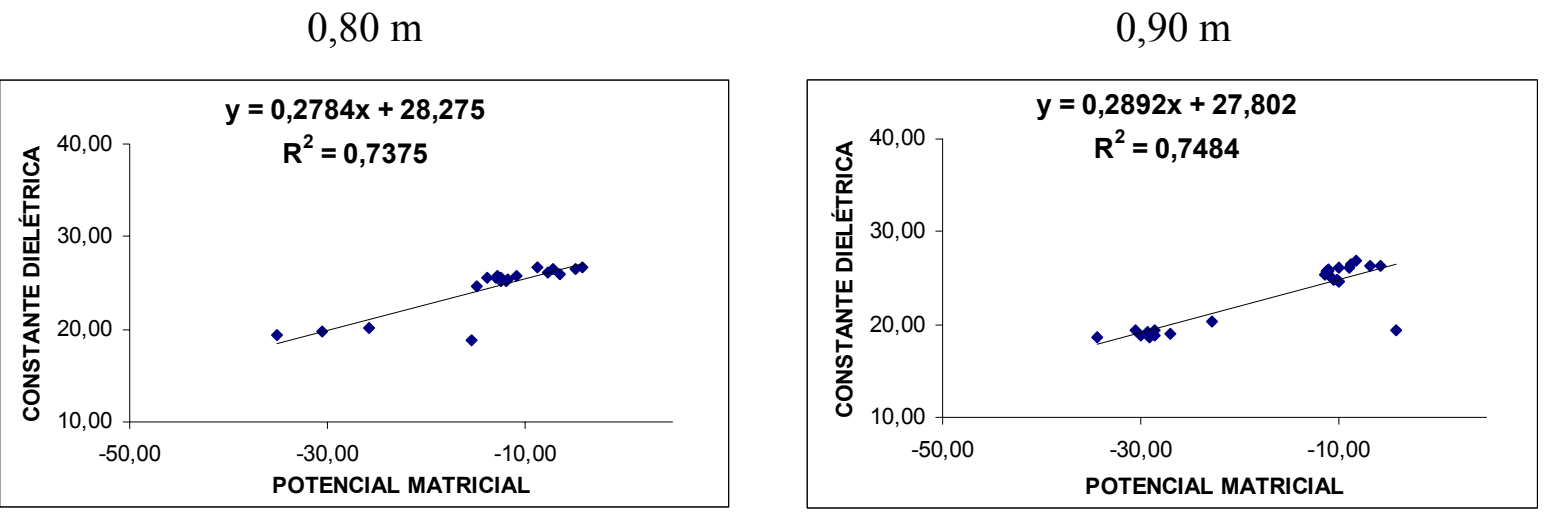

\section{$1,00 \mathrm{~m}$}

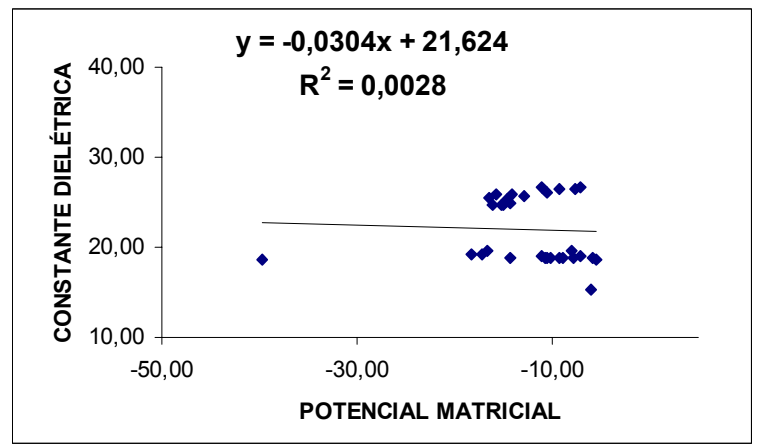

$1,10 \mathrm{~m}$

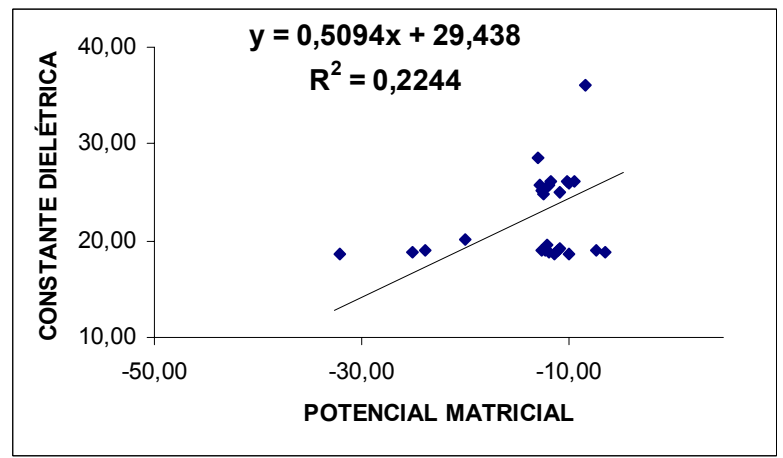

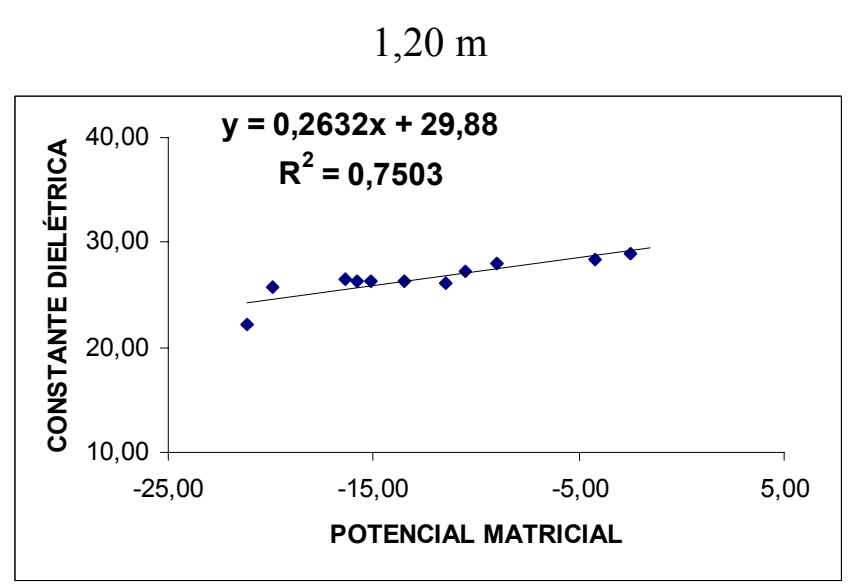

Figura 7 - Correlação entre o potencial matricial e a constante dielétrica aparente, para as profundidades estudadas, durante o período de secagem do solo. 
De uma forma geral, para condições de baixa umidade do solo o desempenho do TDR foi satisfatório, sendo, portanto, utilizável na obtenção de informações sobre a situação hídrica do solo, sob condições nas quais não é possível a utilização do tensiômetro.

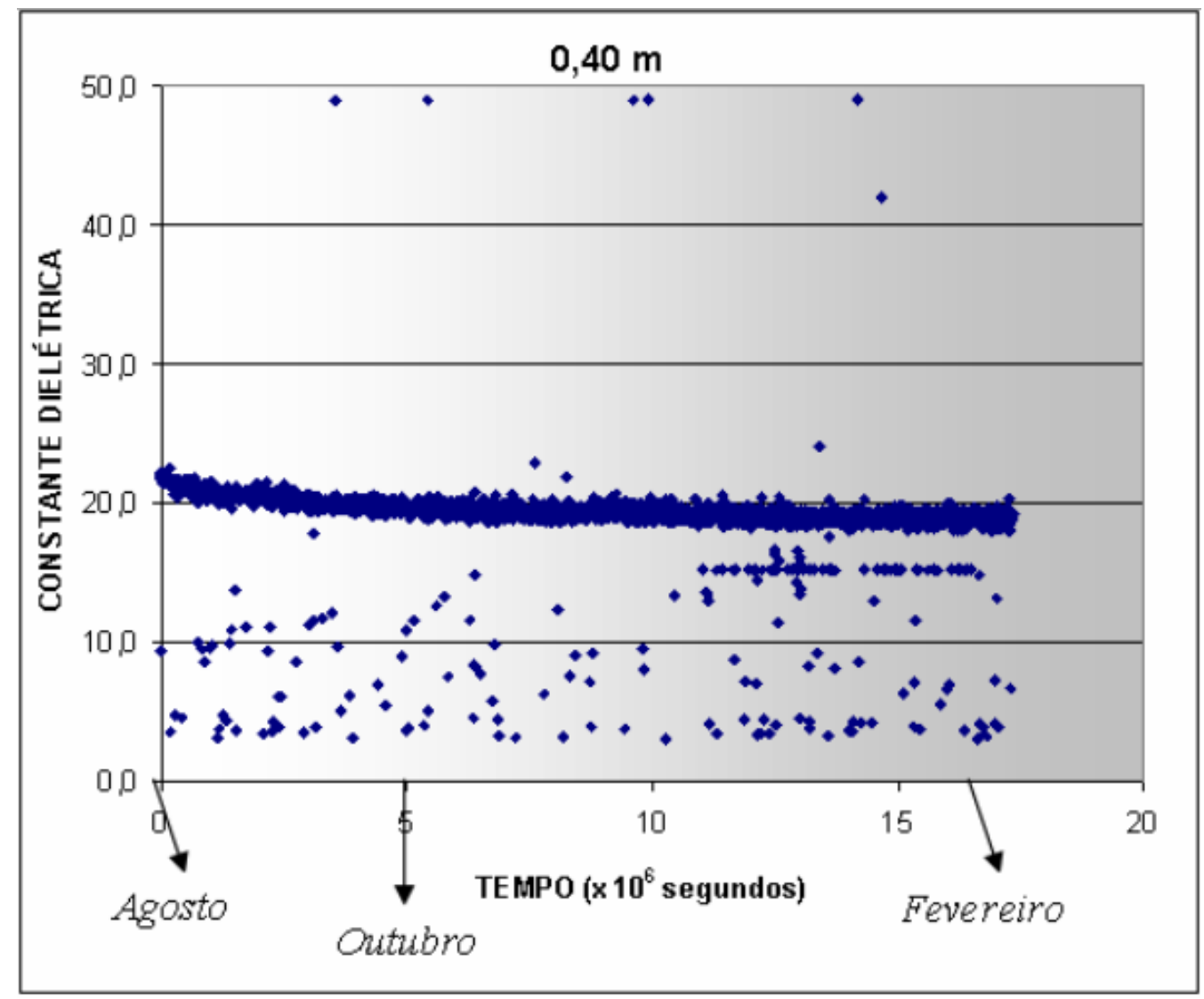

Figura 8 - Dados do comportamento da constante dielétrica ao longo do tempo, durante o período de secagem do solo.

\subsubsection{Período de inundação intermitente}

A Figura 9 apresenta uma seqüência de leituras de tensiômetro na forma de potencial matricial, em $\mathrm{kPa}$, e de leituras de TDR, na forma de constante dielétrica $\left(K_{\mathrm{a}}\right)$, durante uma das inundações, para todas as profundidades, mostrando o momento do início da aplicação da água e seu final. Esta inundação foi a última de uma série de 9, 
consecutivas. Portanto, nesta ocasião, o gradiente de potencial matricial da água no solo, relativamente às profundidades estudadas era baixo. A umidade inicial antes do início da aplicação de água era aproximadamente $0,43 \mathrm{~m}^{3} \mathrm{~m}^{-3}$

O número de leituras de tensiômetro foi maior do que as medições do TDR, devido a alguns problemas ocorridos com o sistema de aquisição de dados na ocasião do ensaio (mais precisamente, uma reprogramação inadequada), prejudicando bastante a análise.

$\mathrm{Na}$ Figura o tempo 2 (horas) corresponde a uma hora após o início da aplicação de água, o 4, três horas, e assim por diante. A falta de dados do TDR no momento da primeira leitura de potencial matricial (meia hora após o início da aplicação de água) impede a identificação de qual instrumento respondeu primeiro à entrada de água no solo.

Os valores de constante dielétrica uma hora após o início da aplicação de água, inesperadamente diminuíram, para as profundidades 0,40, 0,70 e 1,00 m, ao invés de aumentar, sugerindo algum erro do equipamento, ou mais provavelmente, a influência da alta variabilidade dos dados de constante dielétrica acima de $0,25 \mathrm{~m}^{3} \mathrm{~m}^{-3}$ (Tommaselli, 1997). Esta alta variabilidade, ainda segundo o autor, pode ser explicada pela formação de bolsas de ar ou de água ao redor das hastes portadoras de sinal do TDR, problema associado à técnica.

A mesma diminuição ocorreu para o tensiômetro nas profundidades $0,60 \mathrm{e}$ $0,80 \mathrm{~m}$. Neste caso, também o problema de alta variabilidade dos valores de potencial nestas condições pode estar presente.

Sobre a questão da detecção do ponto de saturação do solo, Teixeira (2001), baseada nos valores de umidade de saturação estimados pela equação de van Genuchten (1980), considerou que não houve a saturação, apesar dos manômetros de mercúrio terem indicado que houve, confirmando a hipótese levantada de que existiria ar aprisionado no solo. Considerando que na altura do potencial matricial zero os valores de constante dielétrica correspondem à saturação, verifica-se que, 3 horas após o início 
da aplicação de água, a partir da profundidade $0,80 \mathrm{~m}$ só o TDR indica a saturação (Tabelas 7, 8 e 9, Apêndice). Desta forma, supõe-se a superioridade do TDR pela deteç̧ão mais rápida do momento de saturação do solo.
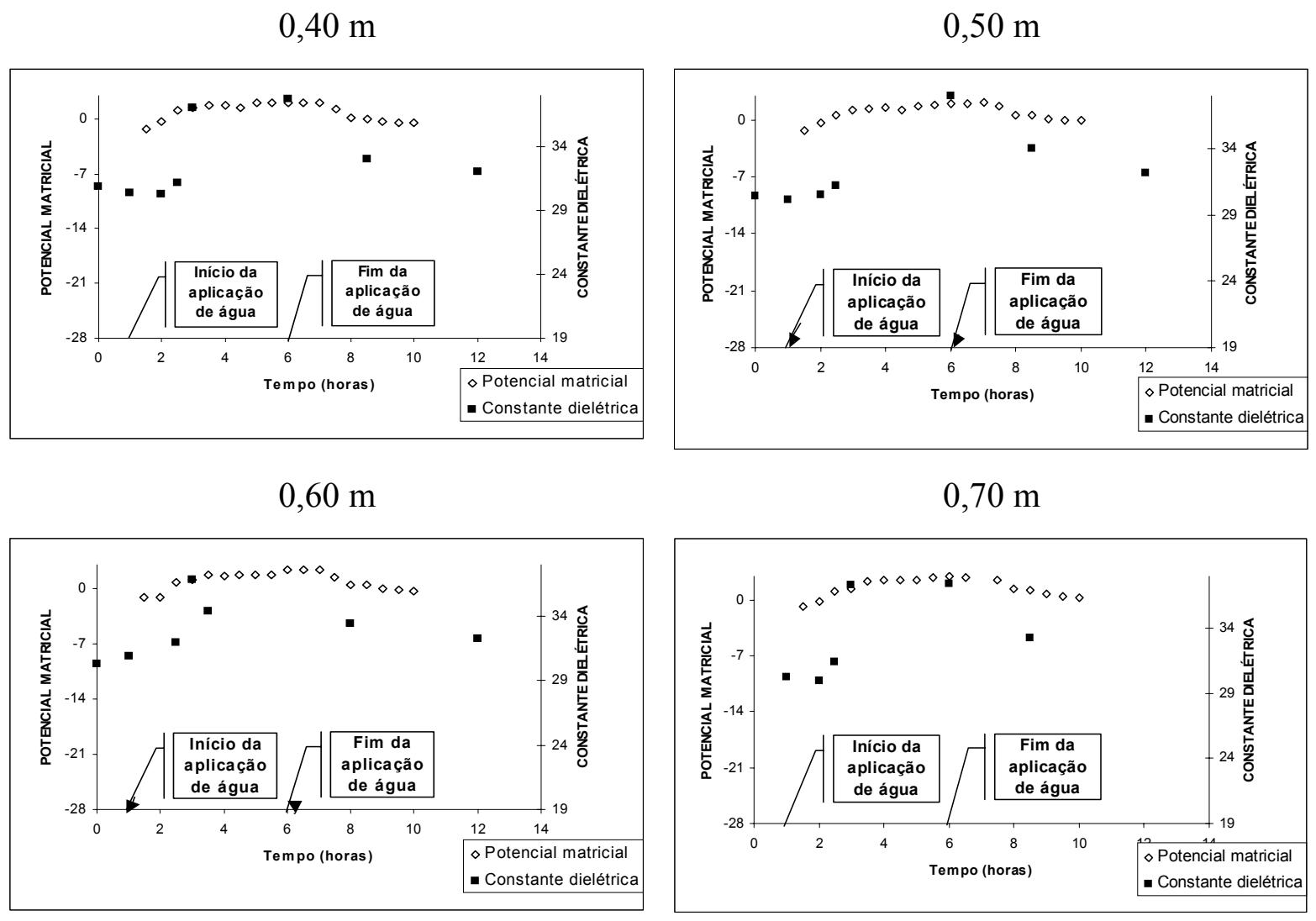

$0,80 \mathrm{~m}$
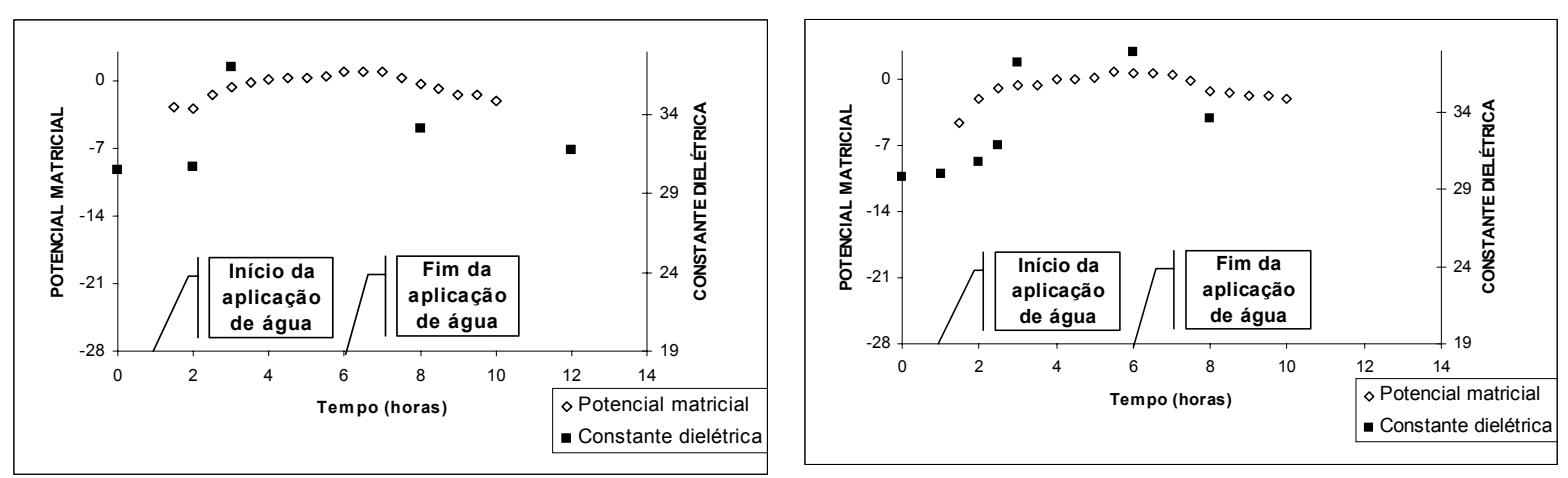

Figura 9 - Correlação entre o potencial matricial e a constante dielétrica aparente, para as profundidades estudadas, para o período de secagem do solo. 
$1,00 \mathrm{~m}$

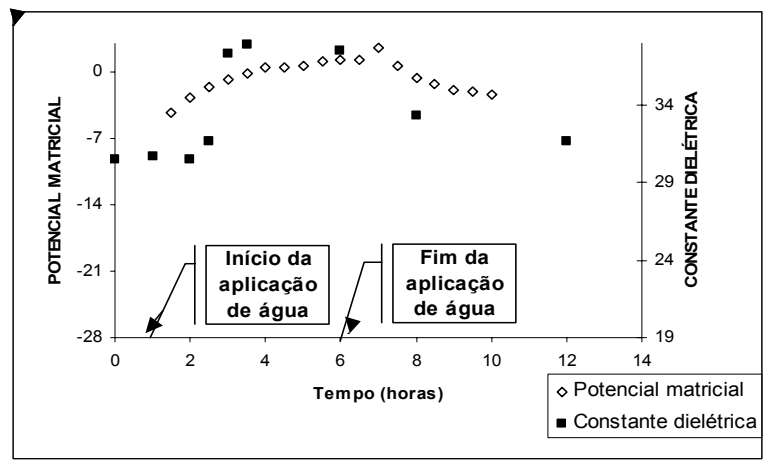

$1,20 \mathrm{~m}$

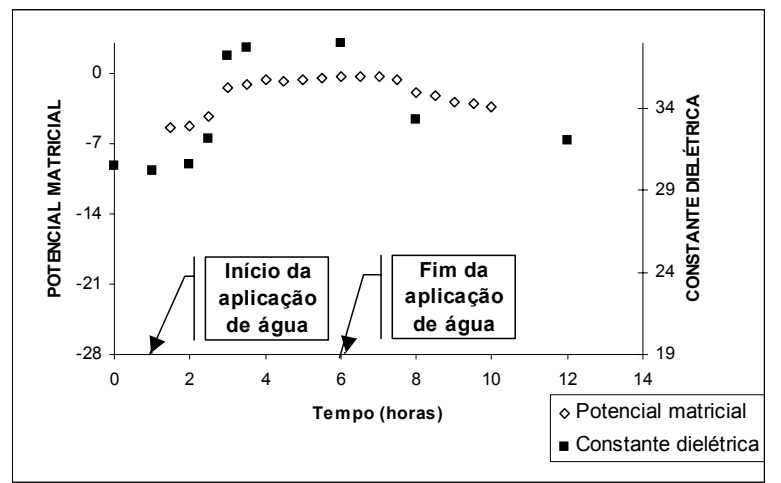

$1,10 \mathrm{~m}$

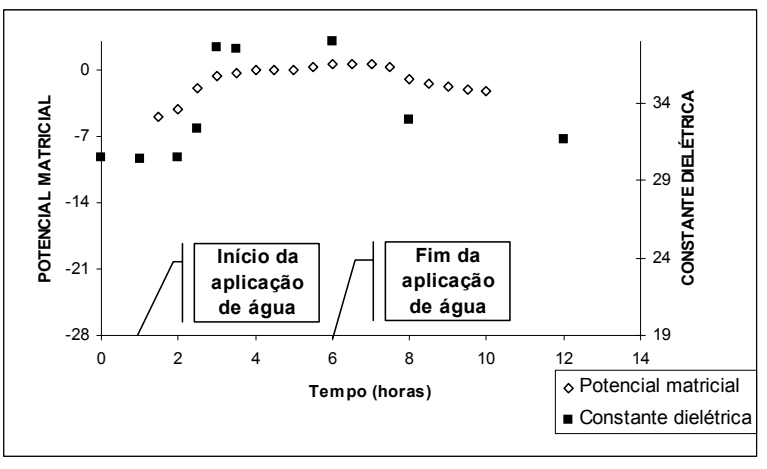

$1,30 \mathrm{~m}$

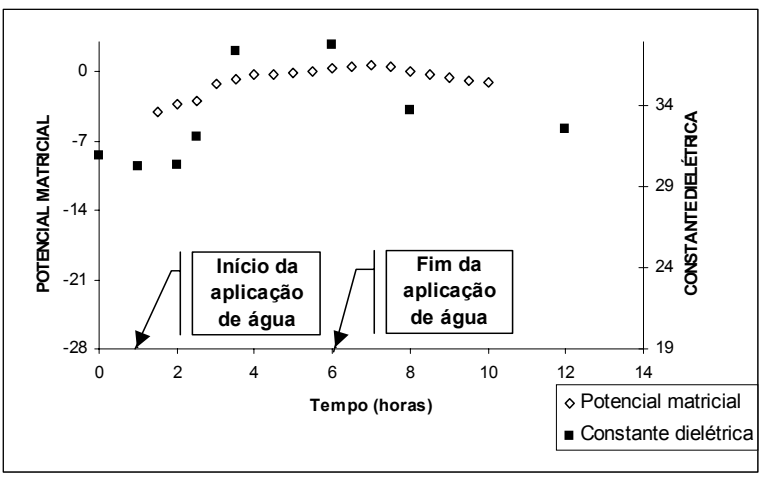

Figura 9 - Comportamento do potencial matricial (em $\mathrm{kPa}$ ) e da constante dielétrica durante uma das inundações realizadas no experimento.

Em relação as várias profundidades, de uma forma geral, o comportamento das variáveis ao longo do tempo (curva) foi similar em todas elas. Nitidamente observase que o TDR detectou a mudança de umidade do solo mais rápido do que o tensiômetro, pois, o comportamento dos valores de $K_{\mathrm{a}}$ ao longo do tempo é similar para todas as profundidades, enquanto que para o tensiômetro, nas maiores profundidades, houve uma demora para atingir os mesmos valores de potencial das profundidades iniciais.

$\mathrm{Na}$ figura pode ser observado também como a declividade da curva $K_{\mathrm{a}}$ ao longo do tempo incrementa acentuadamente acima de um certo ponto, devido ao aumento da umidade do solo (Herrmann Jr, 2001), tal como referido no item 4.1. 
A Figura 10 apresenta a correlação entre as propriedades físicas para o período. As correlações foram parecidas com aquelas do período do método do perfil instantâneo, porém menores para a maioria das profundidades. Portanto, a correlação entre as variáveis em situações de alto teor de água no solo, verificada nas Figuras 6 e 10, mostrou-se bem maior que em situações de baixa umidade.
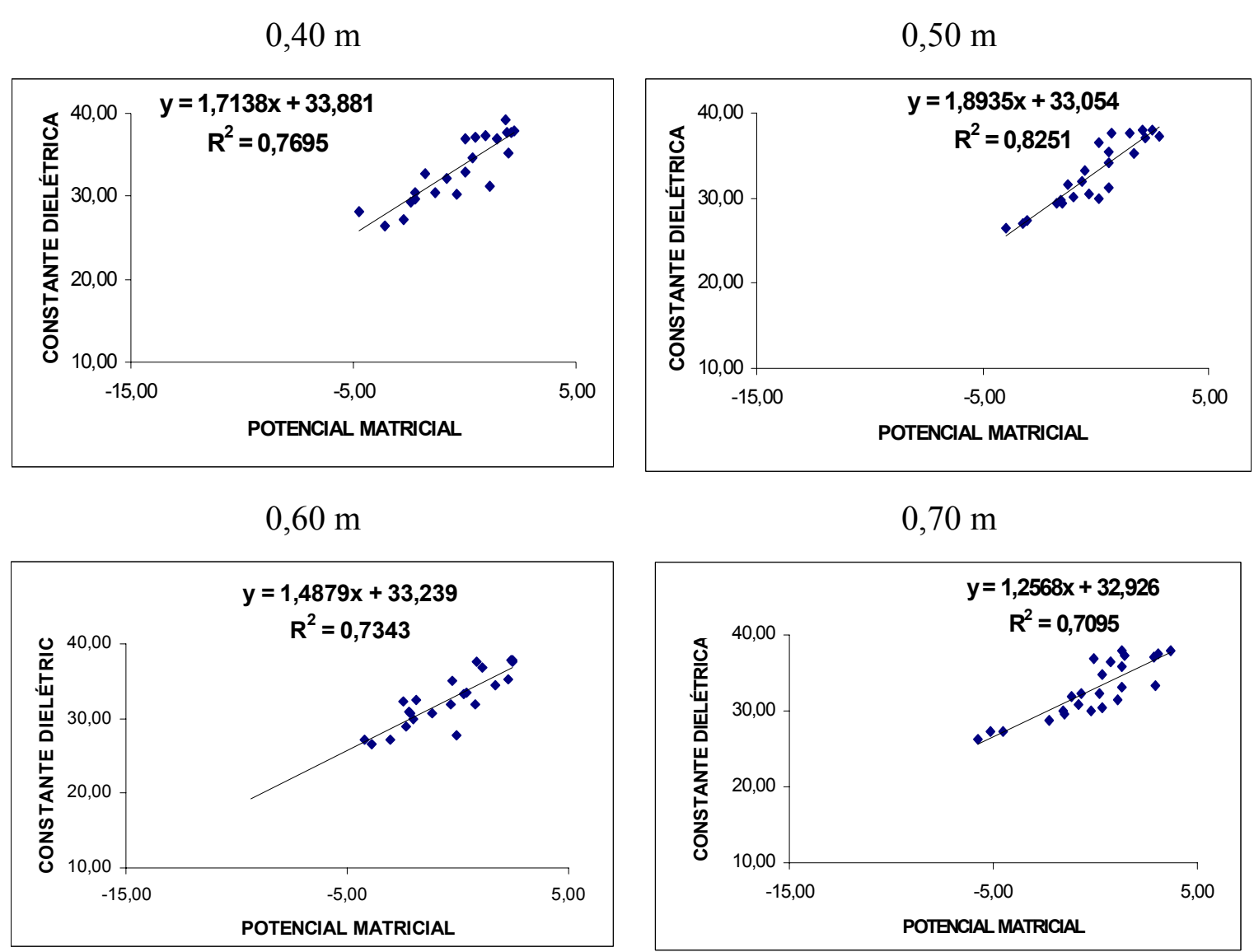

Figura 10 - Correlação entre o potencial matricial (em $\mathrm{kPa}$ ) e a constante dielétrica, para as profundidades estudadas, utilizando os dados das inundações. 

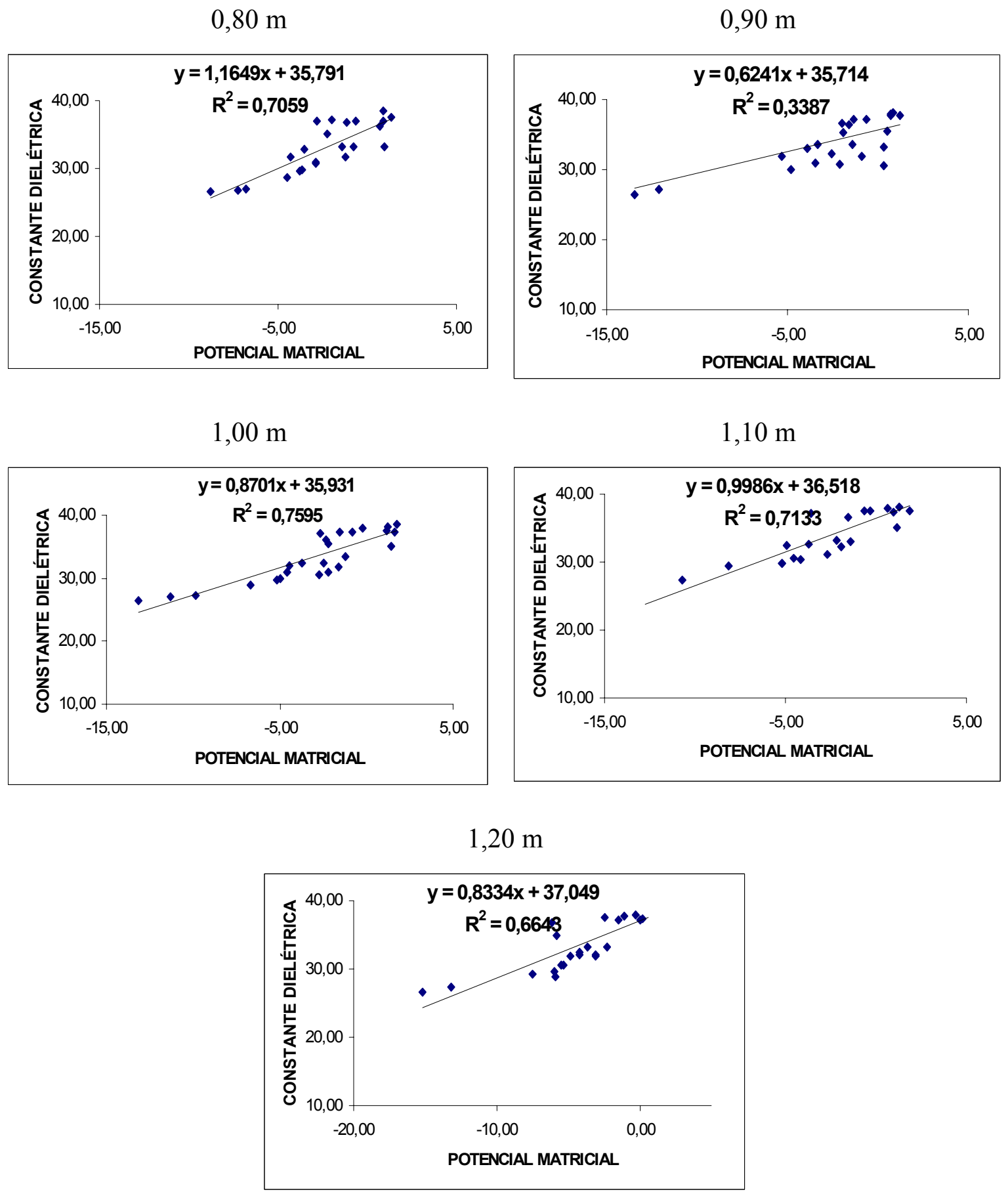

Figura 10 - Correlação entre o potencial matricial (em kPa) e a constante dielétrica, para as profundidades estudadas, utilizando os dados das inundações. 


\subsection{Análise $\theta_{\mathrm{v}}\left(K_{\mathrm{a}}\right) \times \theta_{\mathrm{v}}\left(\psi_{\mathrm{m}}\right)$}

$\mathrm{Na}$ primeira etapa do estudo foi visto como as propriedades físicas em questão se comportaram sob as diferentes condições de variação de umidade do solo. Foi estudada a correlação entre elas na tentativa de quantificar o grau de diferença entre as mesmas. Ao realizar-se a correlação dos dados em separado para cada situação, identificou-se o período cujos dados eram responsáveis pelas baixas correlações nas análises com todos os dados: o período de baixa umidade do solo. Tanto no período de secagem do solo, como através dos ensaios de inundações, evidenciou-se a superioridade do TDR.

A falta de valores absolutos de umidade, porém, torna mais difícil a compreensão das colocações e confirmação das suposições em relação a superioridade de um instrumento sobre o outro.

Uma das vantagens da técnica de TDR, em função do desenvolvimento de modelos, tal como o modelo "universal" de Topp et al. (1980), é de não ser necessária a amostragem destrutiva do solo (Zegelin et al., 1992). No presente trabalho, para calibração do TDR, não foi possível a obtenção da umidade pelo método direto (gravimétrico) devido a modificação da textura, densidade e estrutura por causa da perturbação do solo. Desta forma, optou-se por utilizar, além do referido modelo de Topp, outra calibração, utilizando valores de umidade em função do potencial matricial obtido pela tensiometria.

O uso do tensiômetro na calibração do TDR, porém, implica em introduzir na mesma o erro da calibração do tensiômetro (curva de retenção).

\subsubsection{Dados de um ensaio de condutividade hidráulica conforme o MPI}

A Figura 11 apresenta o comportamento da umidade volumétrica do solo ao longo do tempo para o período obtida através de três formas: tensiometria e curva de retenção, TDR calibrado com os dados de tensiometria e curva de retenção, e pelo modelo de Topp et al., 1980 (equação 5). 
Os valores de umidade obtidos pelo TDR com calibração pelo modelo de Topp foram maiores do que os obtidos via tensiometria e pelo tensiômetro. Exceto para a profundidade $0,50 \mathrm{~m}$ e $0,80 \mathrm{~m}$, em que no início do ensaio os maiores valores foram obtidos pelo TDR (calibrado via tensiômetro) e no restante, obtidos pelo tensiômetro. Logo, pode-se perceber que nestes casos, para os maiores valores de umidade, os valores obtidos pelo TDR foram maiores, e à medida que o solo foi secando, os valores obtidos pelo tensiômetro passaram a ser maiores. Resultados deste tipo já haviam sido relatados por Wang \& Schmugge (1980) mostrando a tendência de superestimativa de $K_{\text {a }}$ para valores elevados de umidade.
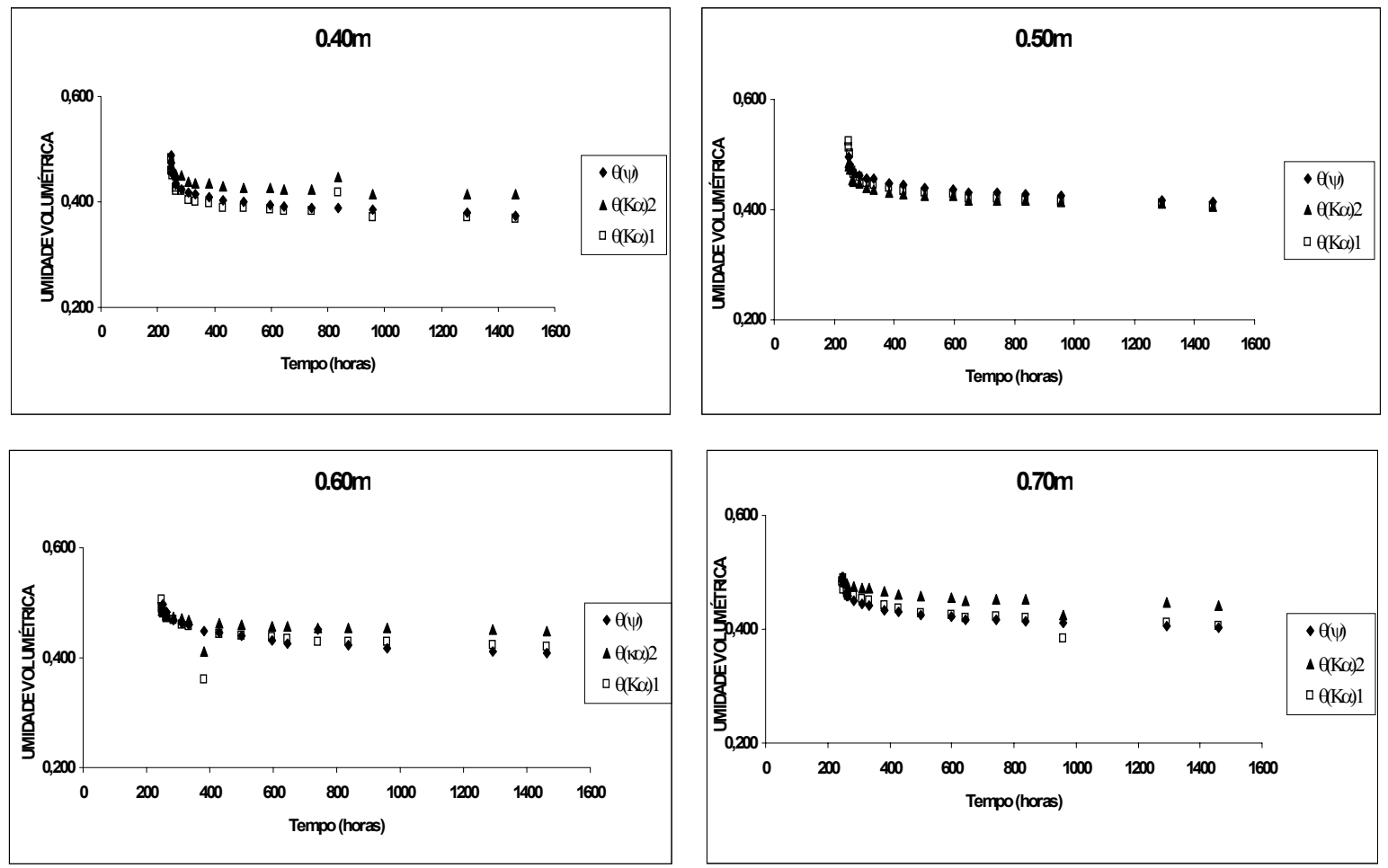

Figura 11 - Umidades volumétricas $\left(\mathrm{m}^{3} \mathrm{~m}^{-3}\right)$ obtidas através do tensiômetro $\left[\theta\left(\psi_{\mathrm{M}}\right)\right]$ e do TDR, utilizando o tensiômetro na calibração $((\theta(\mathrm{Ka}) 1)$ e o modelo de Topp et al., $1980(\theta(\mathrm{Ka}) 2)$. 

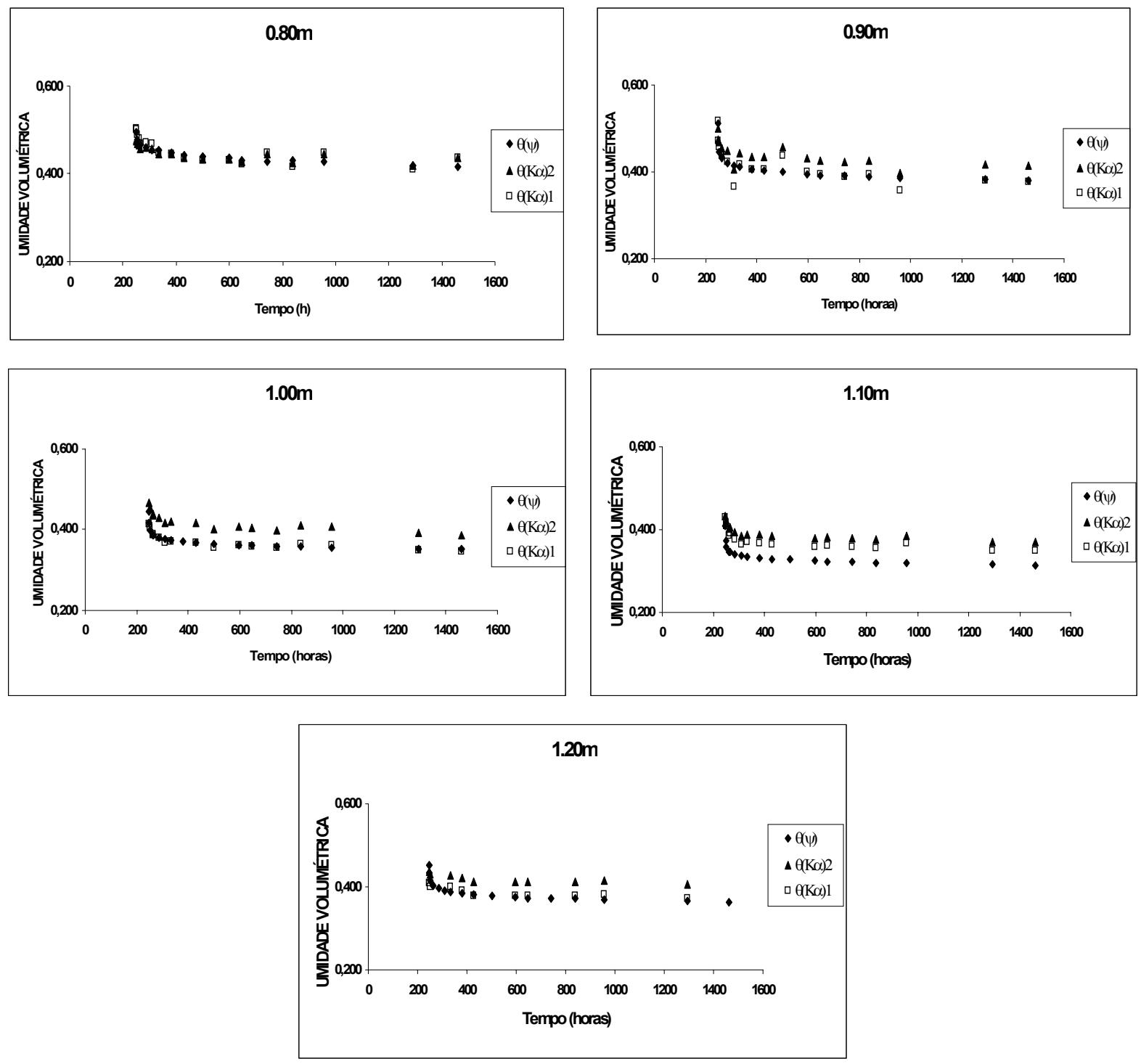

Figura 11 - Umidades volumétricas $\left(\mathrm{m}^{3} \mathrm{~m}^{-3}\right)$ obtidas através do tensiômetro $\left[\theta\left(\psi_{\mathrm{M}}\right)\right]$ e do TDR, utilizando o tensiômetro na calibração $((\theta(\mathrm{Ka}) 1)$ e o modelo de Topp et al., $1980(\theta(\mathrm{Ka}) 2)$.

Teixeira (2001), utilizando os mesmos dados para as profundidades $0,70 \mathrm{~m} \mathrm{e}$ 1,00 m, havia obtido, entretanto, que para os valores máximos de umidade, os valores pelo tensiômetro foram maiores e para valores mínimos, os obtidos pelo TDR foram maiores. A autora abordou, ainda, sobre a concordância entre os valores de umidade 
correspondentes à saturação e umidade residual obtidos pelos instrumentos com àqueles gerados pelo modelo de van Genuchten (1980), apresentados na Tabela 6 (Apêndice), e verificou que ambos produziram valores próximos ao de saturação, mas distantes em relação a umidade residual.

Observa-se uma boa concordância no comportamento apresentado pelos dois instrumentos. Em comparação com a Figura 4a, a impressão é que a concordância é maior do que para os dados das propriedades físicas. A correlação entre os valores de umidade de cada instrumento pode dar a confirmação desta afirmação.

A Figura 12 apresenta a correlação entre os valores de umidade volumétrica $\left(\mathrm{m}^{3} \mathrm{~m}^{-3}\right)$ obtidos a partir de tensiometria e do TDR, ao longo do período, para a calibração usando a tensiometria para fornecimento dos valores de umidade. Pelos coeficientes de determinação observados, tem-se a confirmação, portanto, da superioridade da correlação entre as umidades obtidas pelos instrumentos em relação à correlação entre o potencial matricial e a constante dielétrica. A questão, a partir daí, reside na justificativa para tal diferença. A resposta parece estar relacionada ao fato da calibração do TDR ser feita em função de valores de umidade obtidos pelo próprio tensiômetro.

Uma forma encontrada para tentar resolver esta dúvida foi correlacionar agora, a umidade obtida pelo tensiômetro $\left(\theta\left(\psi_{\mathrm{m}}\right)\right)$ com a umidade obtida pelo TDR, com calibração através da equação 5. A Figura 13 apresenta a correlação para as profundidades estudadas.

Verifica-se que os resultados foram idênticos, logo, pode-se concluir que não houve tendência ao aumento da correlação pela utilização de dados do tensiômetro na calibração do TDR. As umidades obtidas pelos dois métodos de calibração foram muito próximas, conforme evidencia a Figura 14. Portanto, neste caso, seria indiferente a utilização do modelo de Topp et al. (1980) ou a tensiometria e curva de retenção para obtenção da relação $K_{\mathrm{a}} \times$ $\theta$. 
Para o período, o menor coeficiente de determinação foi o obtido para a profundidade 0,90m (Figuras 12 e 13), repetindo o ocorrido quando foram correlacionadas as propriedades físicas (Figura 6). Portanto, conclui-se que neste caso, a transformação para umidade volumétrica em nada influenciou no resultado.

Já para o maior coeficiente de determinação, o mesmo não ocorreu, ou seja, considerando a correlação entre as propriedades, o maior valor foi o obtido para a profundidade $0,70 \mathrm{~m}\left(\mathrm{R}^{2}=0,867\right)$, enquanto que para as umidades, o maior valor foi o obtido para a profundidade $0,50 \mathrm{~m}\left(\mathrm{R}^{2}=0,964\right)$. Supõe-se, então, que neste caso a transformação para umidade tenha tido alguma influência.
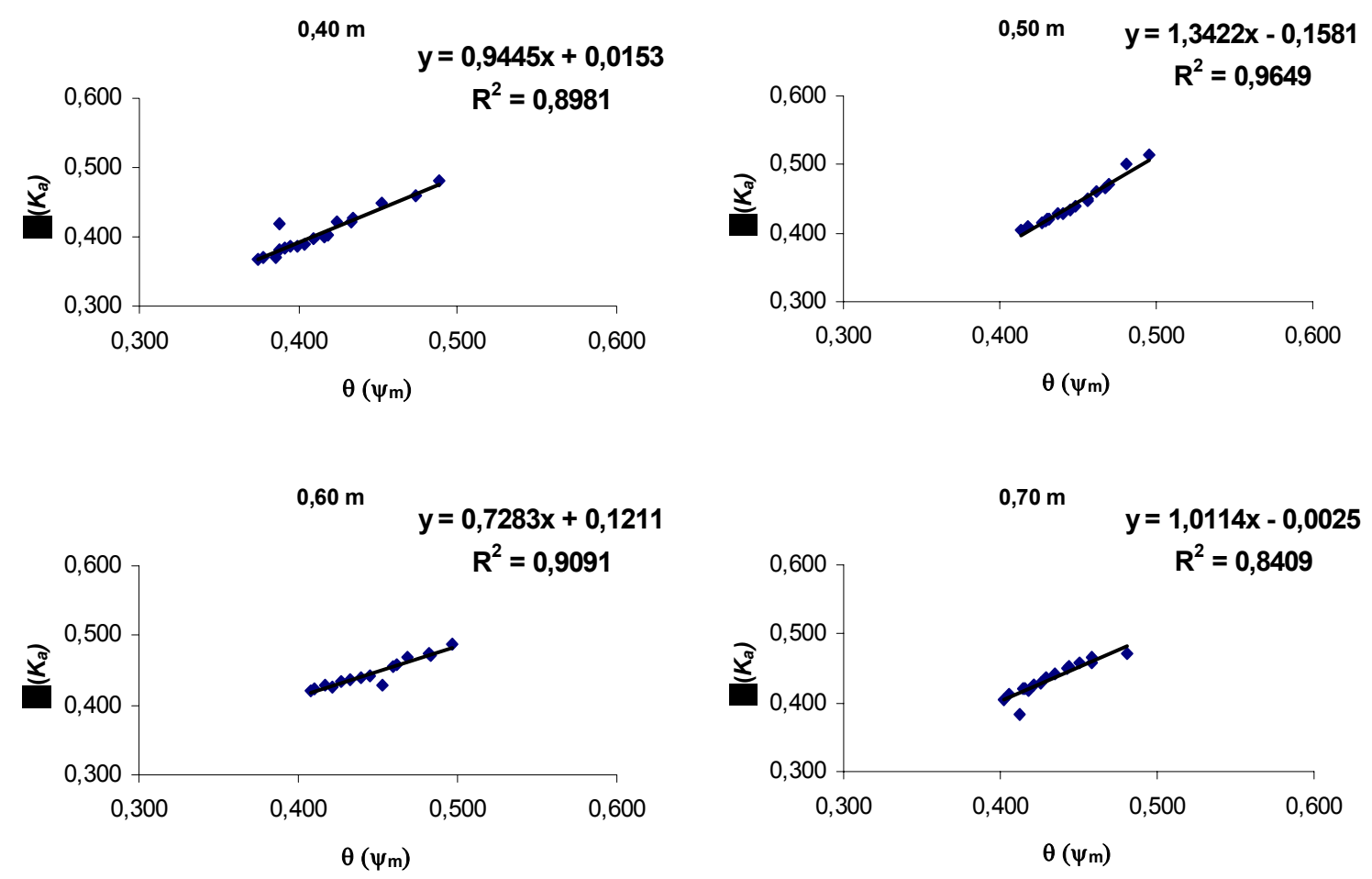

Figura 12 - Correlação entre os valores de umidade volumétrica $\left(\mathrm{m}^{3} \mathrm{~m}^{-3}\right)$ obtidas por tensiometria e curva de retenção e pelo TDR (calibrado com umidades obtidas pelo tensiômetro), utilizando dados de um ensaio de $K(\theta)$ utilizando o MPI, para as profundidades estudadas. 

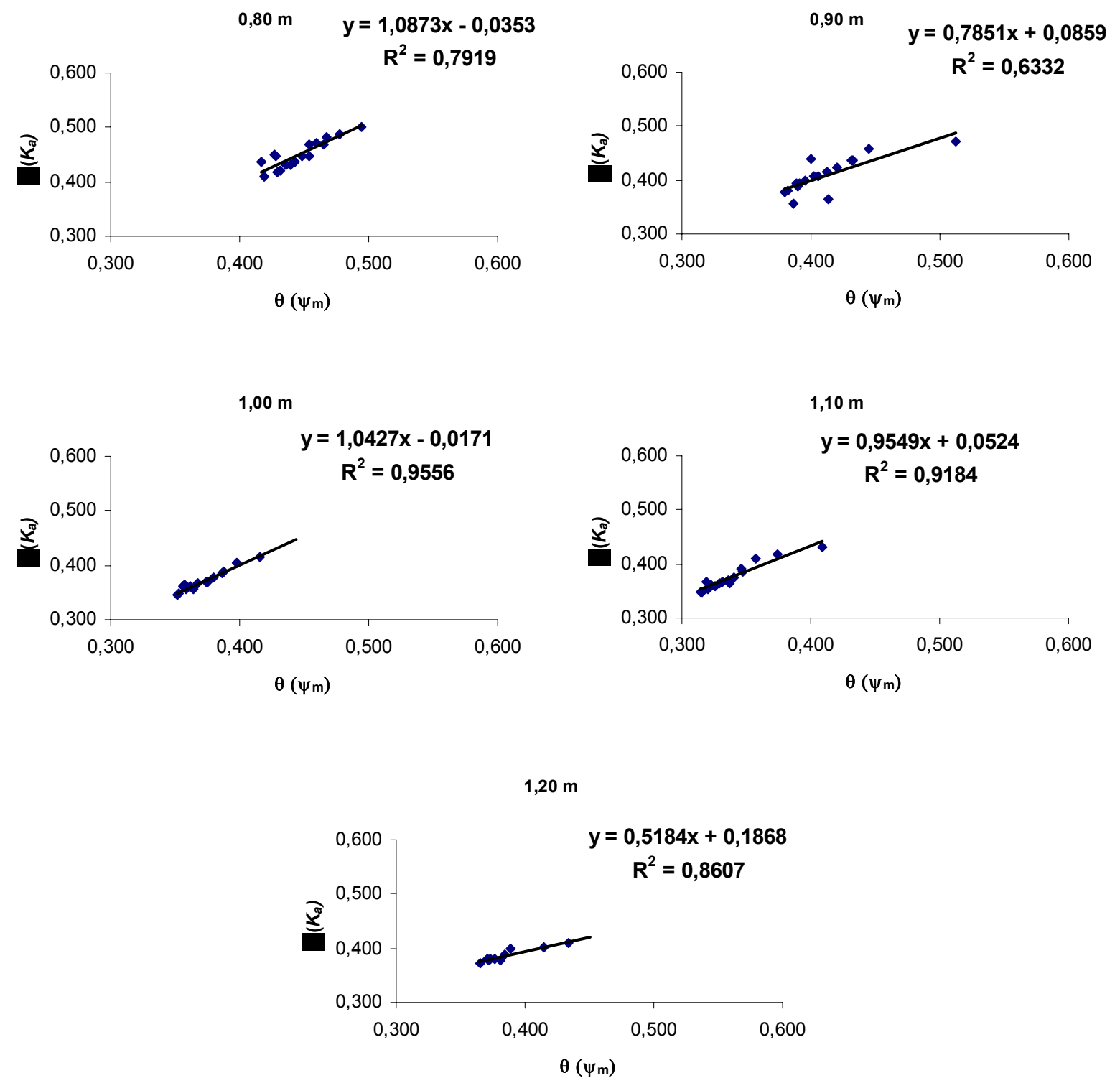

Figura 12 - Correlação entre os valores de umidade volumétrica $\left(\mathrm{m}^{3} \mathrm{~m}^{-3}\right)$ obtidas por tensiometria e curva de retenção e pelo TDR (calibrado com umidades obtidas pelo tensiômetro), utilizando dados de um ensaio de $K(\theta)$ utilizando o MPI, para as profundidades estudadas 

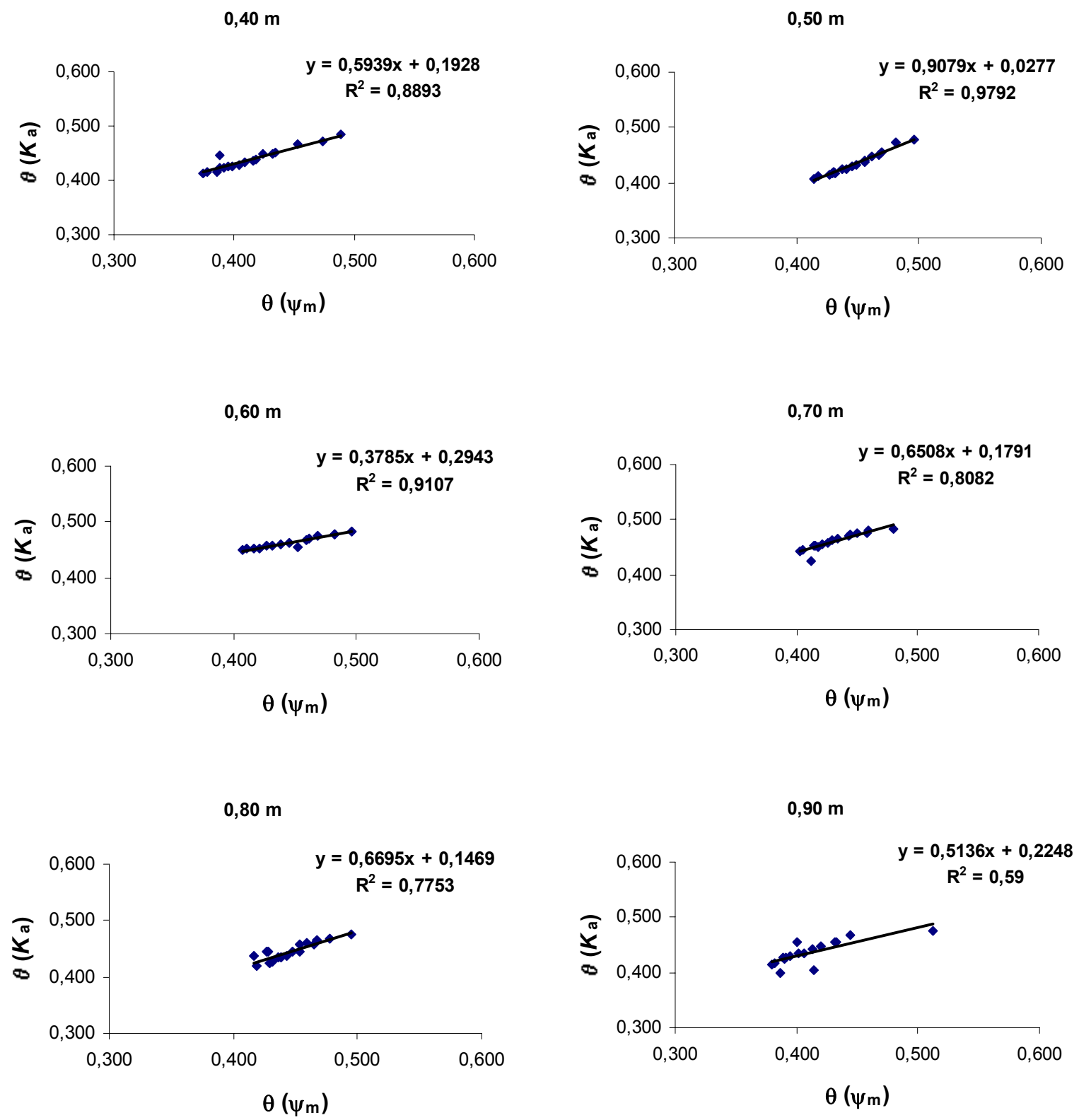

Figura 13 - Correlação entre os valores de umidade volumétrica $\left(\mathrm{m}^{3} \mathrm{~m}^{-3}\right)$ obtidas por tensiometria e curva de retenção e pelo TDR (calibrado com umidades obtidas pelo tensiômetro), utilizando dados de um ensaio de $K(\theta)$ utilizando o MPI, para as profundidades estudadas. 

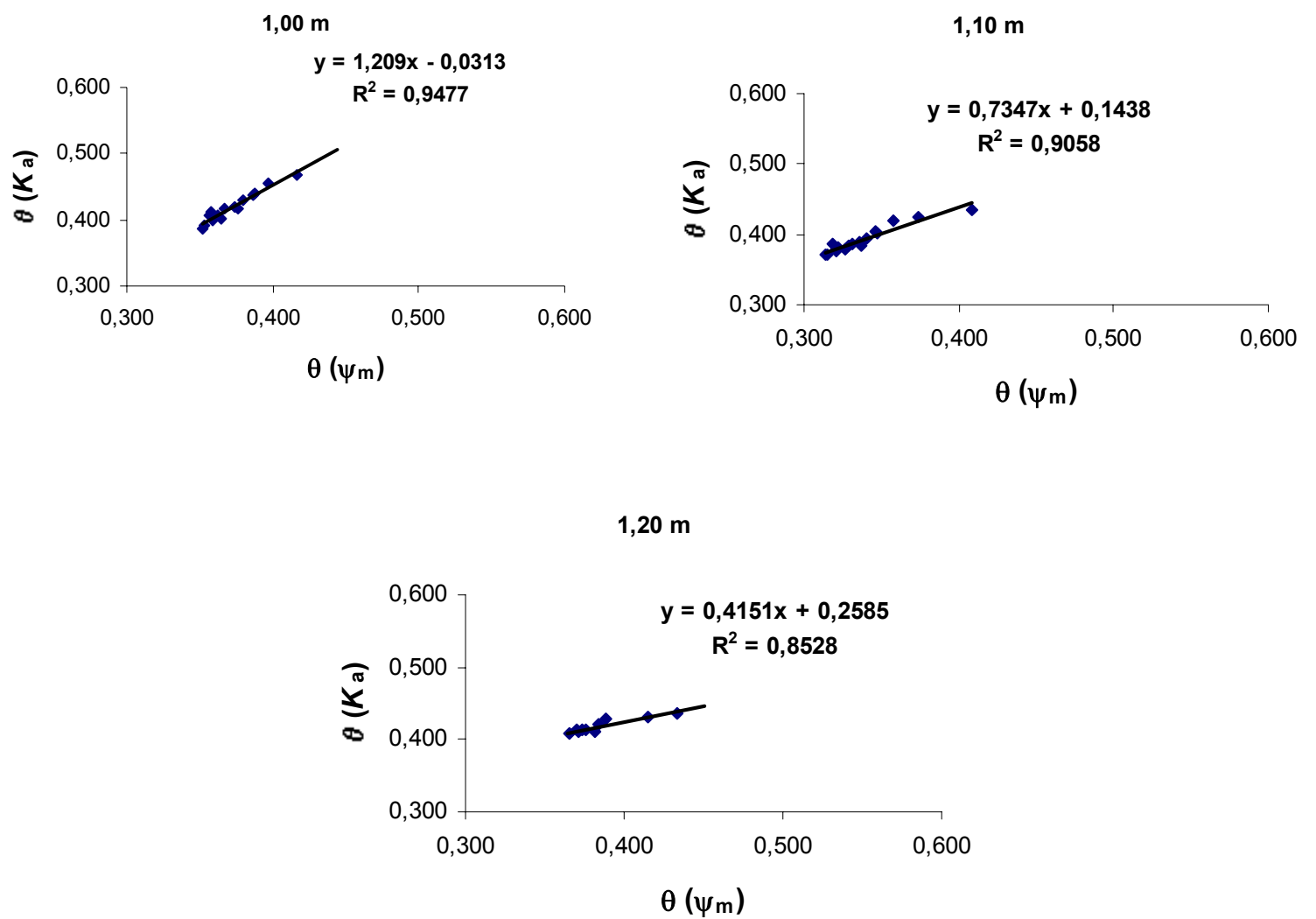

Figura 13 - Correlação entre os valores de umidade volumétrica $\left(\mathrm{m}^{3} \mathrm{~m}^{-3}\right)$ obtidas por tensiometria e curva de retenção e pelo TDR (calibrado com umidades obtidas pelo tensiômetro), utilizando dados de um ensaio de $\mathrm{K}(\theta)$ utilizando o MPI, para as profundidades estudadas. 

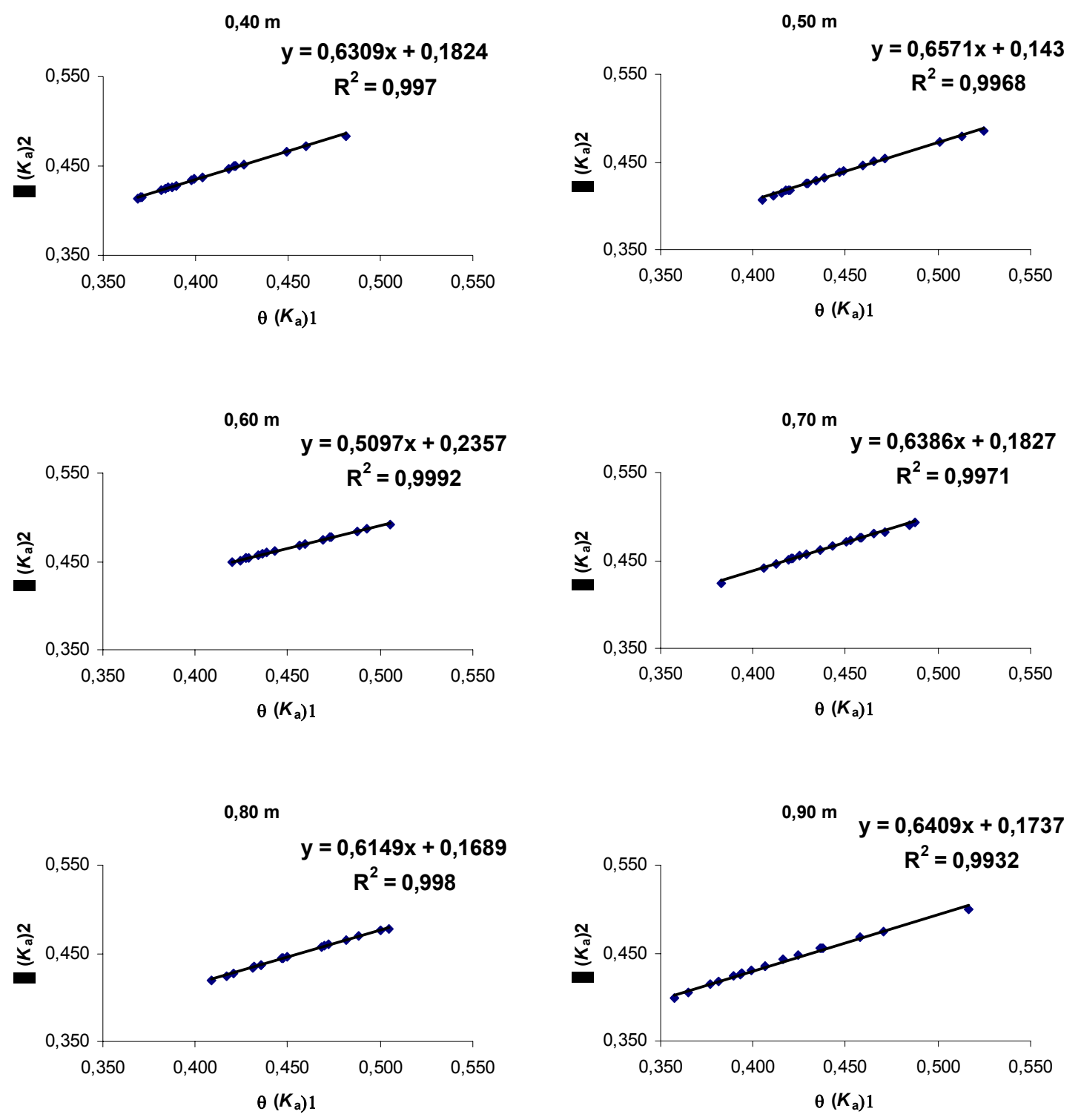

Figura 14 - Correlação entre os valores de umidade volumétrica $\left(\mathrm{m}^{3} \mathrm{~m}^{-3}\right)$ obtidas por tensiometria e curva de retenção e pelo TDR (calibrado com umidades obtidas pelo tensiômetro), utilizando dados de um ensaio de $K(\theta)$ utilizando o MPI, para as profundidades estudadas. 

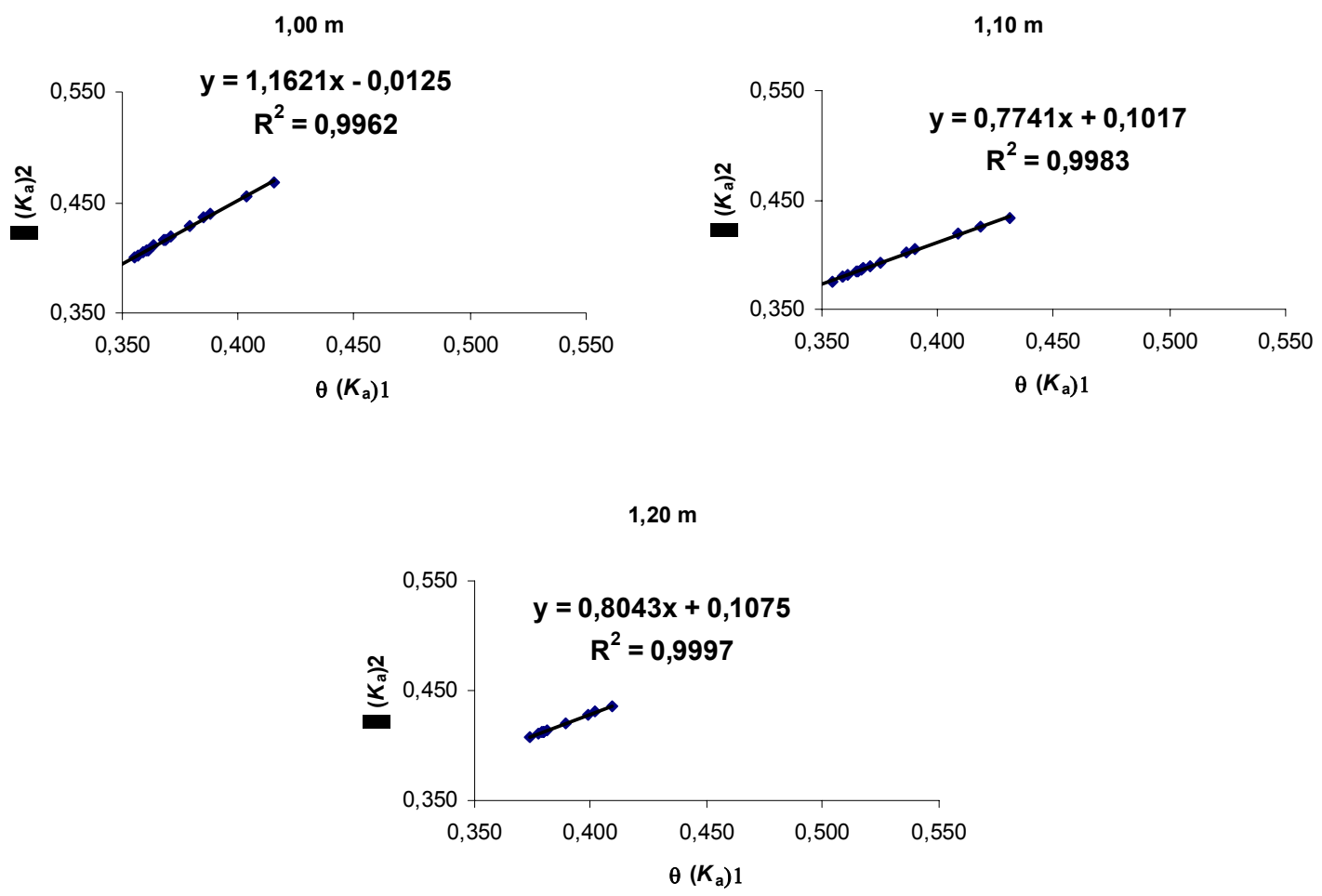

Figura 14 - Correlação entre os valores de umidade volumétrica $\left(\mathrm{m}^{3} \mathrm{~m}^{-3}\right)$ obtidas por tensiometria e curva de retenção e pelo TDR (calibrado com umidades obtidas pelo tensiômetro), utilizando dados de um ensaio de $K(\theta)$ utilizando o MPI, para as profundidades estudadas.

\subsubsection{Período de secagem do solo}

A Figura 15 apresenta os valores de umidade fornecidos pelos instrumentos ao longo do tempo. 

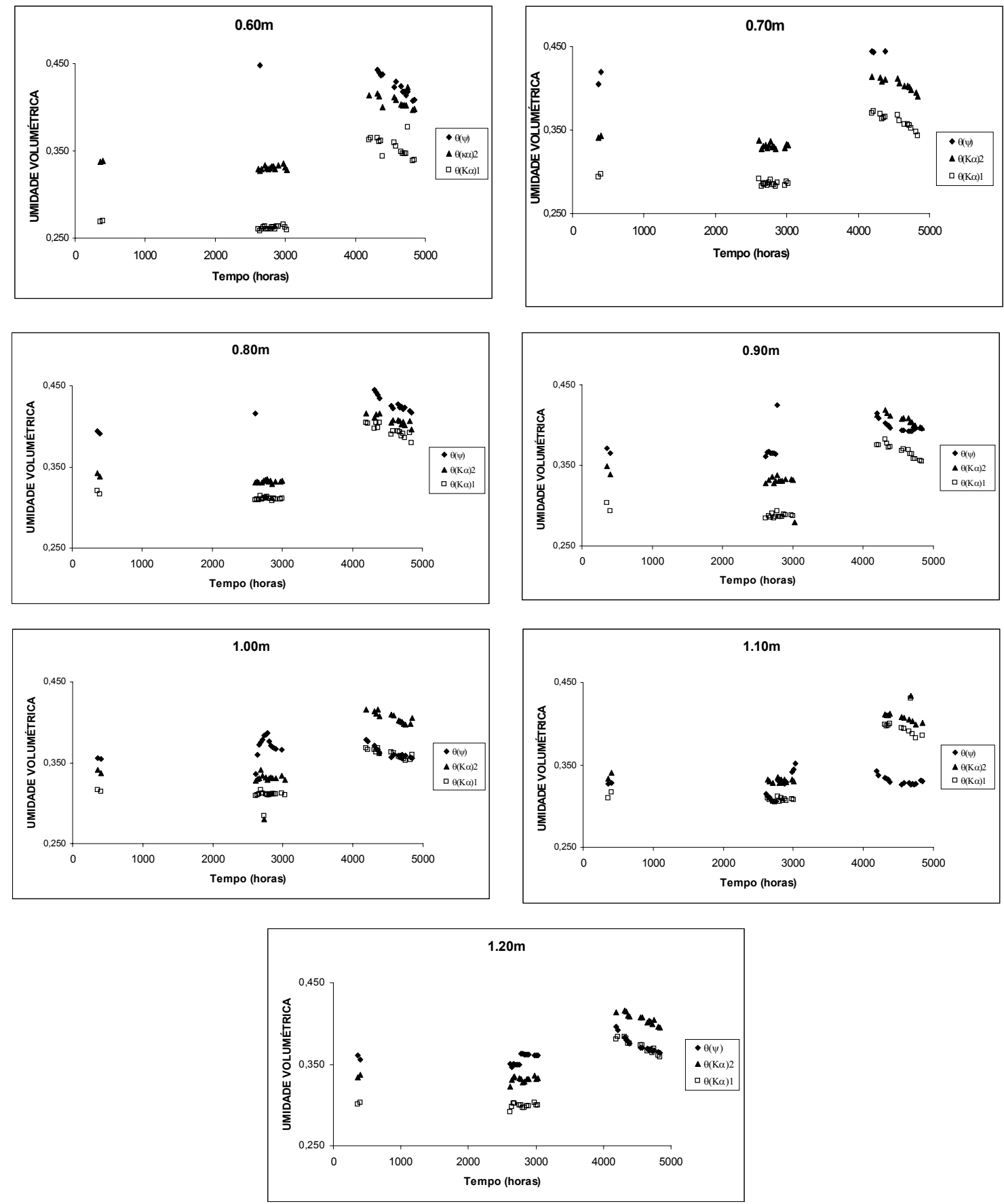

Figura 15 - Umidades volumétricas (m3 m-3) obtidas pelo tensiômetro $\left[\theta\left(\psi_{M}\right)\right]$ e TDR, utilizando o tensiômetro na calibração $[\theta(\mathrm{Ka}) 1]$ e utilizando a equação de Topp et al., 1980 [ $\theta(\mathrm{Ka}) 2]$, durante o período de secagem do solo. 


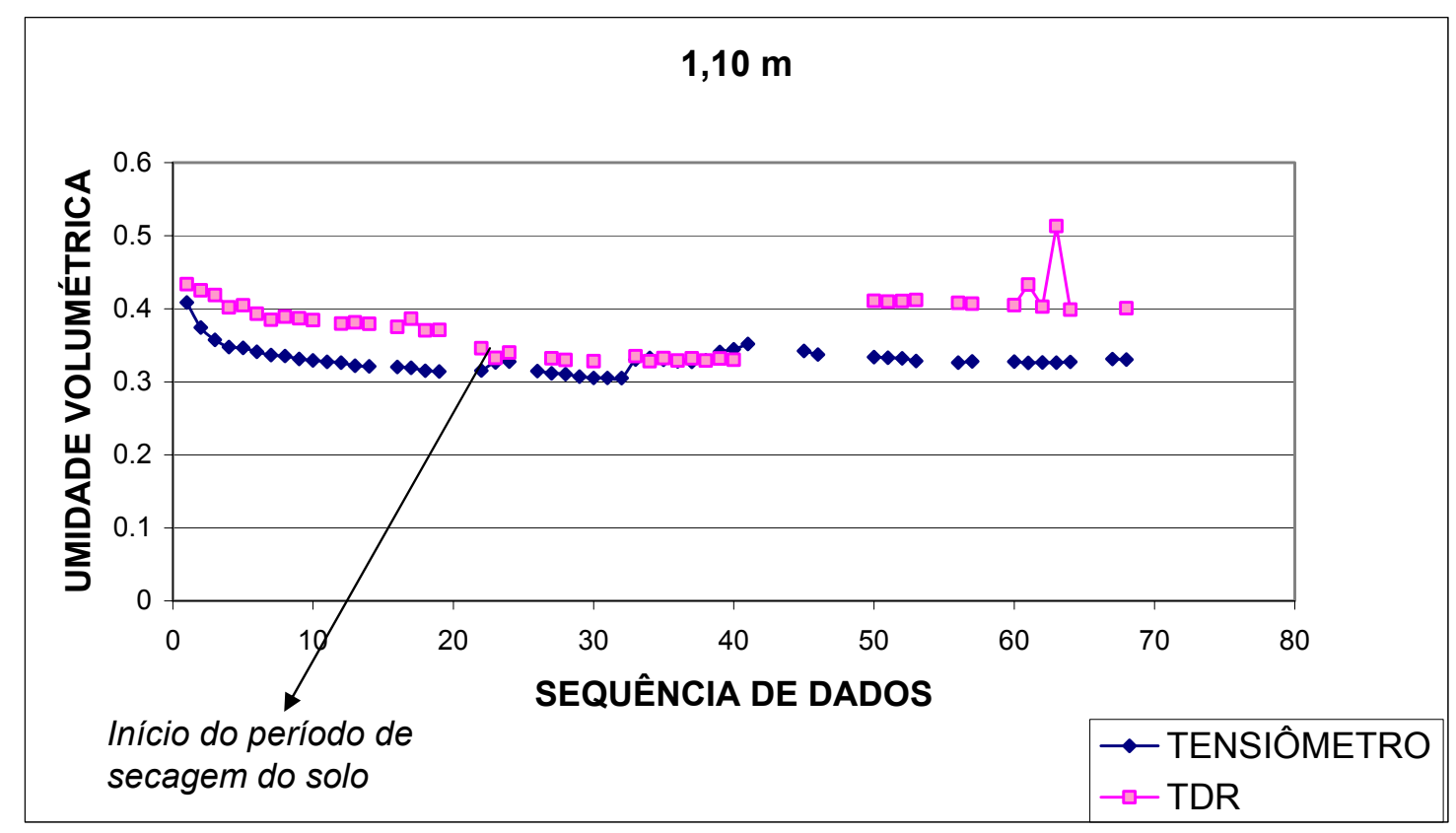

Figura 16 - Seqüência de valores de umidade volumétrica $\left(\mathrm{m}^{3} \mathrm{~m}^{-3}\right)$, obtidos pelo tensiômetro e pelo TDR, durante o intervalo que engloba os dados do ensaio de $\mathrm{K}(\theta)$ utilizando o método do perfil instantâneo e os do período de secagem do solo.

Observa-se que os valores pelo TDR mostraram-se inferiores aos dados disponíveis pelo tensiômetro. $\mathrm{Na}$ verdade, o que verificou-se pela observação da coerência dos dados do período, é que os dados de umidade obtidos a partir do tensiômetro não são seguros, pois os de potencial matricial já não eram confiáveis, uma vez que atuaram próximos ao seu limite de funcionamento.

A Figura 16 mostra uma seqüência de valores consecutivos de umidade volumétrica para cada instrumento, na profundidade $1,10 \mathrm{~m}$, tomada como exemplo, pois observando as Figuras 17 e 18 a seguir, foi a que apresentou menor coeficiente de determinação e pela situação verificada nas outras não diferir tanto, pois a maioria apresenta correlação do tipo fraca (Levin, 1987). Utilizou-se dados anteriores ao período de secagem do solo (dados do ensaio de $K(\theta)$ utilizando o método do perfil instantâneo), 
para verificar se a queda dos valores de umidade iniciada no período anterior continuou acontecendo, conforme esperado.

Verificou-se que logo no início do período de secagem o tensiômetro deixou de funcionar corretamente, pois os valores aumentaram em vez de diminuir (conforme indicado na Figura 16). O não funcionamento do tensiômetro evidencia-se ainda mais a partir da seqüência 50, pois nesse momento aconteceu pequenos acréscimos de umidade, detectados pelo TDR, enquanto os valores do tensiômetro permaneceram quase constantes, o que pode ser claramente observado na figura.

Desta forma, fica claro o porquê dos baixos coeficientes de determinação obtidos desde a correlação entre o potencial matricial e a constante dielétrica no período, o que repetiu-se na correlação obtida entre as umidades pelos dois instrumentos, tanto no caso da uso do tensiômetro, na calibração do TDR (Figura 17), como no caso do uso do modelo empírico de Topp et al., 1980 (Figura 18).

A Figura 19 apresenta a correlação entre as umidades obtidas pelo TDR calibrado pelas duas formas:com umidades obtidas pelo tensiômetro e pelo modelo de Topp. Verificou-se, novamente, excelentes correlações, mostrando a boa concordância entre as duas calibrações. 

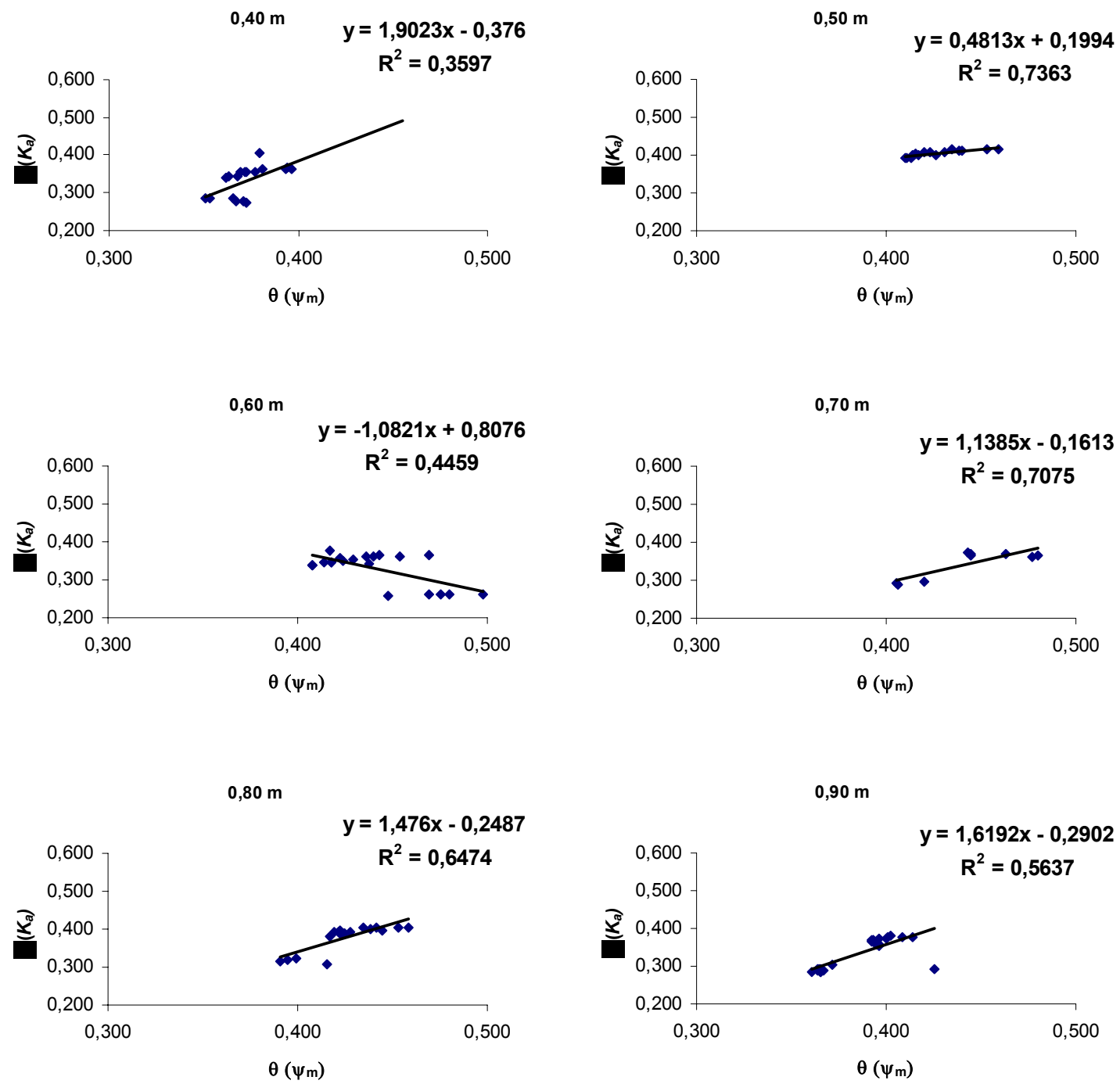

Figura 17 - Correlação entre os valores de umidade volumétrica $\left(\mathrm{m}^{3} \mathrm{~m}^{-3}\right)$ obtidos por tensiometria e curva de retenção e TDR (calibrado via tensiômetro), ao longo do período de secagem do solo. 

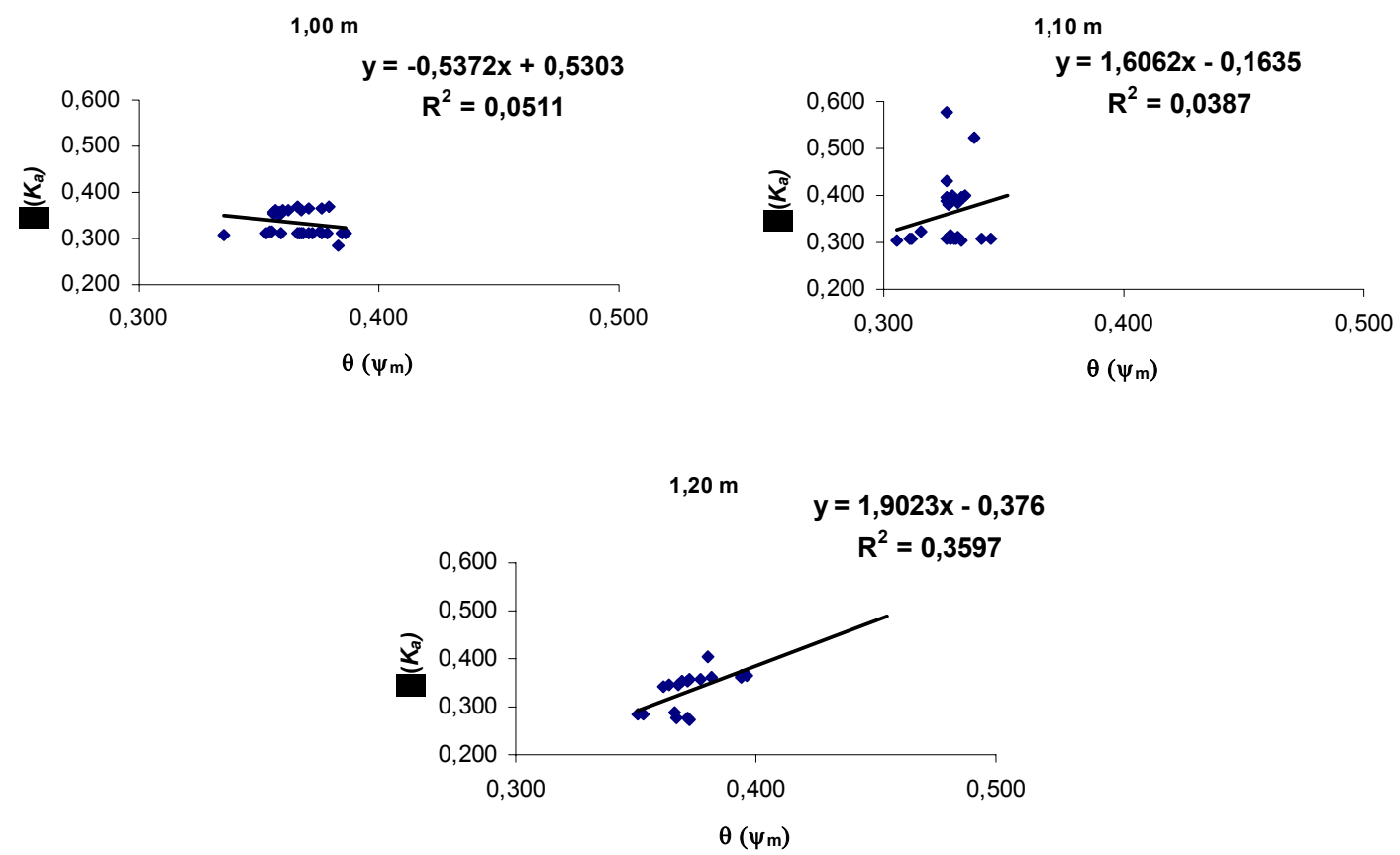

Figura 17 - Correlação entre os valores de umidade volumétrica $\left(\mathrm{m}^{3} \mathrm{~m}^{-3}\right)$ obtidos por tensiometria e curva de retenção e TDR (calibrado via tensiômetro), ao longo do período de secagem do solo.
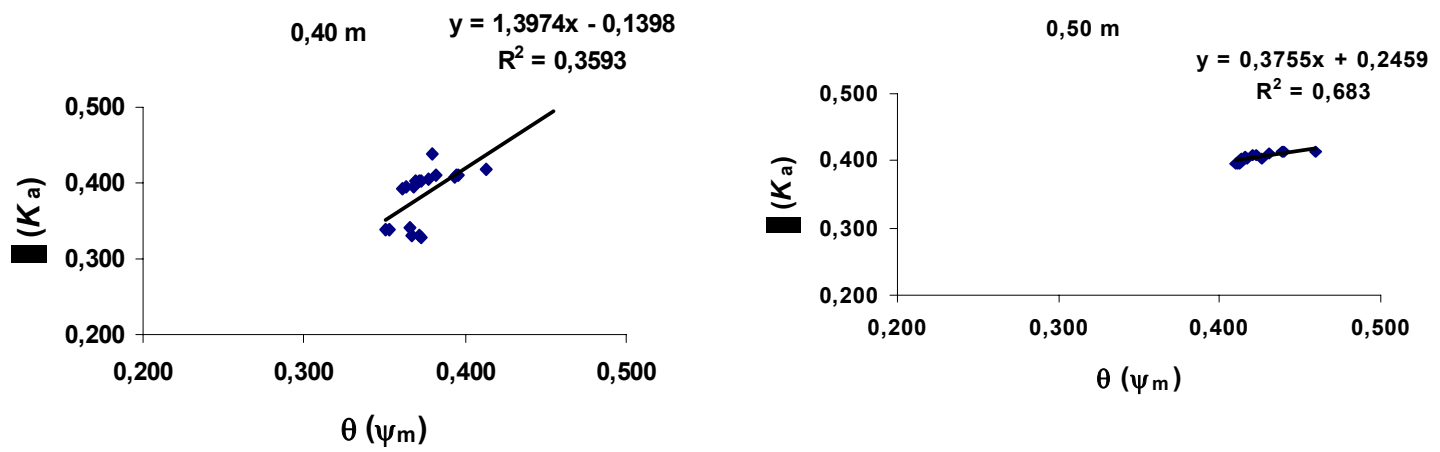

Figura 18 - Correlação entre os valores de umidade volumétrica $\left(\mathrm{m}^{3} \mathrm{~m}^{-3}\right)$ obtidos por tensiometria e curva de retenção e TDR (calibrado pelo modelo de Topp et al., 1980), ao longo do período de secagem do solo. 

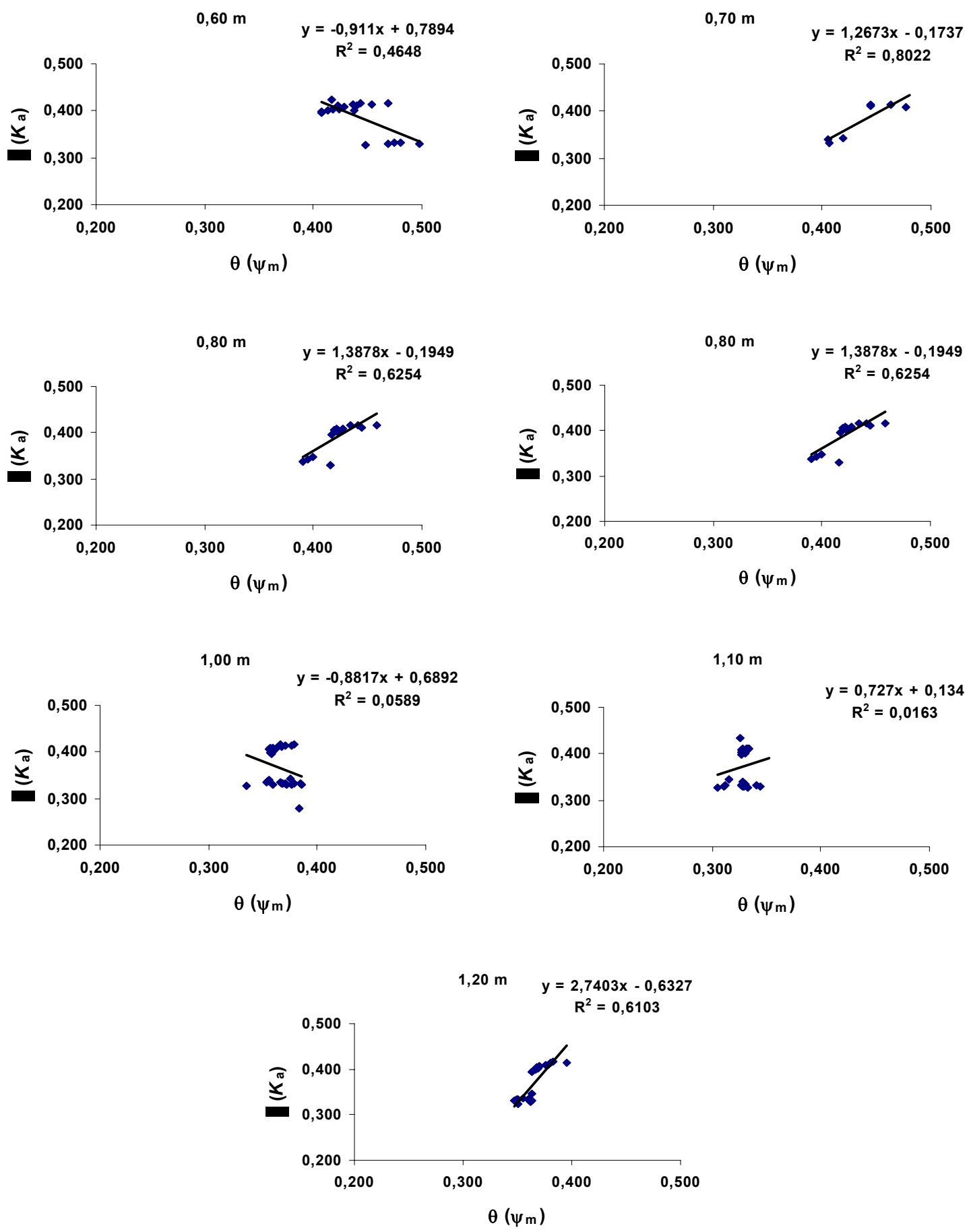

Figura 18 - Correlação entre os valores de umidade volumétrica $\left(\mathrm{m}^{3} \mathrm{~m}^{-3}\right)$ obtidos por tensiometria e curva de retenção e TDR (calibrado pelo modelo de Topp et al., 1980), ao longo do período de secagem do solo. 

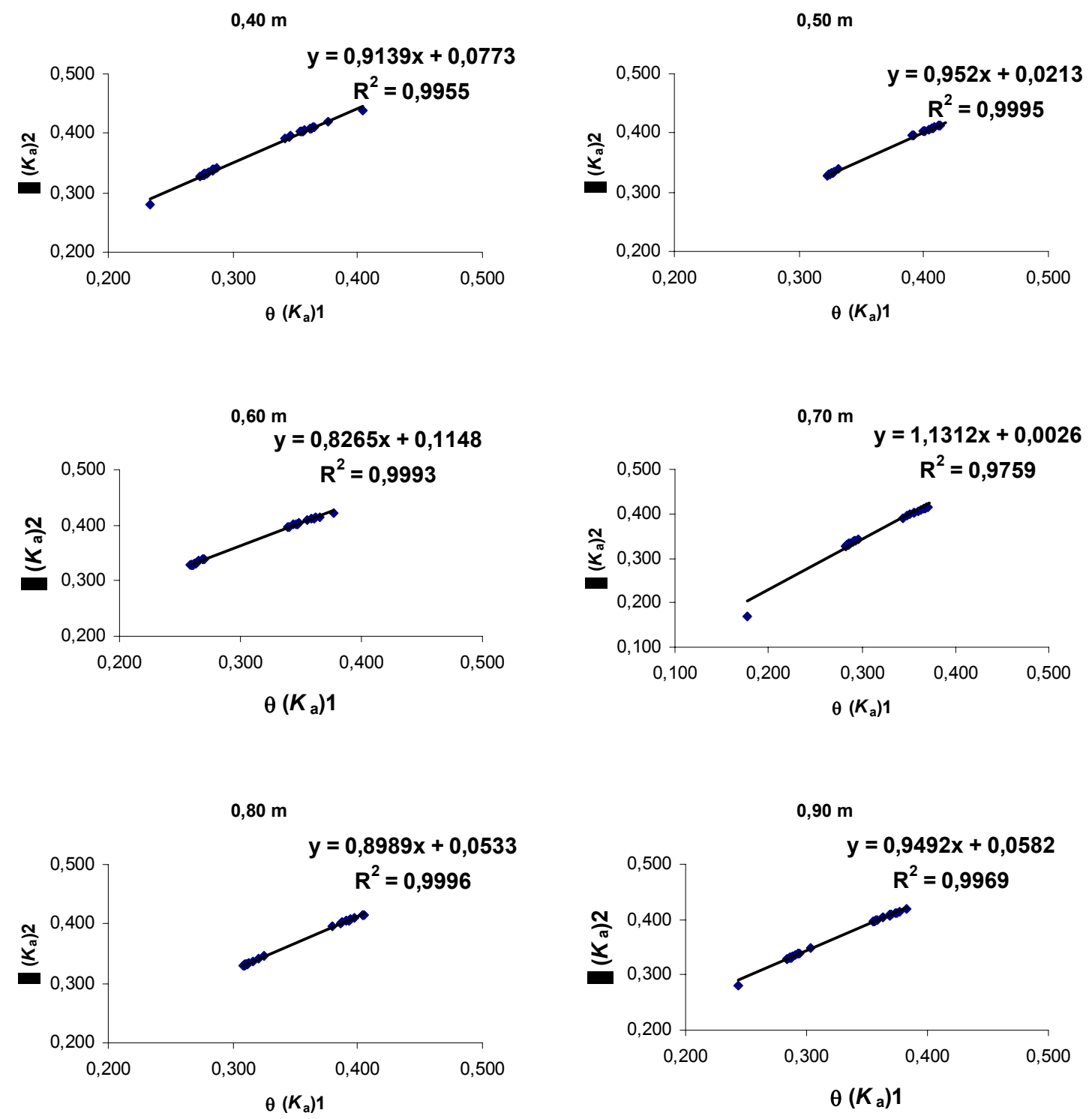

Figura 19 - Correlação entre os valores de umidade volumétrica $\left(\mathrm{m}^{3} \mathrm{~m}^{-3}\right)$ obtidos por TDR calibrado com umidade obtida por tensiometria e curva de retenção e do TDR calibrado pela equação de Topp et al. (1980), ao longo do período de secagem do solo. 

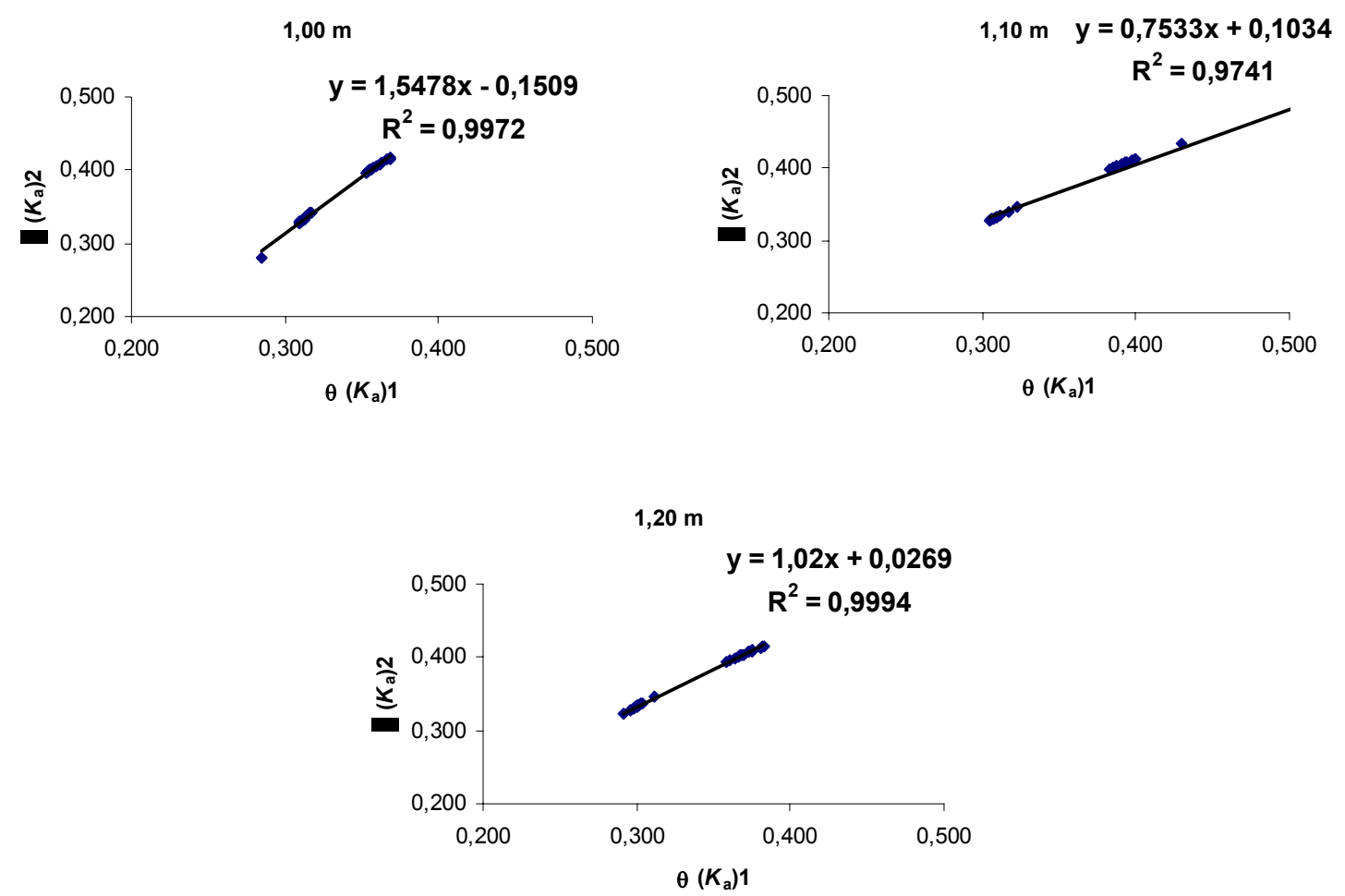

Figura 19 - Correlação entre os valores de umidade volumétrica $\left(\mathrm{m}^{3} \mathrm{~m}^{-3}\right)$ obtidos por TDR calibrado com umidade obtida por tensiometria e curva de retenção e do TDR calibrado pela equação de Topp et al. (1980), ao longo do período de secagem do solo.

\subsubsection{Período de inundações intermitentes}

$\mathrm{Na}$ Figura 20 observam-se as correlações entre os valores de umidade volumétrica $\left(\mathrm{m}^{3} \mathrm{~m}^{-3}\right)$ obtidos por tensiometria e do TDR com calibração usando a tensiometria para fornecimento dos valores de umidade, e na Figura 21, com calibração usando o modelo de Topp et al., 1980.

Em ambas, as correlações foram fracas para as profundidades 0,40, 0,60 e 0,90 m, e moderadas para as demais profundidades. Na Figura 20, o menor coeficiente 
de determinação foi obtido para a profundidade $0,90 \mathrm{~m}$, enquanto que na Figura 21, o menor valor foi obtido para a profundidade $0,60 \mathrm{~m}$.

Em comparação com as correlações entre as propriedades físicas, para o mesmo período, observa-se que houve diminuição do coeficiente de determinação para todas as profundidades, exceto a $0,50 \mathrm{~m}$, considerando TDR calibrado via tensiômetro, ocorrendo o mesmo para o TDR calibrado pelo modelo de Topp et.al (1980), exceto para as profundidades $0,50 \mathrm{~m}$ e $0,70 \mathrm{~m}$.
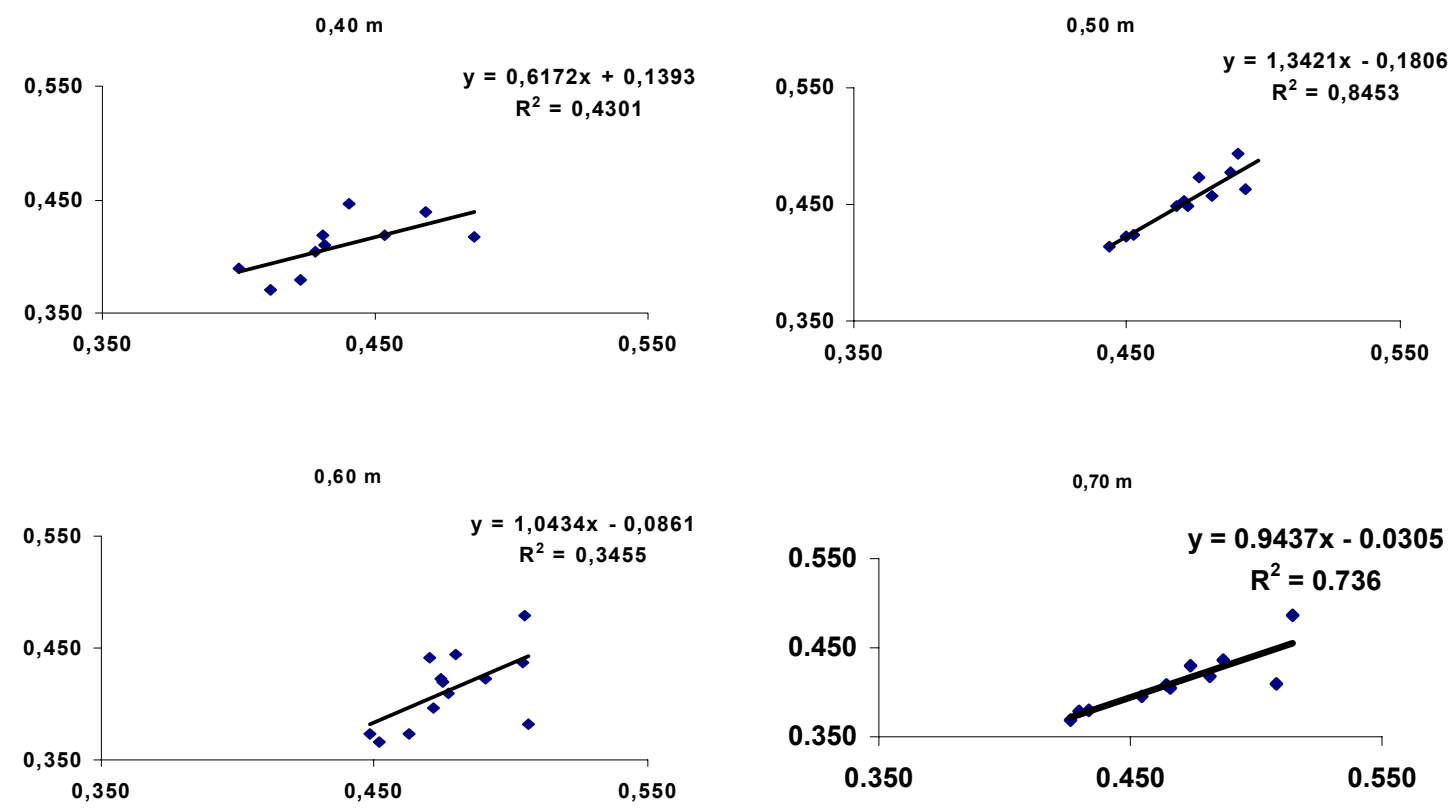

Figura 20 - Correlação entre os valores de umidade volumétrica $\left(\mathrm{m}^{3} \mathrm{~m}^{-3}\right)$ obtidos por tensiometria e curva de retenção e do TDR (calibrado via tensiômetro), para os dados de inundação intermitente do solo. 

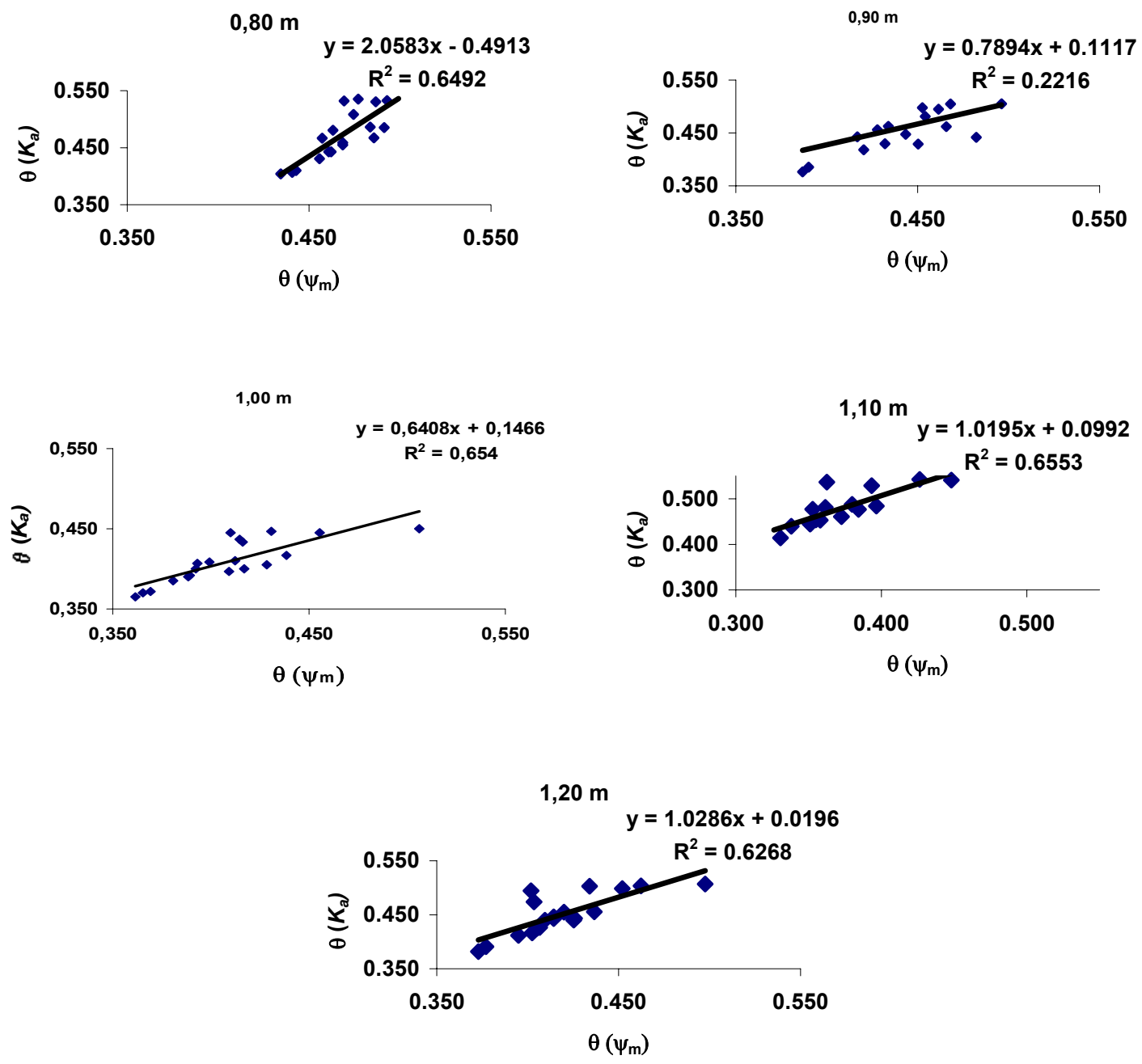

Figura 20 - Correlação entre os valores de umidade volumétrica $\left(\mathrm{m}^{3} \mathrm{~m}^{-3}\right)$ obtidos por tensiometria e curva de retenção e do TDR (calibrado via tensiômetro), para os dados de inundação intermitente do solo. 

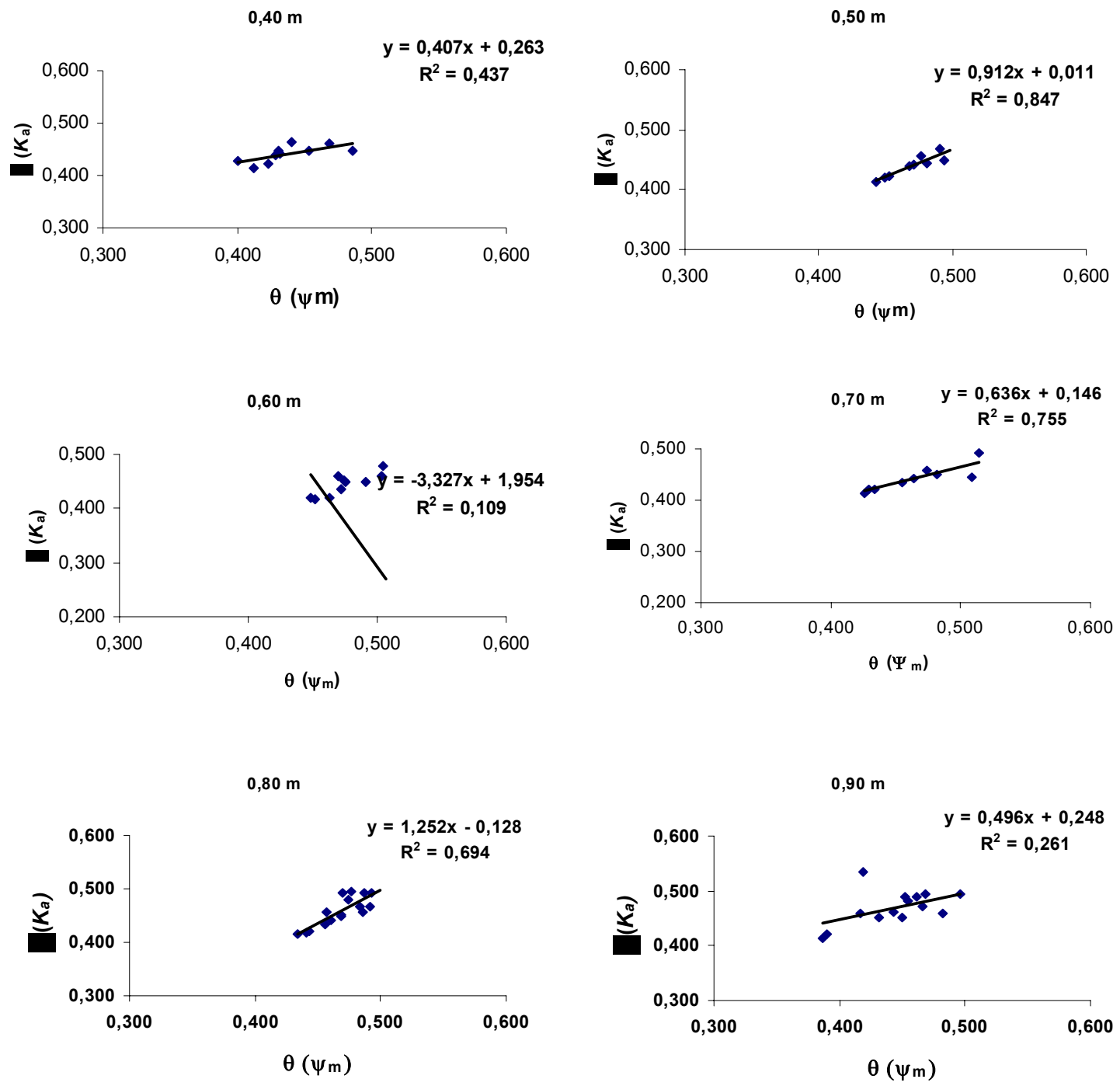

Figura 21 - Correlação entre os valores de umidade volumétrica $\left(\mathrm{m}^{3} \mathrm{~m}^{-3}\right)$ obtidos por tensiometria e curva de retenção e TDR (calibrado pelo modelo de Topp et al., 1980), para os dados de inundação intermitente do solo. 

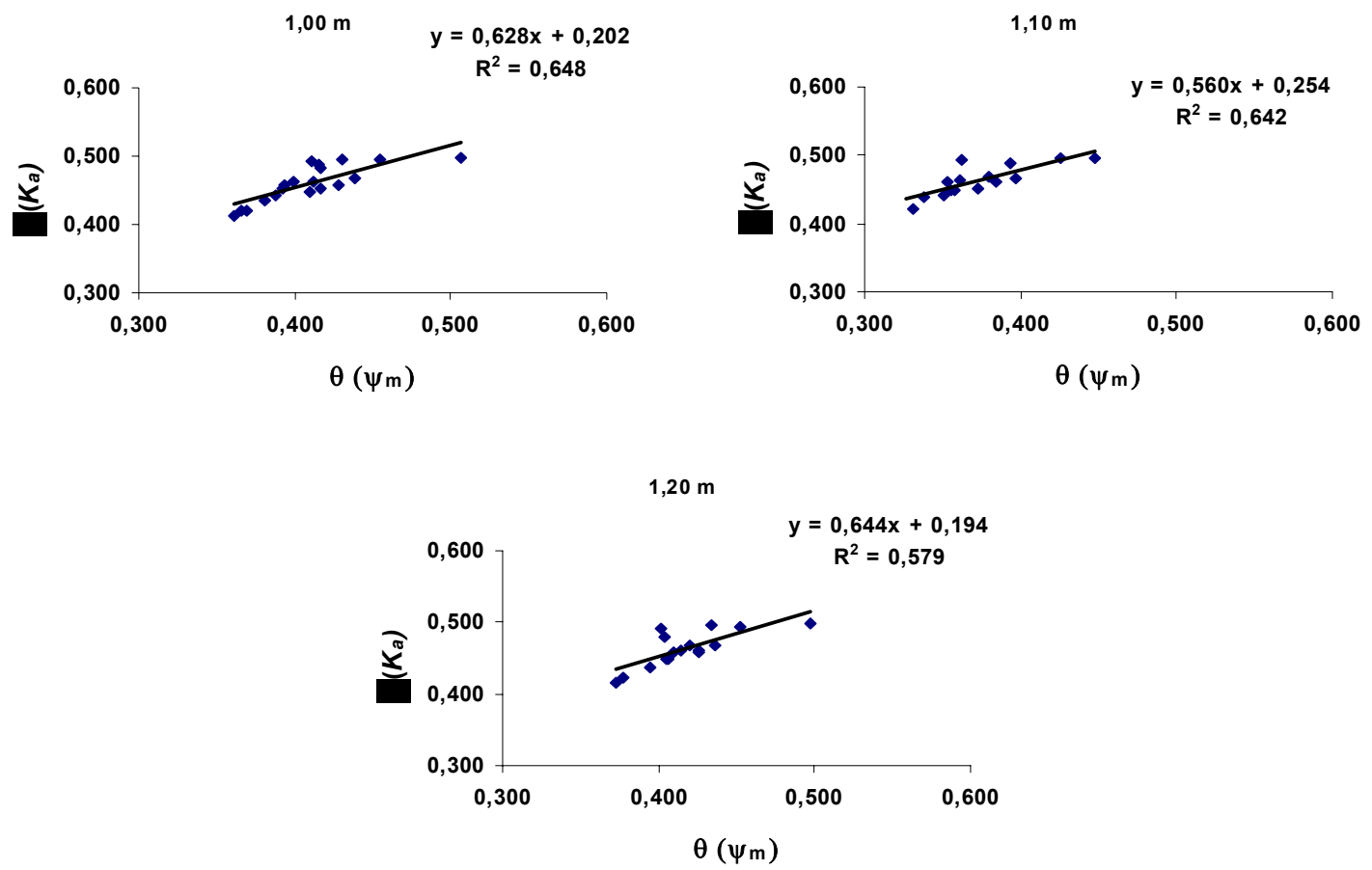

Figura 21 - Correlação entre os valores de umidade volumétrica $\left(\mathrm{m}^{3} \mathrm{~m}^{-3}\right)$ obtidos por tensiometria e curva de retenção e TDR (calibrado pelo modelo de Topp et al., 1980), para os dados de inundação intermitente do solo.
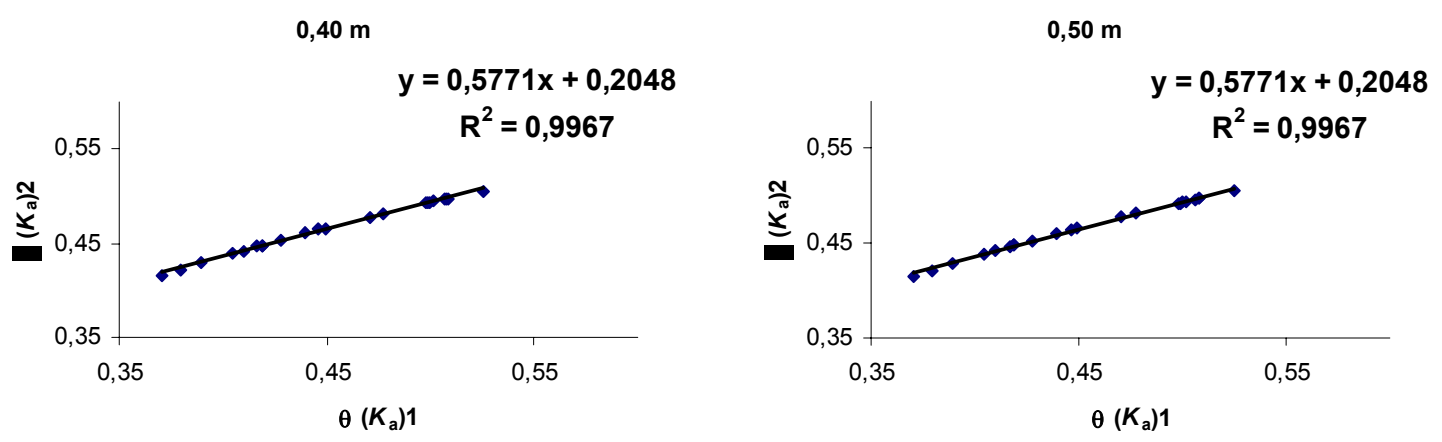

Figura 22 - Correlação entre os valores de umidade volumétrica $\left(\mathrm{m}^{3} \mathrm{~m}^{-3}\right)$ obtidos pelo TDR calibrado com umidade obtida por tensiometria e TDR calibrado pela equação de Topp et al. (1980), ao longo do período de inundação intermitente. 

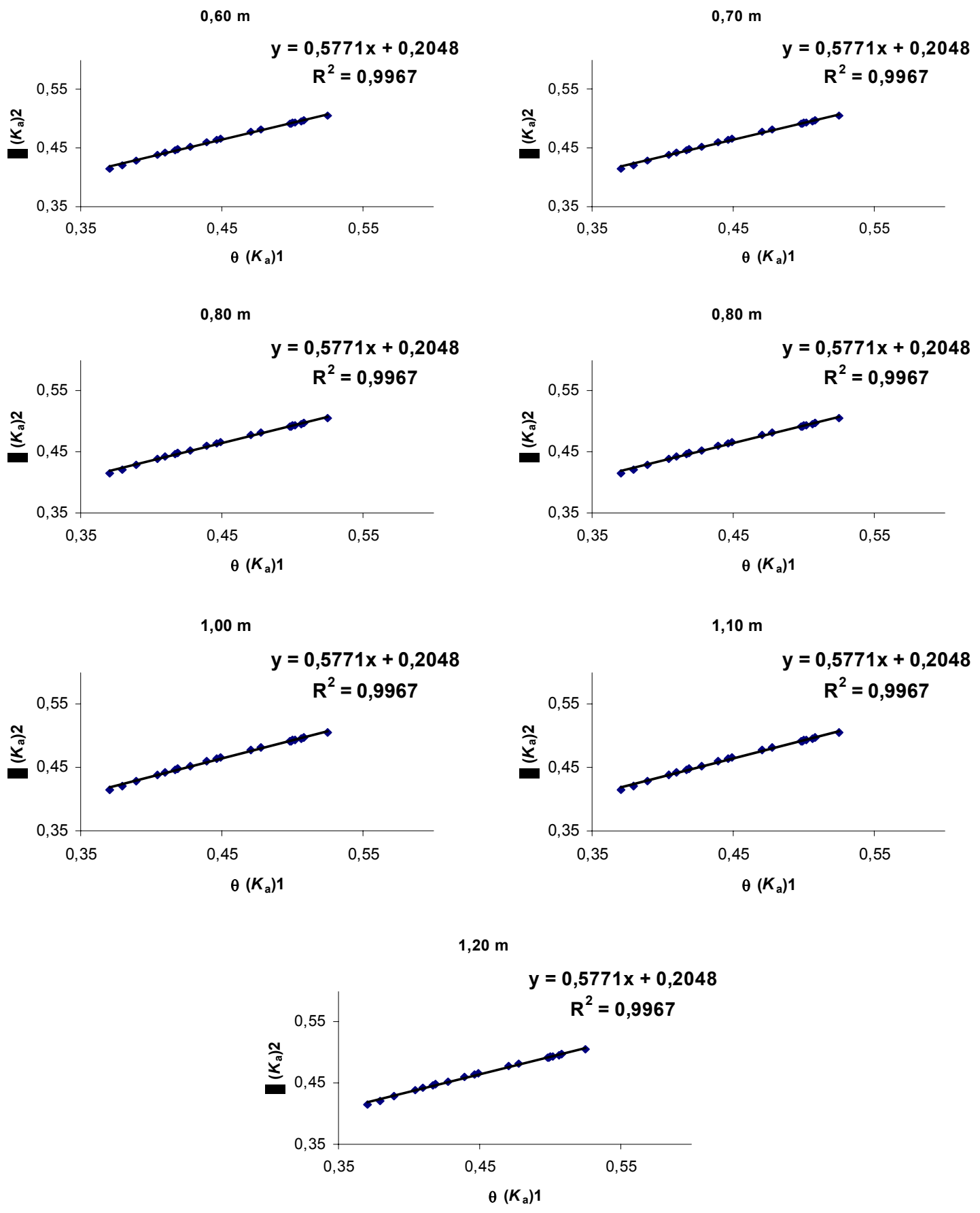

Figura 22 - Correlação entre os valores de umidade volumétrica $\left(\mathrm{m}^{3} \mathrm{~m}^{-3}\right)$ obtidos pelo TDR calibrado com umidade obtida por tensiometria e TDR calibrado pela equação de Topp et al. (1980), ao longo do período de inundação intermitente. 
Em comparação com os valores de umidade de saturação para cada profundidade, estimados pela equação de van Genuchten (1980), apresentados na tabela 6, verifica-se que o TDR detectou que estes foram atingidos nas profundidades 0,40, 0,50, 0,80 e $1,10 \mathrm{~m}$, sendo que nas demais, foram alcançados valores muito próximos (valores da última inundação no apêndice). Verificou-se que para as profundidades em que o valor estimado foi atingido, este ocorreu cerca de 2 horas após o início da inundação. Para as profundidades 0,40 e $0,50 \mathrm{~m}$, o tensiômetro já indicava potencial de pressão meia hora antes, porém para as profundidade $0,80 \mathrm{~m}$, só indicou potencial de pressão uma hora após o TDR ter atingido a umidade de saturação estimada e para 1,10 m, cerca de 2,5 horas. Desta forma, evidencia-se o que já indicava a Figura 8, a detecção mais rápida do TDR do que o tensiômetro.

Quanto a comparação entre as duas calibrações, a figura 22 mostra mais uma vez que houve uma ótima correlação para todas as profundidades estudadas. Verificouse no conjunto de dados, que para algumas profundidades os valores de umidade obtidos pelo TDR calibrado pelo modelo de Topp et al. foram maiores e vice-versa. Para a maioria das profundidades, entretanto, próximo à saturação, os valores foram maiores quando calibrado com o tensiômetro. Embora não faça parte do objetivo inicial, pode-se concluir que a calibração do TDR utilizando valores de umidade fornecidos pelo tensiômetro e curva de retenção, para o solo estudado, foi muito similar a calibração utilizando o modelo de Topp et al. (1980). 


\section{CONCLUSÕES}

- O desempenho da técnica de TDR em períodos de baixa umidade do solo é satisfatório, sendo por isso recomendável em condições que o tensiômetro não mais funciona;

- A técnica de TDR apresentou sensibilidade superior ao tensiômetro, de uma forma geral, na deteç̧ão de mudanças de umidade do solo. 


\section{REFERÊNCIAS BIBLIOGRÁFICAS}

BAKER, J.M.; ALLMARAS, R.R. System for automating and multiplexing soil moisture measurement by time-domain reflectometry. Soil Science Society of America Journal, v. 54, p.1-6, 1990.

DALTON, F. N.; VAN GENUCHTEN, M. T. The time-domain reflectometry method for measuring soil water content and salinity. Geoderma, v. 38, p. 237-250, 1986.

DASBERG, S.; DALTON, F. N. Time domain reflectometry field measurements of soil water content and electrical conductivity. Soil Science Society of America Journal, v. 49, p. 293-297, 1985.

DASBERG, S.; HOPMANS, J.W. Time-domain reflectometry calibration for uniformly and nonuniformly wetted sandy and clayey loam soils. Soil Science Society of America Journal, v.56, p. 1341-1345, 1992.

DAVIS, J.L.; CHUDOBIAK, W.J. In situ meter for measuring relative permittivity of soils. Geology Survey of Canada, Part A, Paper 75-1, p.75-79, 1975.

DIRKSEN, C. Unsaturated hydraulic conductivity in soil analysis: Physical methods. Soil Science Society of America Journal, v.57, p. 660-667, 1993.

DIRKSEN, C. Soil physics measurements. Reiskirchen: Catena-Verlag, 1999. 154 p.

DIRKSEN, C.; DASBERG, S. Improved calibration of time-domain reflectometry soil water content measurements. Soil Science Society of America Journal, v.57, p. 660-667, 1993. 
DOBSON, M. C.; ULABY, F.T.; HALliKAINEN, M. T.; EL-RAYES, M. A. Microwave dielectric behavior of wet soil II. Dielectric mixing models. IEEE Transactions Geoscience Remote Sensors, v. 23, p. 35-46, 1985.

EMPRESA BRASILEIRA DE PESQUISA AGROPECUÁRIA. Sistema brasileiro de classificação de solos. Brasília: EMBRAPA, CNPS, 1999. 412p.

FELLNER-FELDEGG, H. The measurement of dielectrics in the time domain. Journal of Physics Chemical, v.73, p.616-623, 1969.

FERRÉ, P.A.; RUDOLPH, D.L.; KACHANOSKI, R.G. Spatial averaging of water content by time domain reflectometry: implications for twin rod probes with and without dielectric coating. Water Resources Research, v. 32, p. 271-279. 1996.

FRIEDMAN, S.P. Statistical mixing model for the apparent dielectric constant media. Soil Science Society of America Journal, v. 61, p. 742-745. 1997.

GARDNER, C.M.K.; ROBINSON, D.A.; BLYTH, K.; COOPER, J.D. Soil water content. In: SMITH, K.A.; MULLINS, C.E. (Ed.). Soil and environmental analysis: Physical methods., New York: Marcel Dekker, 2000. p.1-75.

HALliKAINEN, M.T.; ULABY, F.T.; DOBSON. M.; EL-RAYES, M.A.; WU, L. Microwave dielectric behavior of wet soil - Part I: Empirical models and experimental observations. IEEE Transactions on Geoscience and Remote Sensing, v.23, n.1, p.25-34, 1985.

HERKELRATH, W.N.; HAMBURG, S.P.; MURPHY, F. Automatic, real time monitoring of soil moisture in a remote field area with time domain reflectometry. Water Resources Research, v.27, p.857-864, 1991.

HERMMANN Jr., P.S. Construção de um equipamento para medida de umidade do solo através de técnica de microondas. São Carlos, 1993. 124p. Dissertação (Mestrado) Escola de Engenharia de São Carlos, Universidade de São Paulo 
HERMMANN Jr., P.S. Aspectos básicos da reflectometria no domínio do tempo (TDR) e potencialidades de aplicação na física do solo. In: MATSURA, E.E.; JAVAREZ Jr.,A.;GOMES, E.P.; SOUZA, C.F. (Ed.). Aplicações da téenica de TDR na agricultura. Campinas: UNICAMP/FEAGRI, 2001. p.37-50.

HIGNETT, C.T. Factors affecting the selecting of a soil water sensing technology. In: International Atomic Energy Agency. Comparison of soil water measurement using the neutron scattering, time domain reflectometry and capacitance methods. Viena: IAEA, 2000. p. 51-64.

HOOK, W.R.; LIVINGSTON, N.J. Propagation velocity errors in time domain reflectometry measurements of soil water. Soil Science Society of America Journal, v.59, p.92-96, 1995.

JONG VAN LIER, Q.; LIBARDI, P.L. Variabilidade dos parâmetros da equação que relaciona a condutividade hidráulica com a umidade do solo no método do perfil instantâneo. Revista Brasileira de Ciência do Solo, v.23, p.1005-1014, 1999.

KENG, J.C.; TOPP, C.G. Measuring water content of soil columns in the laboratory: a comparison of gamma ray attenuation and TDR techniques. Canadian Journal Soil Science, v.63, p.3-43, 1983.

KLEMUNES Jr., J. Determining soil volumetric moisture content using time domain reflectometry. Mc Lean: U.S. Department of Transportation, 1998. 74p.

KLUTE, A.; GARDNER, W.R. Tensiometer response time. Soil Science, v.93, n.1, p. 204-207, 1962.

KUNZELMANN, G.; PASCHOLD, P.J. Assesment of irrigation techniques for asparagus cultivation - Part II. Gemuse-Munchen, v.34, n.10, p.571-574, 1998.

LEDIEU, J.; DE RIDER, P.; DE CLERCK, P.; DAUTEBRAND, S. A method measuring soil water content by time-domain reflectometry. Journal of Hydrolgy, v. 88, p. 319-328, 1986. 
LEVIN, J. Estatística aplicada a ciências humanas. 2.ed. São Paulo: Harbra, 1987. $392 \mathrm{p}$.

LIBARDI, P.L. Dinâmica da água no solo. Piracicaba: o autor, 2000. 509p.

LOOK, B.; REEVES, I. The application of time domain reflectometry for measurement on unfrozen water content in frozen soils. Cold Region Science Technology, v.3, p. $205-210,1982$.

MALICKI, M.A.; PLAGGE, R.; ROTH, C.H. Improving the calibration of dielectric TDR soil moisture determination taking into account the solid soil. European Journal of Soil Science, v. 47, p. 357-366. 1996.

NADLER, A.; DASBERG, S.; LAPID, I. Time Domain Reflectometry measurements of water content and electrical conductivity of layered soils columns. Soil Science Society of America Journal, v.55, p.938-943, 1991.

NOBORIO, K. Measurement of soil water content and electrical conductivity by time domain reflectometry: a review. Computers and Electronics in Agriculture, v.31, p.213-237. 2001.

OR, D.; WRAITH, J.M. Soil water content and water potential relationships. In: SUMMER, M.E. Handbook of Soil Science. Boca Raton: CRC Press, 2000.

OTTO, S.R.L.; ALCAIDE, M. Utilização do método TDR-tensiômetro na obtenção da curva de retenção de água no solo. Revista Brasileira de Engenharia Agrícola e Ambiental, v.5, n.2, p.265-269, 2001.

PAULETTO, E.A.; LIBARDI, P.L.; MANFRON, P.A.; MORAES, S.O. Determinação da condutividade hidráulica de solos a partir da curva de retenção de água. Revista Brasileira de Ciência do Solo, v.12, p.189-195, 1988.

PREVEDELLO, B.M.S.; PREVEDELLO, C.L.; LIBARDI, P.L. Simplificação analítica do perfil instantâneo para obtenção da condutividade hidráulica não saturada em condições de campo. Revista Brasileira de Ciência do Solo, v.5, p. 93-97, 1981. 
RADA, G. R.; ELKINS, G.E. HENDERSON, B.; VAN SAMBEEK, B.; LOPEZ Jr., A. LTPP seasonal monitoring program: instrumentation, installation and data collection guidelines, Mc Lean: U.S. Department of Transportation, 1994. 70 p.

RIBEIRO, R.S.F. Irrigação de precisão. (compact disc) In: CONGRESSO BRASILEIRO DE ENGENHARIA AGRÍCOLA, 30., Foz do Iguaçu,2001. Foz do Iguaçú: SBEA, 2001.

ROBINSON, D. A.; COOPER, J.D.; GARDNER, C. M. K. Modeling the relative permittivity of soils using soil hygroscopic water content. Journal of hydrology, v. 255, p.39-49, 2002.

ROTH, K.; SCHULIN, R.; FLÜLER, H.; ATTINGER, W. Calibration of time-domain reflectometry for water content measurement using a composite dielectric approach. Water Resources Research, v.26, n.10, p.2267-2273, 1990.

ROTH, K.; MALICK, M. A.; PLAGGE, R. Empirical evaluation of the relationship between soil dielectric constant and volumetric water content as the basis for calibrating soil moisture measurements by TDR. Journal of Soil Science, v.43, p.1$13,1992$.

SALVE, R. Near-surface wetting of a ponded basalt surface: observations using time domain reflectometry. Journal of Hydrology, v. 208, p.249-261, 1998.

SELIG, E.T; MANSUKHANI, S. Relationship of soil moisture to the dielectric property. Journal of the Geotechnical Engineering Division, v.101, n.8, p. 755$770,1975$.

SCOTT, M.G.; PHANG, W.A.; PATTERSON, D.E. Developments in situ monitoring of moisture in pavement structures by time domain reflectometry (TDR). Ontario: The Transportation Technology and Energy Branch, 1983. 85 p.

SCHUMUGGE, T.J.; JACKSON, T.J. Survey of methods for soil moisture determination. Water Resources Research, v.16, n.6, p.961-979, 1980. 
TEIXEIRA, C.F.A. Comparação do desempenho de tensiômetros com manômetro de mercúrio, TDR e sonda de nêutrons no monitoramento de água no solo. Piracicaba, 2001. 115p. Tese (Doutorado) - Escola Superior de Agricultura "Luiz de Queiroz", Universidade de São Paulo.

TOMMASELLI, J.T.G. Influência de algumas características do solo sobre a calibração de um aparelho de TDR. Piracicaba, 1997. 109p. Tese (Doutorado) Centro de Energia Nuclear na Agricultura, Universidade de São Paulo.

TOMMASELLI, J.T.G. Critérios para calibração de sondas de TDR. In: MATSURA, E.E.; JAVAREZ Jr.,A.;GOMES, E.P.; SOUZA, C.F. (Ed.). Aplicações da técnica de TDR na agricultura. Campinas: UNICAMP/FEAGRI, 2001. p.85-114.

TOPP, G.C.; DAVIS, J.L.; ANNAN, A.P. Electromagnetic determination of soil water content: measurements in coaxial transmission lines. Water Resources Research, v.16, n.3, p.574-582, 1980.

TOPP, C.G.; FERRÉ, P.A. Measuring water content in soil using TDR: a state-of-the-art in 1998. In: International Atomic Energy Agency. Comparison of soil water measurement using the neutron scattering, time domain reflectometry and capacitance methods. Viena: IAEA, 2000, p.111-124.

VAN GENUCHTEN, M. T. A closed-form equation for predicting the hydraulic conductivity of unsaturated soils. Soil Science Society of America Journal, n. 44, p. 892-898, 1980.

VAZ, C.M.P. Aplicações de sondas espirais de TDR combinadas com tensiômetro e penetômetro. In MATSURA, E.E.; JAVAREZ Jr.,A.;GOMES, E.P.; SOUZA, C.F. (Ed.). Aplicações da técnica de TDR na agricultura. Campinas: UNICAMP/FEAGRI, 2001. p.65-84.

VILLAGRA, M.M.; MATSUMOTO, O.M. BACCHI, O.O.S.; MORAES, S.O.; LIBARDI, PL.; REICHARDT, K. Tensiometria e variabilidade espacial em terra roxa estruturada. Revista Brasileria de Ciência do Solo, v.12, p. 205-210, 1988. 
WANG, J.R.; SCHMUGGE, T.J. An empirical model for the complex dielectric permittivity of soils as a function of water content. IEEE Transactions Geoscience Remote Sensing, v.18, p. 288-295, 1980.

WHALLEY, W.R.; LEEDS-HARRISON, P. B.; JOY, P.; HOEFSLOOT, P. Time Domain Reflectometry and tensiometry combined in an integrated soil water monitoring system. Journal of Agricultural Engineering Resources, v.59, p.141144, 1994.

WEGERHENKEL, M. Using TRIME-TDR for the determination of soil moisture on light sandy soils. Zeitschirift-fur-Pflanzenernahrung-und-Bodenkunde, v.161, n.5, p.577-582, 1998.

WEITZ, A.M.; GRAUEL, W.T.; KELLER, M.; VELDKAMP, E. Calibration of time domain reflectometry technique using undisturbed soil samples from humid tropical soils of volcanic. Water Resources Research. v. 33, p.1241-1249. 1997.

ZEGELIN, S.J.; WHITE, J.; JENKINS, D.R. Improved field probes for soil water content and electrical conductivity measurement using time-domain reflectometry. Water Resources Research, v.25, n.11, p.2367-2376, 1989.

ZEGELIN, S.J.; WHITE, I.; RUSSELL, G.F. A critique of time domain reflectometry technique for determining field soil water content. In: TOPP, G.C.; REYNOLDS, W.D.; GREEN, R.E. (eds.). Advances in measurement of soil physical properties: bringing theory into practice. Madison: Soil Science Society of America, 1992. p. 187-208 (SSSA Special Publication, 30). 
APÊNDICES 
Tabela 1. Dados de granulometria (areia, silte e argila), classe textural, matéria orgânica (M.O.) e densidade dos sólidos $\left(\rho_{\mathrm{s}}\right)$ do solo nas camadas de interesse

\begin{tabular}{cccclcc}
\hline $\begin{array}{c}\text { Prof. } \\
(\mathrm{m})\end{array}$ & $\begin{array}{c}\text { Areia } \\
\left(\mathrm{g} \mathrm{kg}^{-1}\right)\end{array}$ & $\begin{array}{c}\text { Silte } \\
\left(\mathrm{g} \mathrm{kg}^{-1}\right)\end{array}$ & $\begin{array}{c}\text { Argila } \\
\left(\mathrm{g} \mathrm{kg}^{-1}\right)\end{array}$ & Classe Textural & $\begin{array}{c}\text { M.O. } \\
\left(\mathrm{g} \mathrm{kg}^{-1}\right)\end{array}$ & $\begin{array}{c}\rho_{\mathrm{s}} \\
\left(\mathrm{Kg} \mathrm{m}^{-3}\right)\end{array}$ \\
\hline $0-0,40$ & 260 & 160 & 580 & Argilosa & 18 & 2500 \\
$0,40-0,50$ & 180 & 140 & 680 & Muito argilosa & 8 & 2670 \\
$0,50-0,60$ & 180 & 140 & 680 & Muito argilosa & 8 & 2590 \\
$0,60-0,70$ & 210 & 140 & 650 & Muito argilosa & 5 & 2560 \\
$0,70-0,80$ & 150 & 140 & 710 & Muito argilosa & 3 & 2530 \\
$0,80-0,90$ & 230 & 140 & 630 & Muito argilosa & 5 & 2530 \\
$0,90-1,00$ & 170 & 180 & 650 & Muito argilosa & 5 & 2380 \\
$1,00-1,10$ & 210 & 140 & 650 & Muito argilosa & 5 & 2560 \\
$1,10-1,20$ & 190 & 160 & 650 & Muito argilosa & 5 & 2600 \\
$1,20-1,30$ & 190 & 160 & 650 & Muito argilosa & 8 & 2600 \\
\hline
\end{tabular}

(Fonte: Teixeira, 2001) 
Tabela 2. Teores (\%) dos óxidos de Silício, Alumínio, Ferro, Titânio e Manganês para as camadas de interesse.

\begin{tabular}{cccccc}
\hline Prof. & $\mathrm{SiO} 2$ & $\mathrm{Al}_{2} \mathrm{O}_{3}$ & $\mathrm{Fe}_{2} \mathrm{O}_{3}$ & $\mathrm{TiO}_{2}$ & $\mathrm{MnO}$ \\
$(\mathrm{m})$ & & $(\%)$ & & \\
\hline $0-0,40$ & 12,80 & 14,88 & 16,70 & 2,95 & 0,15 \\
$0,40-0,50$ & 17,00 & 18,36 & 16,48 & 2,93 & 0,11 \\
$0,50-0,60$ & 17,30 & 18,86 & 16,94 & 2,85 & 0,10 \\
$0,60-0,70$ & 17,20 & 18,97 & 17,21 & 2,66 & 0,10 \\
$0,70-0,80$ & 16,80 & 18,56 & 16,33 & 2,76 & 0,10 \\
$0,80-0,90$ & 16,20 & 19,07 & 16,26 & 2,81 & 0,10 \\
$0,90-1,00$ & 13,00 & 18,46 & 16,10 & 2,99 & 0,10 \\
$1,00-1,10$ & 16,00 & 18,05 & 15,62 & 2,94 & 0,10 \\
$1,10-1,20$ & 17,90 & 17,85 & 15,22 & 2,80 & 0,10 \\
$1,20-1,30$ & 17,00 & 17,75 & 15,65 & 2,91 & 0,13 \\
\hline$(\mathrm{F} 0$ & & & & & \\
\hline
\end{tabular}

(Fonte: Teixeira, 2001) 
Tabela 3. Valores médios e coeficientes de variação da densidade do solo nas diferentes camadas de interesse

\begin{tabular}{ccc}
\hline Prof. & Densidade do solo & C.V. \\
$(\mathrm{m})$ & $\left(\mathrm{kg} \mathrm{m}^{-3}\right)$ & $(\%)$ \\
\hline $0-0,40$ & 1320 & 2,9 \\
$0,40-0,50$ & 1240 & 7,2 \\
$0,50-0,60$ & 1210 & 4,4 \\
$0,60-0,70$ & 1310 & 3,7 \\
$0,70-0,80$ & 1280 & 3,6 \\
$0,80-0,90$ & 1260 & 2,2 \\
$0,90-1,00$ & 1250 & 6,1 \\
$1,00-1,10$ & 1240 & 1,0 \\
$1,10-1,20$ & 1310 & 2,2 \\
$1,20-1,30$ & 1250 & 0,7 \\
\hline
\end{tabular}

Os valores são médias de três repetições.

(Fonte: Teixeira, 2001) 
Tabela 4. Valores médios e coeficientes de variação da condutividade hidráulica saturada $\left(\mathrm{K}_{\mathrm{sat}}\right)$ obtida com permeâmetro de carga constante, para as diferentes camadas de interesse

\begin{tabular}{|c|c|c|}
\hline $\begin{array}{l}\text { Prof. } \\
\text { (m) }\end{array}$ & $\begin{array}{c}\mathrm{K}_{\mathrm{sat}} \\
\left(\mathrm{m} \mathrm{s}^{-1}\right)\end{array}$ & $\begin{array}{l}\text { C.V. } \\
(\%)\end{array}$ \\
\hline $0-0,40$ & $4,3 \cdot 10^{-5}$ & 32,7 \\
\hline $0,40-0,50$ & $3,5 \cdot 10^{-5}$ & 81,6 \\
\hline $0,50-0,60$ & $1,0 \cdot 10^{-5}$ & 34,4 \\
\hline $0,60-0,70$ & $7,6 \cdot 10^{-6}$ & 48,2 \\
\hline $0,70-0,80$ & $8,1 \cdot 10^{-6}$ & 40,7 \\
\hline $0,80-0,90$ & $6,8 \cdot 10^{-6}$ & 25,0 \\
\hline $0,90-1,00$ & $6,6 \cdot 10^{-6}$ & 36,4 \\
\hline $1,00-1,10$ & $1,0 \cdot 10^{-5}$ & 4,7 \\
\hline $1,10-1,20$ & $1,1 \cdot 10^{-5}$ & 47,2 \\
\hline $1,20-1,30$ & $2,6 \cdot 10^{-6}$ & 16,0 \\
\hline
\end{tabular}

Os valores são médias de três repetições

(Fonte: Teixeira, 2001) 
Tabela 5. Valores médios e coeficientes de variação da porosidade total calculada, para as diferentes camadas do perfil em estudo

\begin{tabular}{ccc}
\hline Prof. & Porosidade total & C.V. \\
$(\mathrm{m})$ & $\left(\mathrm{m}^{3} \mathrm{~m}^{-3}\right)$ & $(\%)$ \\
\hline $0-0,40$ & 0,493 & 3,0 \\
$0,40-0,50$ & 0,524 & 6,7 \\
$0,50-0,60$ & 0,464 & 5,2 \\
$0,60-0,70$ & 0,423 & 5,0 \\
$0,70-0,80$ & 0,404 & 5,3 \\
$0,80-0,90$ & 0,379 & 3,6 \\
$0,90-1,00$ & 0,466 & 7,1 \\
$1,00-1,10$ & 0,465 & 1,2 \\
$1,10-1,20$ & 0,437 & 2,8 \\
$1,20-1,30$ & 0,455 & 0,8 \\
\hline
\end{tabular}

Os valores são médias de três repetições.

(Fonte: Teixeira, 2001) 
Tabela 6. Parâmetros de ajuste da equação de van Genuchten (1980) correspondentes às diferentes profundidades de interesse

\begin{tabular}{ccccccccccc}
\hline & & \multicolumn{1}{c}{ Profundidade $(\mathrm{m})$} \\
Parâmetro & 0,40 & 0,50 & 0,60 & 0,70 & 0,80 & 0,90 & 1,00 & 1,10 & 1,20 \\
\hline$\alpha(1 / \mathrm{m})$ & 8,41 & 5,80 & 3,86 & 17,21 & 3,75 & 29,60 & 73,26 & 38,44 & 20,79 \\
$\mathrm{~m}$ & 0,3331 & 0,2320 & 0,3185 & 0,1508 & 0,2007 & 0,1559 & 0,1619 & 0,1950 & 0,1554 \\
$\mathrm{n}^{*}$ & 1,4995 & 1,3021 & 1,4673 & 1,1776 & 1,2510 & 1,1846 & 1,1932 & 1,2422 & 1,1839 \\
$\theta_{\mathrm{r}}\left(\mathrm{m}^{3} \mathrm{~m}^{-3}\right)$ & 0,313 & 0,298 & 0,312 & 0,251 & 0,272 & 0,222 & 0,226 & 0,256 & 0,209 \\
$\theta_{\mathrm{s}}\left(\mathrm{m}^{3} \mathrm{~m}^{-3}\right)$ & 0,494 & 0,498 & 0,507 & 0,517 & 0,500 & 0,548 & 0,554 & 0,542 & 0,519 \\
$\mathrm{r}^{2}$ & 0,990 & 0,987 & 0,984 & 0,954 & 0,974 & 0,976 & 0,967 & 0,969 & 0,992 \\
\hline
\end{tabular}

* $\mathrm{n}$ dependente de $\mathrm{m}$

(Fonte: Teixeira, 2001) 
Tabela 7. Valores de potencial matricial, constante dielétrica e umidades volumétricas $\left(\mathrm{m}^{3} \mathrm{~m}^{-3}\right)$ em função do potencial matricial e da constante dielétrica, com calibração feita utilizando o tensiômetro e curva de retenção $(\theta(\mathrm{Ka}) 1)$ e pelo modelo de Topp et al., $1980(\theta(\mathrm{Ka})$ 2), durante a última inundação, para as profundidades $0,40,0,50$ e $0,60 \mathrm{~m}$.

\begin{tabular}{|c|c|c|c|c|c|c|c|c|c|c|c|c|c|c|c|}
\hline \multirow[t]{2}{*}{ Horário } & \multicolumn{5}{|c|}{$0,40 \mathrm{~m}$} & \multicolumn{5}{|c|}{$0,50 \mathrm{~m}$} & \multicolumn{5}{|c|}{$0,60 \mathrm{~m}$} \\
\hline & $\Psi m$ & $\theta(\Psi \mathrm{m})$ & Ka & $\theta(K a) 1$ & $\theta(K a) 2$ & $\Psi m$ & $\theta(\Psi \mathrm{m})$ & $K a$ & $\theta(K a) 1$ & $\theta(K a) 2$ & $\Psi m$ & $\theta(\Psi \mathrm{m})$ & Ka & $\theta(K a) 1$ & $\theta(K a) 2$ \\
\hline 07:00 & & & 30,803 & 0,423 & 0,450 & & & 30,437 & 0,461 & 0,447 & & & 30,283 & 0,415 & 0,446 \\
\hline 08:00 & & & 30,316 & 0,417 & 0,447 & & & 30,151 & 0,458 & 0,445 & & & 30,858 & 0,423 & 0,451 \\
\hline $08: 30$ & $-1,38$ & 0,451 & & & & $-1,3$ & 0,475 & & & & $\begin{array}{c}- \\
1,181\end{array}$ & 0,491 & & & \\
\hline 09:00 & $-0,33$ & 0,486 & 30,305 & 0,417 & 0,446 & $-0,29$ & 0,494 & 30,559 & 0,462 & 0,448 & $\stackrel{-}{1,097}$ & 0,492 & & & \\
\hline 09:30 & 1,103 & & 31,192 & 0,428 & 0,453 & 0,549 & & 31,248 & 0,470 & 0,454 & 0,793 & & 31,911 & 0,437 & 0,458 \\
\hline $10: 00$ & 1,439 & & 37,027 & 0,499 & 0,492 & 1,221 & & & & & 1,087 & & 36,796 & 0,502 & 0,491 \\
\hline $10: 30$ & 1,649 & & & & & 1,389 & & & & & 1,675 & & 34,433 & 0,471 & 0,476 \\
\hline 11:00 & 1,733 & & & & & 1,599 & & & & & 1,549 & & & & \\
\hline $11: 30$ & 1,355 & & & & & 1,221 & & & & & 1,717 & & & & \\
\hline $12: 00$ & 2,027 & & & & & 1,683 & & & & & 1,759 & & & & \\
\hline $12: 30$ & 2,069 & & & & & 1,893 & & & & & 1,801 & & & & \\
\hline $13: 00$ & 2,069 & & 37,675 & 0,507 & 0,496 & 2,061 & & 38,044 & 0,550 & 0,499 & 2,347 & & & & \\
\hline $13: 30$ & 2,111 & & & & & 2,061 & & & & & 2,347 & & & & \\
\hline $14: 00$ & 2,027 & & & & & 2,145 & & & & & 2,347 & & & & \\
\hline $14: 30$ & 1,229 & & & & & 1,767 & & & & & 1,423 & & & & \\
\hline $15: 00$ & 0,095 & & & & & 0,549 & & & & & 0,457 & & 33,466 & 0,458 & 0,469 \\
\hline $15: 30$ & 0,011 & & 32,959 & 0,449 & 0,466 & 0,549 & & 34,059 & 0,503 & 0,473 & 0,415 & & & & \\
\hline $16: 00$ & $-0,33$ & 0,486 & & & & 0,213 & & & & & $0, \overline{-}$ & 0,507 & & & \\
\hline $16: 30$ & $-0,45$ & 0,482 & & & & $-0,04$ & 0,498 & & & & $\begin{array}{c}- \\
0,173\end{array}$ & 0,506 & & & \\
\hline $17: 00$ & $-0,49$ & 0,480 & & & & $-0,08$ & 0,497 & & & & 0,299 & 0,504 & & & \\
\hline 19:00 & & & 32,047 & 0,438 & 0,459 & & & 32,138 & 0,481 & 0,460 & & & 32,24 & 0,441 & 0,461 \\
\hline
\end{tabular}


Tabela 8. Valores de potencial matricial, constante dielétrica e umidades volumétricas $\left(\mathrm{m}^{3} \mathrm{~m}^{-3}\right)$ em função do potencial matricial e da constante dielétrica, com calibração feita utilizando o tensiômetro e curva de retenção $(\theta(\mathrm{Ka}) 1)$ e pelo modelo de Topp et al., $1980(\theta(\mathrm{Ka}) 2)$, durante a última inundação, para as profundidades $0,70,0,80$ e $0,90 \mathrm{~m}$.

\begin{tabular}{|c|c|c|c|c|c|c|c|c|c|c|c|c|c|c|c|}
\hline \multirow[t]{2}{*}{ Horário } & \multicolumn{5}{|c|}{$0,70 \mathrm{~m}$} & \multicolumn{5}{|c|}{$0,80 \mathrm{~m}$} & \multicolumn{5}{|c|}{$0,90 \mathrm{~m}$} \\
\hline & $\Psi m$ & $\theta(\Psi \mathrm{m})$ & Ка & $\theta(K a) 1$ & $\theta(K a) 2$ & $\Psi m$ & $\theta(\Psi m)$ & Ka & $\theta(K a) 1$ & $\theta(K a) 2$ & $\Psi m$ & $\theta(\Psi \mathrm{m})$ & Ka & $\theta(K a) 1$ & $\theta(K a) 2$ \\
\hline 07:00 & & & & & & & & 30,47 & 0,452 & 0,448 & & & 29,812 & 0,417 & 0,443 \\
\hline 08:00 & & & 30,283 & 0,413 & 0,446 & & & & & & & & 30,008 & 0,419 & 0,444 \\
\hline $08: 30$ & $-0,81$ & 0,483 & & 0,076 & $-0,053$ & $\begin{array}{c}- \\
2,751\end{array}$ & 0,470 & & & & $\begin{array}{c}- \\
4,565\end{array}$ & 0,422 & & & \\
\hline 09:00 & $-0,18$ & 0,508 & 29,998 & 0,409 & 0,444 & $\begin{array}{c}- \\
2,877\end{array}$ & 0,468 & 30,703 & 0,455 & 0,450 & $2, \overline{129}$ & 0,450 & 30,803 & 0,429 & 0,450 \\
\hline 09:30 & 1,121 & & 31,438 & 0,425 & 0,455 & $\overline{1,407}$ & 0,484 & & & & $\overline{0,911}$ & 0,482 & 31,877 & 0,442 & 0,458 \\
\hline $10: 00$ & 1,457 & & 37,308 & 0,491 & 0,494 & $\overline{-}$ & 0,493 & 37,015 & 0,533 & 0,492 & $\overline{0,617}$ & 0,496 & 37,222 & 0,505 & 0,494 \\
\hline $10: 30$ & 2,339 & & & & & $\overline{-}, \overline{105}$ & 0,499 & & & & $\stackrel{-}{0,659}$ & 0,494 & & & \\
\hline $11: 00$ & 2,465 & & & & & 0,189 & & & & & $\stackrel{-}{0,071}$ & 0,541 & & & \\
\hline $11: 30$ & 2,507 & & & & & 0,231 & & & & & $0, \overline{0} 29$ & 0,545 & & & \\
\hline $12: 00$ & 2,591 & & & & & 0,231 & & & & & 0,097 & & & & \\
\hline $12: 30$ & 2,801 & & & & & 0,441 & & & & & 0,811 & & & & \\
\hline $13: 00$ & 3,053 & & 37,405 & 0,492 & 0,495 & 0,903 & & 38,403 & 0,550 & 0,501 & 0,685 & & 37,946 & 0,514 & 0,498 \\
\hline $13: 30$ & 2,843 & & & & & 0,945 & & & & & 0,685 & & & & \\
\hline $14: 00$ & 3,095 & & & & & 0,903 & & & & & 0,517 & & & & \\
\hline $14: 30$ & 2,465 & & & & & 0,231 & & & & & 0,155 & 0,531 & & & \\
\hline $15: 00$ & 1,373 & & & & & $\begin{array}{c}- \\
0,357\end{array}$ & 0,496 & 33,166 & 0,485 & 0,467 & $\overline{1,289}$ & 0,469 & 33,594 & 0,462 & 0,470 \\
\hline $15: 30$ & 1,289 & & 33,212 & 0,445 & 0,468 & $\overline{-} \overline{-} 777$ & 0,491 & & & & $\overline{1,415}$ & 0,466 & & & \\
\hline $16: 00$ & 0,785 & & & & & $\overline{1,449}$ & 0,483 & & & & $\stackrel{-}{1,793}$ & 0,457 & & & \\
\hline $16: 30$ & 0,533 & & & & & $\begin{array}{c}- \\
1,491\end{array}$ & 0,483 & & & & $\begin{array}{c}- \\
1,835\end{array}$ & 0,456 & & & \\
\hline $17: 00$ & 0,365 & & & & & $\begin{array}{c}- \\
2,079\end{array}$ & 0,476 & & & & 2,045 & 0,452 & & & \\
\hline $19: 00$ & & & & & & & & 31,719 & 0,468 & 0,457 & & & & & \\
\hline
\end{tabular}


Tabela 9. Valores de potencial matricial, constante dielétrica e umidades volumétricas $\left(\mathrm{m}^{3} \mathrm{~m}^{-3}\right)$ em função do potencial matricial e da constante dielétrica, com calibração feita utilizando o tensiômetro e curva de retenção $(\theta(\mathrm{Ka}) 1)$ e pelo modelo de Topp et al., $1980(\theta(\mathrm{Ka}) 2)$, durante a última inundação, para as profundidades $1,00,1,10$ e $1,20 \mathrm{~m}$.

\begin{tabular}{|c|c|c|c|c|c|c|c|c|c|c|c|c|c|c|c|}
\hline \multirow[t]{2}{*}{ Horário } & \multicolumn{5}{|c|}{$1,00 \mathrm{~m}$} & \multicolumn{5}{|c|}{$1,10 \mathrm{~m}$} & \multicolumn{5}{|c|}{$1,20 \mathrm{~m}$} \\
\hline & $\Psi \mathrm{m}$ & $\theta(\Psi \mathrm{m})$ & Ka & $\theta(K \mathbf{a}) 1$ & $\theta(K a) 2$ & $\Psi m$ & $\theta(\Psi \mathrm{m})$ & Ka & $\theta(K a) 1$ & $\theta(K a) 2$ & $\Psi \mathrm{m}$ & $\theta(\Psi \mathrm{m})$ & Ka & $\theta($ Ka $) 1$ & $\theta(\mathrm{Ka}) 2$ \\
\hline 07:00 & & & 30,459 & 0,396 & 0,448 & & & 30,526 & 0,454 & 0,448 & & & 30,481 & 0,425 & 0,448 \\
\hline 08:00 & & & 30,725 & 0,397 & 0,450 & & & 30,393 & 0,452 & 0,447 & & & 30,173 & 0,422 & 0,445 \\
\hline 08:30 & $-4,279$ & 0,394 & & & & $\overline{4,875}$ & 0,353 & & & & $\overline{5,429}$ & 0,406 & & & \\
\hline 09:00 & $-2,725$ & 0,409 & 30,504 & 0,396 & 0,448 & $\overline{4,161}$ & 0,358 & 30,459 & 0,453 & 0,448 & $5, \overline{303}$ & 0,407 & 30,603 & 0,426 & 0,449 \\
\hline 09:30 & $-1,591$ & 0,428 & 31,697 & 0,405 & 0,457 & $\overline{1, \overline{9} 35}$ & 0,384 & 32,353 & 0,477 & 0,462 & $4, \overline{253}$ & 0,414 & 32,115 & 0,443 & 0,460 \\
\hline $10: 00$ & $-0,793$ & 0,455 & 37,295 & 0,445 & 0,494 & $\overline{0,633}$ & 0,426 & 37,626 & 0,542 & 0,496 & $\overline{1,481}$ & 0,452 & 37,222 & 0,499 & 0,494 \\
\hline $10: 30$ & $-0,205$ & 0,507 & 37,946 & 0,450 & 0,498 & $\overline{0,339}$ & 0,448 & 37,503 & 0,541 & 0,495 & $\overline{1, \overline{103}}$ & 0,462 & 37,7 & 0,504 & 0,497 \\
\hline $11: 00$ & 0,4667 & & & & & $0, \overline{0} 87$ & 0,478 & & & & $\overline{0,725}$ & 0,476 & & & \\
\hline $11: 30$ & 0,4667 & & & & & $\stackrel{-}{0,087}$ & 0,478 & & & & $\overline{-} \overline{-} 767$ & 0,474 & & & \\
\hline $12: 00$ & 0,5927 & & & & & $0, \overline{-} 45$ & 0,484 & & & & $\overline{0}, \overline{6} 83$ & 0,478 & & & \\
\hline $12: 30$ & 10,547 & & & & & 0,333 & & & & & $\overline{0,515}$ & 0,486 & & & \\
\hline $13: 00$ & 11,807 & & 37,491 & 0,447 & 0,495 & 0,669 & & 37,97 & 0,547 & 0,498 & $\overline{0,305}$ & 0,498 & 38,007 & 0,507 & 0,498 \\
\hline $13: 30$ & 12,647 & & & & & 0,669 & & & & & $\overline{0, \overline{263}}$ & 0,500 & & & \\
\hline $14: 00$ & 25,247 & & & & & 0,669 & & & & & $\overline{0,305}$ & 0,498 & & & \\
\hline $14: 30$ & 0,6347 & & & & & 0,333 & & & & & $\overline{0,683}$ & 0,478 & & & \\
\hline $15: 00$ & $-0,709$ & 0,460 & 33,328 & 0,416 & 0,468 & $\overline{0, \overline{9} 27}$ & 0,412 & 32,948 & 0,484 & 0,466 & $\overline{1, \overline{9} 01}$ & 0,443 & 33,281 & 0,456 & 0,468 \\
\hline $15: 30$ & $-1,213$ & 0,439 & & & & $1, \overline{3} 89$ & 0,397 & & & & $2, \overline{2} 79$ & 0,437 & & & \\
\hline $16: 00$ & $-1,927$ & 0,421 & & & & 1,809 & 0,387 & & & & $2, \overline{8} 67$ & 0,428 & & & \\
\hline $16: 30$ & $-2,095$ & 0,418 & & & & 2,103 & 0,381 & & & & $3, \overline{0} 77$ & 0,426 & & & \\
\hline $17: 00$ & $-2,473$ & 0,412 & & & & 2,313 & 0,378 & & & & 3,329 & 0,423 & & & \\
\hline 19:00 & & & 31,697 & 0,405 & 0,457 & & & 31,697 & 0,468 & 0,457 & & & 32,047 & 0,442 & 0,459 \\
\hline
\end{tabular}

